\title{
Cifra multicanal para maior segurança em redes TCP/IP
}

\author{
Sylvio Ximenez de Azevedo Neto \\ DisSERTAÇÃO APRESENTADA \\ $\mathrm{AO}$ \\ Instituto DE MATEMÁticA E EstatísticA \\ DA \\ Universidade DE SÃo PAUlo \\ PARA \\ OBTENÇÃO DO TÍTULO \\ $\mathrm{DE}$ \\ Mestre em CiÊnCIAS
}

Programa: Mestrado em Ciência da Computação

Orientador: Prof. Dr. Routo Terada

São Paulo, novembro de 2013 


\section{Cifra multicanal para maior segurança em redes TCP/IP}

Esta versão da dissertação contém as correções e alterações sugeridas pela Comissão Julgadora durante a defesa da versão original do trabalho, realizada em 30/11/2013. Uma cópia da versão original está disponível no

Instituto de Matemática e Estatística da Universidade de São Paulo.

Comissão Julgadora:

- Prof. Dr. Routo Terada (orientador) - IME-USP

- Prof. Dr. Marcel Parolin Jackowski - IME-USP

- Prof. Dr. Hellinton Hatsuo Takada - INSPER 


\section{Agradecimentos}

Agradeço a Deus o sincronismo dos diversos fatores aleatórios que me possibilitaram ingressar, cursar e, principalmente, concluir este programa de mestrado em tempo hábil e sem barreiras intransponíveis.

Em especial, agradeço a admirável paciência nipônica do meu orientador, Prof. Dr. Routo Terada, referência em criptografia, excelente mestre dentro e fora da sala de aula, sempre sereno, exato e aberto à troca de ideias.

Gostaria de mencionar em agradecimento os integrantes do grupo do Laboratório de Segurança de Dados (LSD), do período de 2010 a 2013 , cujo companheirismo, energia e alegria, marcaram-me profundamente. São eles: Prof ${ }^{\mathrm{a}}$. Dra ${ }^{\mathrm{a}}$. Denise Goya, Rafael Will, Cléber Okida, Dionathan Nakamura, Bernardo Magri, Fábio Monteiro, Carlos Lombizani, Reynaldo Cáceres, Wellinton Souza e Ewerton Rodrigues.

E, por fim, agradeço e dedico esse trabalho à minha família, à minha amorosa esposa Karla Liane Teixeira Ximenez de Azevedo, aos meus pais, João Bernardo Ximenez de Azevedo e Luiz Carlos Teixeira, às minhas mães, Cazue Nagata e Lourdes Beti Teixeira, e aos meus avós, Sylvio Ximenez de Azevedo e Maria Therezinha Marques dos Santos de Azevedo, sempre muito presentes em minha vida, são o refúgio da minha consciência, a minha eterna fonte de energia, inspiração, paz e harmonia. 


\section{Resumo}

AZEVEDO NETO, S. X. Cifra multicanal para maior segurança em redes TCP/IP. 2013. 55 f. Dissertação (Mestrado) - Instituto de Matemática e Estatística, Universidade de São Paulo, São Paulo, 2013.

Neste documento apresentamos uma cifra multicanal inspirada nas técnicas de telecomunicações de espalhamento espectral (Spread Spectrum), ou como também conhecido, difusão espectral, para prevenir escuta em uma rede de computadores TCP/IP. Mostramos que dividindo um texto-ilegível ciphertext em blocos de tamanho fixo e transmitindo-os aleatoriamente através de diversos canais estabelecidos entre os agentes (transmissor - receptor) é possível aumentar a complexidade da criptanálise por um suposto adversário não autorizado que esteja escutando a comunicação, dessa forma aumentando relativamente a segurança. Mostramos teoricamente que o tempo de quebra da cifra multicanal cresce em ordem fatorial ou exponencial em função do número de canais utilizados na comunicação. Além disso, adaptado a um esquema de difusão binária herdado do AES (Advanced Encryption Standard) é possível incrementar a segurança da cifra multicanal para maior resiliência contra a criptanálise diferencial.

Palavras-chave: cifra, rede, segurança, multicanal, protocolo. 


\section{Abstract}

AZEVEDO NETO, S. X. Multichannel cipher for higher TCP/IP security. 2013. 55 f. Dissertação (Mestrado) - Instituto de Matemática e Estatística, Universidade de São Paulo, São Paulo, 2013.

In this work we present a multichannel cipher inspired on telecommunications Spread Spectrum techniques to prevent eavesdropping in a TCP/IP network. We show that splitting any ciphertext into fixed size blocks and sending them randomly through multiple channels established between the agents (transmitter and receiver) it is possible to increase the complexity of cryptanalysis by a supposed not authorized adversary that might be eavesdropping the communication, in this way, relatively increasing the security. We show theoretically that the brake time of multichannel cipher grows in factorial or exponential order, in function of the number of channel used in the communication. Moreover adapted to binary spread scheme inherited from AES (Advanced Encryption Standard) it is possible to increase the cipher security for more resilience against differential cryptanalysis.

Keywords: cipher, network, security, multichannel, protocol. 


\section{Sumário}

$\begin{array}{ll}\text { Lista de Abreviaturas } & \text { ix }\end{array}$

Lista de Símbolos $\quad$ xi

Lista de Figuras $\quad$ xiii

Lista de Tabelas $\quad$ xv

1 Introdução 1

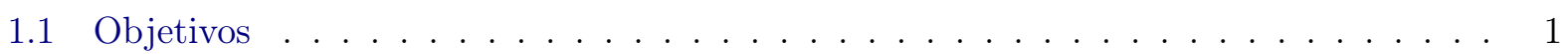

1.2 Justificativa . . . . . . . . . . . . . . . . . . . . . 2

1.3 Hipóteses . . . . . . . . . . . . . . . . . . . . . . . . . . 2

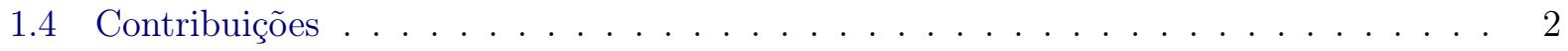

1.5 Organização do Trabalho . . . . . . . . . . . . . . . . . . . . . . . . . 2

2 Espalhamento espectral $\quad 3$

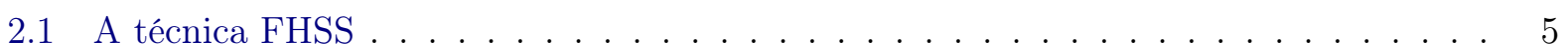

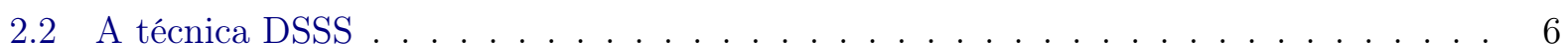

3 A cifra multicanal $\quad 9$

3.1 Criptografia de chave secreta ou simétrica . . . . . . . . . . . . . . . . 9

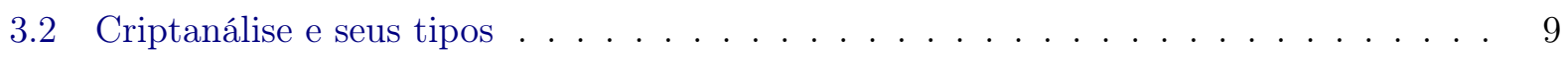

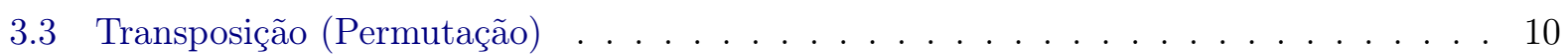

3.4 Composição . . . . . . . . . . . . . . . . . . . . . . 11

3.5 A rede TCP $/ \mathrm{IP}$ e a interceptação de pacotes . . . . . . . . . . . . . . . . . . . 11

3.5 .1 O protocolo IP . . . . . . . . . . . . . . . . . . . . 11

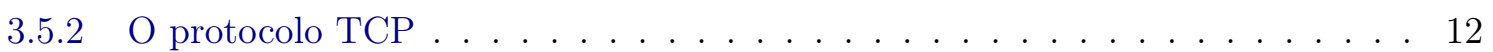

3.6 Criptanálise diferencial . . . . . . . . . . . . . . . . . . . . . 13

3.7 A cifra multicanal proposta . . . . . . . . . . . . . . . . . 15

3.7.1 Geração e troca da chave de sessão $k$ e da sequência aleatória $i \quad \ldots . \ldots . .16$

3.7.2 A demultiplexação e envio de dados através dos múltiplos canais . . . . . . . 17

3.7.3 Multiplexação (montagem) dos dados recebidos . . . . . . . . . . . . . . . . 18

4 Características da cifra multicanal $\quad 21$

5 Metodologia $\quad 25$ 
6 Implementação

6.1 Aplicação de transferência de arquivos . . . . . . . . . . . . . . . . . . . . . . 29

6.1.1 Resultados da aplicação de transferência de arquivos . . . . . . . . . . . . . 30

6.2 Segurança em relação à criptanálise diferencial f . . . . . . . . . . . . . . . . 36

6.2.1 Resultados dos experimentos em relação à criptanálise diferencial . . . . . . . . 39

7 Conclusões

53

7.1 Sugestões para Pesquisas Futuras . . . . . . . . . . . . . . . . . . . 53

Referências Bibliográficas $\quad 55$ 


\title{
Lista de Abreviaturas
}

\author{
AES Padrão de encriptação avançado (Advanced Encryption Standard) \\ BSON JSON binário (Binary JSON) \\ DES Padrão de encriptação de dados (Data Encryption Standard) \\ DSSS Espalhamento espectral por sequência direta (Direct Sequence Spread Spectrum) \\ EOF Fim de arquivo (End Of File) \\ FHSS Espalhamento espectral por salto em frequência (Frequency Hopping Spread Spectrum) \\ FIPS Padrão de processamento de informação federal (Federal Information Processing \\ Standard) \\ FTP Protocolo de Transferência de Arquivos (File Transfer Protocol) \\ GF Corpo de Galois (Galois Field) \\ GSM Sistema global para comunicações móveis (Global System for Mobile Communications) \\ HTTP Protocolo de transferência de hipertexto (Hypertext Transfer Protocol) \\ HTTPS Protocolo seguro de transferência de hipertexto (Hypertext Transfer Protocol Secure) \\ IID Independente e Identicamente Distribuída (Independent and Identically Distributed) \\ IP Protocolo de Internet (Internet Protocolo) \\ ISO Organização Internacional para Padronização ( International Organization for \\ Standardization) \\ JSON Notação de objetos javascript (Javascript Object Notation) \\ MP3 MPEG-1/2, camada de audio 3 (MPEG-1/2, Audio Layer 3) \\ MPEG Grupo de Especialistas em Imagens com Movimento (Moving Picture Experts Group) \\ NIST Instituto Nacional de Padrões e Tecnologia (National Institute of Standards and \\ Technology) \\ OSI (Modelo de) Interconexão de sistemas abertos (Open Systems Interconnection) \\ PDF Formato de documento portátil (Portable Document Format) \\ RF Frequência de Rádio (Radio Frequency) \\ SMP S-Box/deslocamento de Bytes, mistura de colunas e permutação (S-Box/ShiftBytes, \\ Mix Columns and Permutation) \\ SMTP Protocolo de transferência de correio simples (Simple Mail Transfer Protocol) \\ TCP Protocolo de controle de transmissão (Transmission Control Protocol) \\ TLS Proteção de camada de transporte (Transport Layer Security) \\ USRP Periférico de rádio de software universal (Universal Software Radio Peripheral) \\ WCDMA Acesso múltiplo por código-divisão de banda larga (Wide-Band Code-Division \\ Multiple Access) \\ WWW Rede mundial de computadores (World Wide Web)
}




\section{Lista de Símbolos}

$\oplus \quad$ Operação binária ou-exclusivo

$f_{k}(x) \quad$ Função de criptografia de um algoritmo qualquer

$f_{k}^{-1}(y) \quad$ Função de decriptografia de um algoritmo qualquer

$k \quad$ Chave criptográfica, segredo utilizado pelas funções de criptografia e decriptografia

$x \quad$ Texto-legível qualquer, entrada da função criptográfica, ou resultado da operação de decriptografia

y Texto-ilegível qualquer, resultado da operação de criptografia ou entrada da função decriptográfica

$\Delta x \quad$ Número de diferença binária entre dois blocos de entrada distintos $x^{\prime}$ e $x^{\prime \prime}$

$\Delta y \quad$ Número de diferença binária entre dois blocos de saída distintos $y^{\prime}$ e $y^{\prime \prime}$ 


\section{Lista de Figuras}

2.1 Representação de um sinal antes e depois da aplicação da técnica de espalhamento espectral em termos de densidade energética. . . . . . . . . . . . . . . . . 4

2.2 Representação da modulação FHSS em rádio-frequência. . . . . . . . . . . . . . . . . 5

2.3 Representação do FHSS - Frequência por Tempo. . . . . . . . . . . . . . . . . . . . 6

2.4 Representação da modulação DSSS em rádio-frequência. . . . . . . . . . . . . . . . 6

2.5 Simulação da operação de modulação do DSSS através da operação binária xor. . . . 6

2.6 Simulação da operação de demodulação do DSSS através da operação binária xor. . . 7

3.1 Representação de um canal de comunicação seguro, estabelecido pelo uso de um algoritmo de criptografia (cifra) simétrico. . . . . . . . . . . . . . . . . 9

3.2 Representação do cabeçalho IP. . . . . . . . . . . . . . . . . . . . . . . . . . 12

3.3 Representação do cabeçalho TCP. . . . . . . . . . . . . . . . . . . . . . . . 13

3.4 Ilustração do processo de abertura de múltiplas conexões socket TCP/IP. . . . . . . 14

3.5 Representação da obtenção dos deltas $(\Delta x$ e $\Delta y)$ para a criptanálise diferencial. . . . 15

3.6 Representação da interceptação normal de um canal seguro. . . . . . . . . . . . . . . . 15

3.7 Representação da comunicação pela cifra multicanal, interceptada por um criptanalista. 16

3.8 Comunicação multicanal, com um canal específico para a troca de chaves. . . . . . . 17

3.9 Geração e troca da chave de sessão $k$ e da sequência aleatória $i \ldots \ldots$. . . . . . . . 18

3.10 Envio de dados em esquema multicanal. . . . . . . . . . . . . . . . . . . . . . . 19

3.11 Remontagem dos dados. . . . . . . . . . . . . . . . . . . . . . . . . . . 19

4.1 Distribuição de números aleatórios de 1 a 50, pela classe [java.security.SecureRandom] da plataforma Java. . . . . . . . . . . . . . . . . . . . . . . . 23

4.2 Distribuição de números aleatórios de 1 a 500, pela classe [java.security.SecureRandom] da plataforma Java. . . . . . . . . . . . . . . . . . . . . . . . 23

4.3 Crescimento de uma função fatorial . . . . . . . . . . . . . . . . . . . . . . . . . 24

5.1 Alteração de bits seguindo a combinação através dos $k$ agrupamentos. O valores mais claros na ilustração representam os bits alterados. . . . . . . . . . . . . . . . . . 27

6.1 Tempos de inicialização para diferentes números de canais. . . . . . . . . . . . . . . . 31

6.2 Tempos de transferência, overhead e total da comunicação para um arquivo de 100

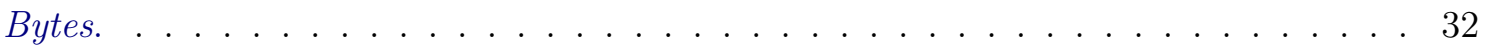

6.3 Tempos de transferência, overhead e total da comunicação para um arquivo de 40

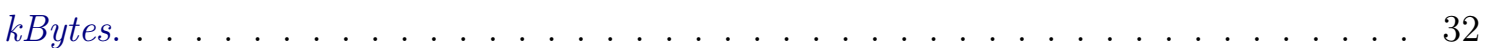


6.4 Tempos de transferência, overhead e total da comunicação para um arquivo de 500

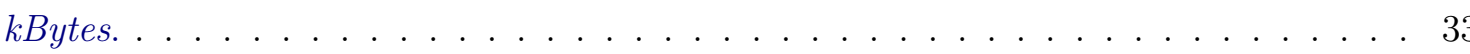

6.5 Tempos de transferência, overhead e total da comunicação para um arquivo de 1.1 MBytes.

6.6 Tempos de transferência, overhead e total da comunicação para um arquivo de 6.6

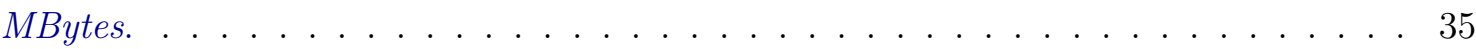

6.7 Exemplo mostrando que a operação de permutação não causa difusão binária. . . . 37

6.8 Representação da cifra SMP para a operação criptográfica. . . . . . . . . . . . . . . . 39

6.9 Representação da operação inversa da cifra SMP. . . . . . . . . . . . . . . . . . . . 40

6.10 Total de bits alterados para a permutação binária. . . . . . . . . . . . . . . . . 40

6.11 Total de bits alterados para a permutação de blocos de 4 bits. . . . . . . . . . . . . . 41

6.12 Total de bits alterados para a permutação de blocos de 8 bits. . . . . . . . . . . . . . 41

6.13 Total de bits alterados para a permutação de blocos de 16 bits. . . . . . . . . . . . . 42

6.14 Total de bits alterados para a permutação de blocos de 32 bits. . . . . . . . . . . . . 42

6.15 Total de bits alterados para a permutação de blocos de 64 bits. . . . . . . . . . . . . 43

6.16 Estatística dos bits alterados para a permutação binária. . . . . . . . . . . . . . . 44

6.17 Estatística dos bits alterados para a permutação de blocos de 4 bits. . . . . . . . . . 44

6.18 Estatística dos bits alterados para a permutação de blocos de 8 bits. . . . . . . . . . 45

6.19 Estatística dos bits alterados para a permutação de blocos de 16 bits. . . . . . . . . . 45

6.20 Estatística dos bits alterados para a permutação de blocos de 32 bits. . . . . . . . . . 45

6.21 Estatística dos bits alterados para a permutação de blocos de 64 bits. . . . . . . . . . 46

6.22 Coeficiente de variação (desvio padrão pela média) para a permutação binária. . . . 47

6.23 Coeficiente de variação (desvio padrão pela média) para a permutação de blocos de

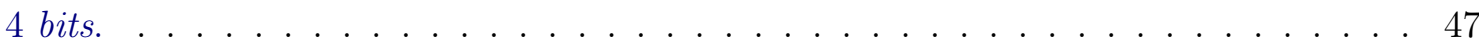

6.24 Coeficiente de variação (desvio padrão pela média) para a permutação de blocos de

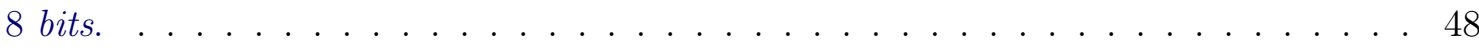

6.25 Coeficiente de variação (desvio padrão pela média) para a permutação de blocos de

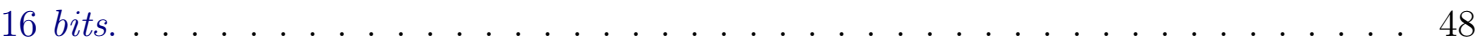

6.26 Coeficiente de variação (desvio padrão pela média) para a permutação de blocos de

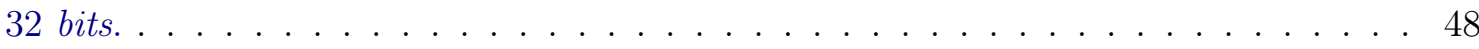

6.27 Coeficiente de variação (desvio padrão pela média) para a permutação de blocos de

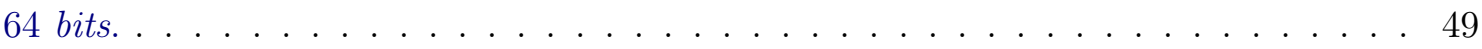

6.28 Média de bits trocados por posição em permutação binária. . . . . . . . . . . . . . 50

6.29 Média de bits trocados por posição em permutação de blocos de 4 bits. . . . . . . . . 50

6.30 Média de bits trocados por posição em permutação de blocos de 8 bits. . . . . . . . . 51

6.31 Média de bits trocados por posição em permutação de blocos de 16 bits. . . . . . . . . 51

6.32 Média de bits trocados por posição em permutação de blocos de 32 bits. . . . . . . . 51

6.33 Média de bits trocados por posição em permutação de blocos de 64 bits. . . . . . . . . 52 


\section{Lista de Tabelas}

3.1 Exemplo de transposição. . . . . . . . . . . . . . . . . . . . . . . . . 11

6.1 Tempos de transmissão de dados de um arquivo de 100 Bytes $(\mathrm{ms}) \ldots$. . . . . . . . . 31

6.2 Tempos de transmissão de dados de um arquivo de 40 kBytes $(\mathrm{ms})$. . . . . . . . . . . 31

6.3 Tempos de transmissão de dados de um arquivo de 500 kBytes (ms). . . . . . . . . . 33

6.4 Tempos de transmissão de dados de um arquivo de 1,1 MBytes (ms) . . . . . . . . . . 33

6.5 Tempos de transmissão de dados de um arquivo de 6,6 MBytes (ms) . . . . . . . . . . 34

6.6 Tempos de transmissão de dados em um abordagem serializada normal (ms). . . . . 35

6.7 Tabela de constantes de deslocamento em função do tamanho do bloco de entrada do AES . . . . . . . . . . . . . . . . . . . . . . . . . . 38 


\section{Capítulo 1}

\section{Introdução}

No GSM (Global System for Mobile Communications), padrão de tecnologia para as redes de telefonia celular, além dos protocolos e algoritmos de segurança que autenticam os usuários à rede e criptografam os dados de voz e serviços que são transmitidos no ar, existe uma outra proteção não tão aparente que dificulta muito a interceptação e, consequentemente, a obtenção das informações que trafegam pelo ar, é a técnica FHSS (Frequency Hopping Spread Spectrum), espalhamento espectral por salto em frequência, uma técnica de transmissão onde os dados da informação são divididos e transmitidos separadamente em diversos canais de rádio frequência. Com a utilização dessa técnica, embora existam diversos trabalhos acadêmicos e técnicos que comprovam que os algoritmos criptográficos utilizados pelo GSM não sejam tão seguros, é, ainda, relativamente difícil encontrar ataques práticos que de fato consigam quebrar o fluxo cifrado das informações (voz e dados) do GSM.

Essa dificuldade é devida ao custo de se montar uma infraestrutura de escuta em diversos canais e pela posterior dificuldade de obtenção, identificação e ordenação dos blocos do fluxo de dados transmitido.

A ideia deste trabalho é estudar as características da técnica FHSS aplicada à criptografia no contexto da segurança de uma rede de computadores TCP/IP. Verificando se é viável o seu uso e qual seria o seu ganho em segurança.

Para esse estudo propomos uma cifra genérica de transmissão multicanal, inspirado nas estratégias principais de espalhamento de espectro existentes, dividindo uma informação (um textoilegível, criptografado) a ser transmitida, pelo número de canais (sockets TCP/IP) estabelecidos previamente entre um transmissor e receptor, e transmitindo seus blocos de dados aleatoriamente por estes canais.

Uma implementação de uma aplicação de transferência de arquivos utilizando esta cifra proposta é apresentada, e da qual é possível extrair informações de overhead ${ }^{1}$, tempos de processamento, taxa de transferência e outras propriedades dessa cifra. Além disso, um estudo empírico é apresentado para testar a segurança da cifra multicanal em relação a criptanálise diferencial, uma técnica muito conhecida, apresentada pela primeira vez por Biham e Shamir (1991).

\subsection{Objetivos}

O objetivo dessa pesquisa é verificar as propriedades do espalhamento da informação em múltiplos canais como uma função criptográfica, de forma a aumentar a segurança de um sistema de comunicação.

\footnotetext{
${ }^{1}$ Dado a administração de múltiplos canais e encapsulamento de protocolo.
} 


\subsection{Justificativa}

Até o momento, a utilização de múltiplos canais na criptografia tem se limitado ao uso em protocolos, em geral, utilizando canais heterogêneos (e.g. Takács (2007), Michtchenko e Vilnaski (2007)) para dificultar o acesso do adversário ao segredo (chave), utilizado na operação criptográfica. Não foram encontrados trabalhos fora do âmbito das telecomunicações que utilizasse o espalhamento da informação como forma de segurança.

Com a computação em nuvem (cloud computing), com o poder dos chips de múltiplos núcleos e máquinas virtuais cada vez mais populares, a cifra multicanal pode facilmente ser um vetor a mais de segurança entre a comunicação dos sistemas que rodam nesses ambientes.

\subsection{Hipóteses}

As seguintes hipóteses serão consideradas e verificadas ao longo desse trabalho:

- A possibilidade de simular as características do espalhamento espectral em um esquema multicanal em comunicações TCP/IP, em uma rede de computadores;

- A distribuição aleatória de blocos de uma informação (texto-ilegível) em múltiplos canais (cifra multicanal) pode aumentar a segurança da transmissão;

- Existe um gerador de números aleatórios de distribuição uniforme e de uso prático em computadores convencionais para a implementação da cifra multicanal;

- A cifra multicanal é mais resistente à criptanálise diferencial.

\subsection{Contribuições}

As principais contribuições deste trabalho:

- A proposta de uma cifra multicanal baseada em uma técnica de espalhamento espectral, para aumento de segurança nas comunicações TCP/IP;

- Uma análise da cifra multicanal proposta em relação à criptanálise diferencial;

- Um método de difusão binária que pode ser aplicado em outras cifras e sistemas criptográficos, incluindo o GSM, uma tecnologia de rede de celulares.

\subsection{Organização do Trabalho}

No Capítulo 2 apresentamos os conceitos e as características das principais técnicas de espalhamento espectral, nas quais se basearam a concepção da cifra multicanal. No Capítulo 3, fazemos uma revisão dos conceitos fundamentais de criptografia relacionados ao trabalho e detalhamos a nossa proposta da cifra multicanal. No Capítulo 4 mostramos as características e as propriedades da cifra multicanal proposta, introduzindo as questões do aumento de segurança esperado. No Capítulo 5 detalhamos a metodologia empregada neste trabalho. No Capítulo 6 detalhamos duas implementações experimentais, uma da cifra multicanal em uma aplicação de transferência de arquivos. E a outra, específica para a análise da cifra multicanal em relação a segurança contra a criptanálise diferencial. Apresentamos os dados resultantes dos experimentos realizados com essas implementações e fazemos uma análise de seu significado.

Finalmente, no Capítulo 7 discutimos algumas conclusões que podemos tirar dos resultados obtidos e apresentamos algumas propostas para trabalhos futuros. 


\section{Capítulo 2}

\section{Espalhamento espectral}

Neste capítulo apresentaremos uma introdução sobre o espalhamento espectral e o funcionamento da técnica FHSS (Frequency-Hopping Spread Spectrum) que inspirou o desenvolvimento da cifra multicanal, devido à complexidade que causa na transmissão de dados, o que aumenta a dificuldade de interceptação por um possível adversário, interessado na comunicação.

Técnicas de espalhamento espectral são bem conhecidas e utilizadas em telecomunicações, seu desenvolvimento começa em meados de 1950, principalmente no uso militar, tratam-se de técnicas de transmissão onde um sinal é difundido sobre uma banda de frequência muito mais larga que a banda de fato necessária para a transmissão de uma determinada informação. O espalhamento espectral é realizado por meio de um código, um pseudo-ruído independente, aplicado ao sinal da informação. A aplicação desse código é uma modulação com o objetivo de difundir a energia do sinal de informação, assim difundindo-o em uma largura de banda muito maior do que a do original, segundo Meel (1999). A recepção sincronizada pelo mesmo código da modulação é a forma de remontar a mensagem (de-spread) e recuperar a informação no receptor.

São várias as razões para a utilização dessas técnicas, as aplicações iniciais foram as comunicações táticas anti-interferência (anti-jamming), sistemas de orientação e sistemas anti-múltiplos-caminhos (anti-multi-path systems). Hoje são muitas as aplicações das técnicas de espalhamento espectral, são elas (Fazel e S.Kaizer (2008)):

- Resistência contra ruídos e interferências;

- Baixa probabilidade de interceptação, dificuldade de detecção do sinal de transmissão;

- Múltiplo acesso;

- Recepção multi-caminho (multi-path);

- Diversidade de recepção;

- Variação de alta resolução (high resolution ranging);

- Tempo universal preciso (accurate universal timing).

A figura 2.1 ilustra a difusão da energia empregada em uma transmissão normal e em uma transmissão que utiliza uma técnica de espalhamento espectral qualquer. Na cifra multicanal não nos preocuparemos com a questão energética da transmissão e o aspecto do domínio de frequências será transformado em uma comunicação paralela.

Existem algumas técnicas de espalhamento espectral, as duas mais importantes ${ }^{1}$ utilizadas são:

\footnotetext{
${ }^{1}$ Em termos das tecnologias mais utilizadas, já que são utilizadas nos padrões de comunicação sem fio: Bluetooth, Wifi e nas redes digitais modernas de telefonia celular. Existem outras técnicas, como por exemplo, o THSS (TimeHopping Spread Spectrum) e o CSS (Chirp Spread Spectrum), mas essas não serão consideradas nesse trabalho, pois são utilizadas em tecnologias muito específicas.
} 


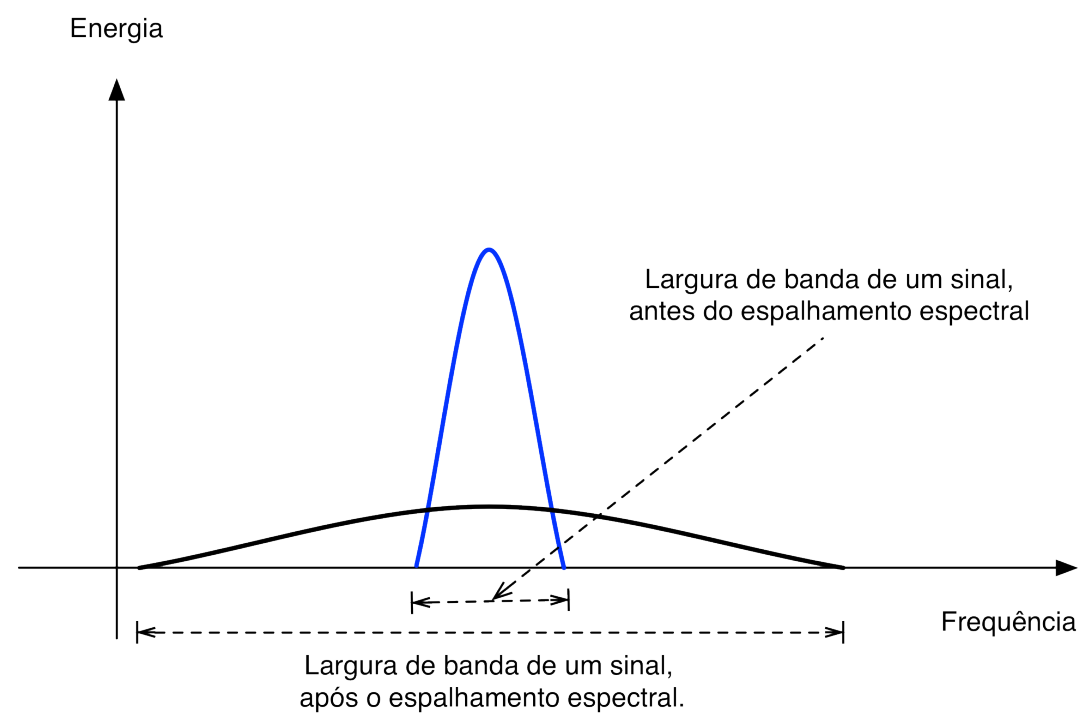

Figura 2.1: Representação de um sinal antes e depois da aplicação da técnica de espalhamento espectral em termos de densidade energética.

- DSSS (Direct Sequence Spread Spectrum) - Neste método um código pseudo-ruído é multiplicado diretamente no sinal da informação antes da modulação. Esse mecanismo é utilizado pelas redes Wifi 802.11a/b/g e nas redes de $3^{\mathrm{a}}$ geração das redes de telefonia com a tecnologia WCDMA (Wide-band Code Division Multiple Access).

- FHSS (Frequency-Hopping Spread Spectrum, do inglês Espalhamento Espectral por Salto em Frequência) - Neste método o código pseudo-ruído é utilizado na etapa de modulação alterando a frequência da portadora ${ }^{2}$, selecionando o uso dos os canais de comunicação. Essa técnica é utilizada no padrão de comunicação Bluetooth e nas redes de telefonia GSM.

A tecnologia de telefonia celular GSM utiliza um método de FHSS para evitar a interferência entre antenas e também como método de interleaving ${ }^{3}$, de acordo com Eberspacher et al. (2001). O emprego de tal método dificulta em muito a escuta (eavesdropping) de uma comunicação por um adversário mal intencionado, pois ele deve manter toda uma infraestrutura para cada um dos canais envolvidos, identificar e montar na sequência certa (que ele desconhece) o fluxo (stream) de comunicação cifrado (texto-ilegível) e, por fim quebrar a cifra da família A5 em que o fluxo foi cifrado, para obter a mensagem original.

A família de algoritmos A5 é a responsável pela privacidade na comunicação das redes GSM, é atualmente composta por três membros: A5/1, A5/2 e A5/3. Todos os três algoritmos tem sido estudados pela academia, com vários trabalhos publicados de criptanálise e de melhoria de segurança.

O A5/2 foi totalmente quebrado pelo trabalho de Barkan et al. (2006), já o A5/1 tem chave muito pequena, e através do poder computacional dos tempos atuais e associado às estratégias de ataque como as rainbow tables (time-tradeoff) é possível encontrar a chave em tempo relativamente curto, conforme Nohl (2009). E mesmo para o A5/3, o padrão mais moderno, já existem alguns ataques relevantes, segundo Dunkelman et al. (2010), embora ainda sem implementações práticas.

Mas a questão é que embora haja uma certa fragilidade nos protocolos de segurança GSM (utilizando os algoritmos A5/1 ou A5/3), ainda é muito difícil realizar uma quebra prática e real do padrão, contras as operadoras de telefonia celular existentes, os trabalhos baseiam-se em ambientes

\footnotetext{
${ }^{2}$ Sinal base que possibilita a transmissão, onde o sinal de informação é modulado. Nas transmissões de rádio é uma onda eletromagnética na faixa aproximada de $3 \mathrm{kHz}$ até $240 \mathrm{GHz}$, a radiofrequência.

${ }^{3}$ Técnica usada principalmente em telecomunicações de intercalação aleatória dos dados para evitar a perda de contexto de uma mensagem transmitida por rádio.
} 
simulados, e não existem muitas ferramentas implementadas e difundidas, a ferramenta que mais se aproxima de tal objetivo é o projeto Airprobe ${ }^{4}$, um framework para a interceptação e escuta do GSM, mas está descontinuado desde 2009 e apresenta sérias limitações, foi desenvolvido para uma plataforma de hardware muito específica, documentação desatualizada e insuficiente e que requerem um conhecimento razoável e específico de rádio telecomunicações.

Essas limitações se explicam pela dificuldade em se lidar com altas frequências de rádio da faixa em que o GSM está localizado, normalmente com o uso de equipamentos específicos, e com um custo considerável $^{5}$; pela complexidade da demodulação do sinal GSM, que requer um conhecimento em telecomunicações e em eletrônica considerável; pelo caráter estritamente acadêmico das maioria dos trabalhos publicados; e, pelo que nos interessa aqui, a estratégia de FHSS empregada em seu canais de comunicação, que ao quebrar e espalhar o fluxo da comunicação, aumenta considerável e diretamente os custos e a complexidade da interceptação e da reconstrução do fluxo de dados de uma determinada comunicação. É o caso justamente do projeto Airprobe, que analisa somente os canais que não sofrem a ação dessa estratégia, normalmente os canais de controle, ou comunicações em ambiente controlado (laboratório com estações rádio-base no controle do pesquisador).

A seguir detalhamos as técnicas FHSS e o DSSS.

\section{$2.1 \quad$ A técnica FHSS}

Na técnica FHSS a informação é dividida em pacotes e transmitida ao longo do espectro do domínio de frequências. O salto (hopping) é a troca da frequência do sinal da portadora, onde o sinal da informação é modulado. O código (pseudo-ruído) é utilizado para selecionar a frequência do sinal da portadora. A figura 2.2 ilustra o processo de modulação de um sinal utilizando a técnica FHSS.

Os pacotes de informação a cada momento são modulados em frequências diferentes, em uma representação da transmissão do tempo pela frequência, parecem saltar de um canal a outro, daí o seu nome (figura 2.3).

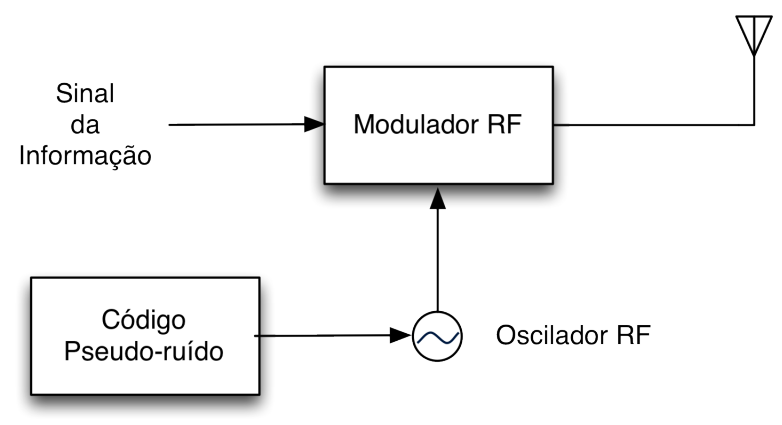

Figura 2.2: Representação da modulação FHSS em rádio-frequência.

Essa característica de salto, pode ser simulada na rede TCP/IP através do estabelecimento de múltiplos canais de comunicação (sockets) e da divisão e transmissão aleatória da informação por esses canais. Repare que a técnica FHSS não causa um embaralhamento no tempo, somente na de frequência, na simulação TCP/IP, o salto é feito pela seleção do socket onde o pacote será transmitido, no lugar da frequência. Essa simulação, utilizando pacotes TCP/IP, é a base da cifra multicanal apresentada nesse trabalho.

\footnotetext{
${ }^{4}$ Fonte: https://svn.berlin.ccc.de/projects/airprobe/, acessado pela última vez em 30/07/2013

${ }^{5}$ Embora existam hoje em dia algumas opções mais acessíveis - o USRP Universal Software Radio Peripheral, http://www.ettus.com, com custo em torno de US\$1.000,00.
} 


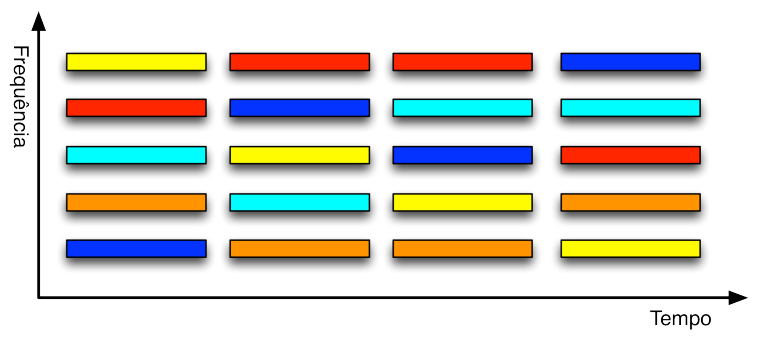

Figura 2.3: Representação do FHSS - Frequência por Tempo.

\section{$2.2 \quad$ A técnica DSSS}

Na técnica DSSS, um sinal aleatório, o código pseudo-ruído, é multiplicado ao sinal da informação diretamente ao longo do tempo ${ }^{6}$. Esse sinal aleatório representa uma sequência de valores 1 e -1, em uma frequência muito maior que o sinal da informação. A informação pode ser recuperada aplicando um sinal que representa o código de modulação inverso, uma sequencia inversa de valores 1 e -1. A figura 2.4 ilustra o esquema dessa técnica de modulação.

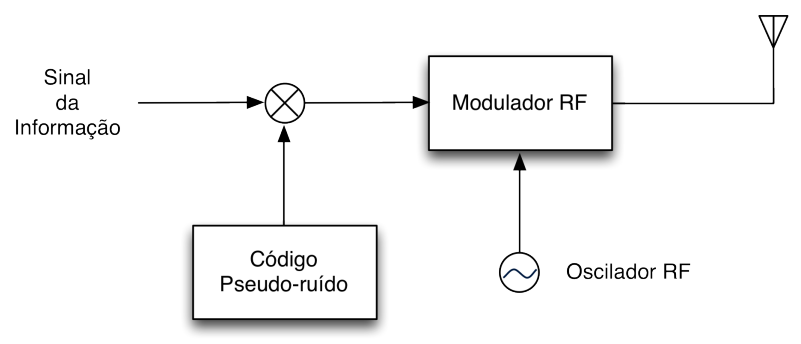

Figura 2.4: Representação da modulação DSSS em rádio-frequência.

A característica da aplicação de um código ruído pode ser simulada em uma operação binária $\operatorname{xor}(\oplus$, ou-exclusivo), combinando um vetor de bits $x$, representando a informação, com um outro vetor de bits $k$ de tamanho $n_{k}=v \cdot n_{x}$, onde $v$ representa a proporção do aumento da "frequência" desejada e $n_{x}$ o tamanho do vetor $x$. Nas figuras 2.5 e 2.6 , exemplificamos isso nas operações de modulação e demodulação, respectivamente.

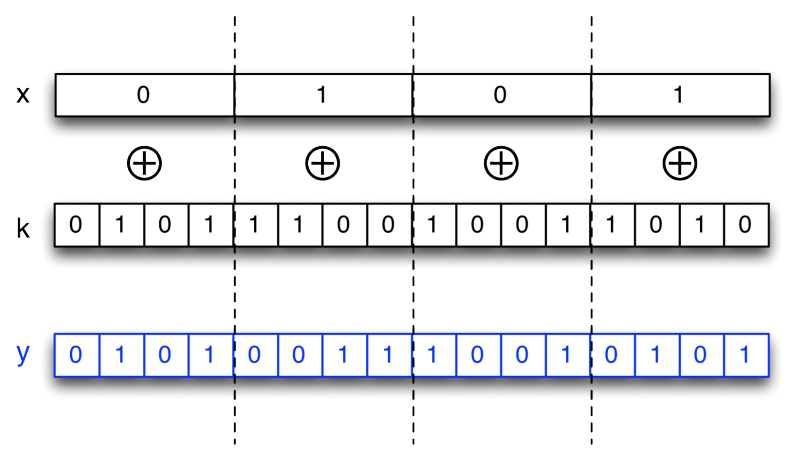

Figura 2.5: Simulação da operação de modulação do DSSS através da operação binária xor.

A princípio consideramos utilizar essa técnica também na cifra multicanal, mas nos exemplos do DSSS pode-se reparar que há um aumento expressivo da informação e também de geração de redundância dos valores binários, por esse motivo, apesar de interessante, ignoramos essa técnica nesse trabalho.

\footnotetext{
${ }^{6}$ Em sinais de rádio audíveis, o sinal resultante lembra um ruído branco, um som de estática.
} 


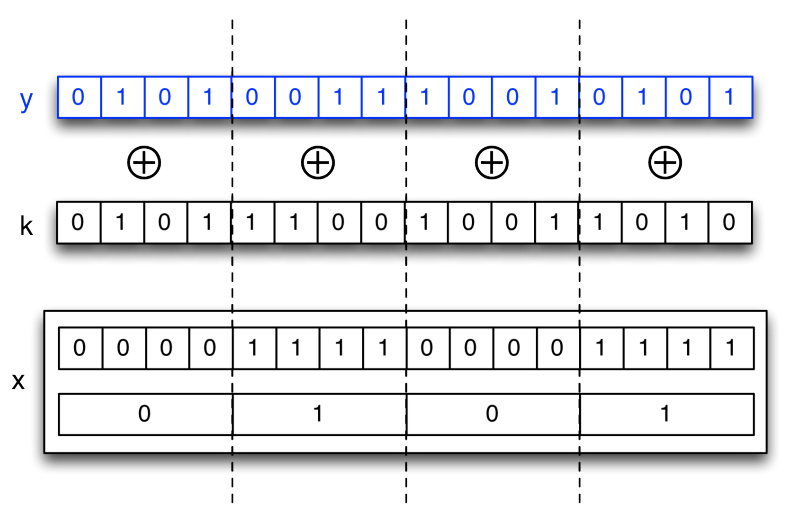

Figura 2.6: Simulação da operação de demodulação do DSSS através da operação binária xor.

Neste capítulo apresentamos uma introdução sobre as técnicas de espalhamento espectral, detalhamos o funcionamento das duas principais o DSSS e o FHSS. Em particular, a técnica FHSS, possui uma característica interessante que queremos reproduzir na cifra multicanal. 


\section{Capítulo 3}

\section{A cifra multicanal}

Neste capítulo fazemos uma revisão sobre os conceitos de criptografia, dos tipos de criptanálise e das redes TCP/IP, na sequência, apresentamos a nossa proposta da cifra multicanal e seu esquema geral de funcionamento.

Os conceitos de criptografia, os tipos de criptanálise e as definições de transposição e composição de funções criptográficas detalhados a seguir foram extraídos do livro Terada (2008).

\subsection{Criptografia de chave secreta ou simétrica}

Em um modelo de comunicação onde um agente A (Alice) comunica-se de forma segura com um agente B (Beto) (figura 3.1), conforme representação da figura 3.1. Alice com a chave $k$, criptografa um texto legivel $x$ (texto original, ou em inglês plaintext obtendo um texto ilegivel, $f_{k}(x)=y$. O texto $y$ é transmitido para o computador de destino do Beto, onde $y$ é decriptografado pelo algoritmo inverso do utilizado por Alice, $f_{k}^{-1}(y)$, obtendo-se $x$ se e só se o destinatário Beto conhecer a chave $k$. Para quem desconhece a chave $k$, um possível adversário, um agente $\mathrm{C}$ interceptador (o Criptanalista Carlos), é computacionalmente difícil obter-se $x$ somente a partir do conhecimento de $y$, isso se o algoritmo $f(x)$ for bem projetado, seguro.

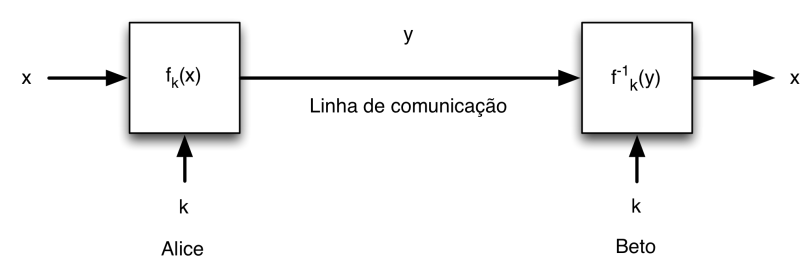

Figura 3.1: Representação de um canal de comunicação seguro, estabelecido pelo uso de um algoritmo de criptografia (cifra) simétrico.

\subsection{Criptanálise e seus tipos}

Ao analisar a segurança de um algoritmo criptográfico, o criptanalista Carlos tem o objetivo de quebrar ${ }^{1}$ um texto ilegível $y$ interceptado, ou quebrar a chave secreta $k$.

Os tipos de ataque que Carlos pode realizar são:

1. Ataque por só-texto-ilegível: $\mathrm{O}$ criptanalista Carlos tenta adquirir conhecimento útil à quebra analisando um ou mais ilegíveis $y$. Se este tipo de ataque for computacionalmente viável o algoritmo em questão é considerado totalmente inseguro e inútil, quebrado.

\footnotetext{
${ }^{1} \mathrm{O}$ termo "quebrar"aqui tem o significado de atingir o objetivo, contra um texto-ilegível, significa descobrir o texto-legível original. Contra a chave secreta, significa descobrí-la.
} 
2. Ataque por texto legivel conhecido: $\mathrm{O}$ criptanalista Carlos $^{2}$ possui e analisa pares $(x, y)$ de texto legível e ilegível correspondentes.

3. Ataque por texto legível escolhido: Além do descrito no ataque anterior (texto legível conhecido), o criptanalista Carlos pode escolher os legíveis $x$ e obter os $y$ correspondentes. Ele vai escolher $x$ que apresente alguma característica estrutural que aumente o seu conhecimento do algoritmo e da chave em uso. Com o conhecimento adquirido ele pode deduzir o legível correspondente a um ilegível novo.

4. Ataque adaptativo por texto legivel escolhido: Além do descrito no ataque anterior (texto legível escolhido), a escolha de um novo $x$ pelo criptanalista Carlos pode depender dos ilegíveis $\bar{y}$ analisados anteriormente. Desta forma a escolha de um novo $x$ é condicionada ao conhecimento já adquirido pela análise dos $\bar{y}$ já analisados.

5. Ataque por texto ilegivel escolhido: O criptanalista Carlos escolhe inicialmente o ilegível y e então obtém o legível $x$ correspondente. Supõe-se que Carlos só tenha acesso ao algoritmo de decriptografia (sem acesso à chave secreta $k$ ) e o seu objetivo é, mais tarde, sem ter mais acesso à decriptografia, ser capaz de deduzir $x$ correspondente a um $y$ novo.

6. Ataque adaptativo por texto ilegível escolhido: Além do descrito no item anterior (texto ilegível escolhido), a escolha de um novo $y$ pelo criptanalista Carlos pode depender dos ilegíveis $\bar{y}$ analisados anteriormente. Dessa forma a escolha de um novo $y$ é condicionada ao conhecimento já adquirido pela análise dos $\bar{y}$ já analisados.

Ainda, segue abaixo, outros tipos de ataques que podem ser aplicáveis em outros cenários e que podem ser compostos com os ataques descritos acima ou entre si:

1. Ataque por chaves conhecidas: O criptanalista Carlos conhece algumas chaves já usadas e utiliza tal conhecimento para deduzir chaves novas.

2. Ataque por replay: O criptanalista Carlos grava as comunicações legítimas entre Alice e Beto, e depois usa parte da gravação para o seu proveito. Se a parte da gravação usada não é alterada, este ataque é chamado de passivo, caso contrário, de ativo.

3. Personificação: O criptanalista Carlos simula um outro usuário legítimo. Por exemplo, toma o lugar de Alice sem que Beto consiga notar qualquer diferença.

4. Ataque por dicionário: Muito utilizado para deduzir senhas quando o criptanalista Carlos tem acesso ao arquivo de senha legítimas criptografadas; Carlos calcula antecipadamente as senhas criptografadas $y$ correspondentes às senhas $x$ mais comuns (Ex: nome de pessoas, números de telefones, data de nascimento, e suas combinações, etc.) e compara com os y calculados e armazenados no arquivo de senhas legítimas; se encontrar um $y$ igual no arquivo, ele já possui a senha $x$ válida correspondente.

\subsection{Transposição (Permutação)}

Trata-se de uma cifra onde uma chave secreta $k$ é uma permutação $c_{1}, c_{2}, \ldots, c_{n}$ dos inteiros de 1 a $n$. Seja $x=\left\{x_{1}, x_{2}, \ldots, x_{n}\right\}$ um texto legível, onde $x_{j}$ representa cada dígito ou letra de $x$. A transposição consiste em transpor cada $x_{j}$ na posição $j$ para a posição $c_{j}$.

Por exemplo, para $n=4$ o texto legível $x=$ "SATURNOS" é criptografado para $y=$ "AUSTNSRO", conforme a tabela 3.1. Observer que a chave $\{3,1,4,2\}$ é utilizada duas vezes.

\footnotetext{
${ }^{2}$ Nesse e nos tipos de ataque a seguir, supomos que o criptanalista tem pleno acesso ao algoritmo (sem conhecer a chave secreta $k$ ) e não é necessariamente um adversário, uma pessoa mal-intencionada ou um intruso, mas pode ser um especialista que objetiva descobrir as vulnerabilidades do algoritmo, objeto do estudo, que fora projetado por outra pessoa, eventualmente.
} 


\begin{tabular}{|l|c|c|c|c|c|c|c|c|}
\hline posição j & 1 & 2 & 3 & 4 & 1 & 2 & 3 & 4 \\
\hline legível & $\mathrm{S}$ & $\mathrm{A}$ & $\mathrm{T}$ & $\mathrm{U}$ & $\mathrm{R}$ & $\mathrm{N}$ & $\mathrm{O}$ & $\mathrm{S}$ \\
\hline chave & 3 & 1 & 4 & 2 & 3 & 1 & 4 & 2 \\
\hline ilegível & $\mathrm{A}$ & $\mathrm{U}$ & $\mathrm{S}$ & $\mathrm{T}$ & $\mathrm{N}$ & $\mathrm{S}$ & $\mathrm{R}$ & $\mathrm{O}$ \\
\hline
\end{tabular}

Tabela 3.1: Exemplo de transposição.

O número total de chaves possíveis é $n$ ! (i.e. fatorial de $\mathrm{n}$ ). Mas essa cifra preserva a frequência das letras se $x$ for uma língua natural, é então sensível a inferências estatísticas.

Para um texto legível $x$ binário, $x_{j}$ é no mínimo um bit ou um conjunto de bits previamente estabelecidos. Neste caso a inferência estatística é mais difícil desde que o $x_{j}$ binário não apresente um padrão de codificação conhecido (ASCII ou EBCDIC, por exemplo).

A operação de transposição está associada com a ideia de difusão, que segundo Menezes et al. (1996), refere-se a reorganização ou espalhamento dos bits em uma mensagem de tal forma que qualquer redundância no texto legivel seja difundida no texto ilegível.

\subsection{Composição}

Sejam dadas duas funções $f$ e $g$ tais que $f(x)=t$ e $g(t)=y$, com $x \in A, t \in B, y \in C$.

A composição $g f$ das funções $f$ e $g$ é definida por $g f(x)=g(f(x))=y$.

A maioria dos algoritmos criptográficos modernos consiste em uma composição de várias funções $f_{j}$ para obter $y=f_{n} f_{n-1} \ldots f_{2} f_{1}=F(x)$. Assim, mesmo que cada uma das $f_{j}$ não seja isoladamente segura, a função composta $F(x)$ é relativamente mais segura.

Em particular, a cifra multicanal proposta nesse trabalho pode ser considerada como a aplicação uma segunda função criptográfica no sistema, com o objetivo de deixá-lo mais seguro, até mesmo em aqueles que usam cifras já fragilizadas por uma criptanálise qualquer.

\subsection{A rede TCP/IP e a interceptação de pacotes}

O par de protocolos TCP/IP é hoje um dos mais importantes do mundo, está presente no dia a dia de bilhões de pessoas e é parte integrante da economia global. É sobre esse par que estão alguns dos mais utilizados e famosos protocolos, é o caso do HTTP(S) (HyperText Transfer Protocol (Secure)), o protocolo da WWW (World Wide Web), o SMTP (Simple Mail Transfer Protocol) para o envio de e-mails, o FTP (File Transfer Protocol) para a troca de arquivos, e muitos outros.

Não é escopo desse trabalho detalhar o funcionamento da rede TCP/IP, só apresentaremos o fundamental para o entendimento da interceptação dos dados dos canais de comunicação estabelecidos por esse protocolo.

Em relação ao modelo OSI (Open System Interconnection, modelo de rede conceitual, ISO/IEC 7498-1), os protocolos TCP e IP, correspondem às camadas 4, de transporte, e 3, de rede, respectivamente. A seguir, um pouco mais de detalhe sobre os protocolos.

\subsubsection{O protocolo IP}

O IP (Internet Protocol) é um protocolo de rede responsável por entregar pacotes de dados de uma fonte (source) para a um destinatário (target), agentes dessa rede de comunicação que são identificados por um endereço IP (IP $A d d r e s s^{3}$ ), uma das principais informações do procolo. O

\footnotetext{
${ }^{3}$ Número de identificação das máquinas possui atualmente duas versões: IPV4 e IPV6, na primeira os números são organizados por 4 grupos de octetos (1 byte) representados em decimal no intervalo de 0 a 255 , e na segunda, a versão mais moderna, os números de identificação são organizados em oito grupos de 2 bytes, representados em 4 dígitos em hexadecimal. A revisão do protocolo IP, que acabou gerando a versão IPv6, foi necessária devido ao explosivo crescimento da internet, que alcançou o limite de combinações de números possíveis da versão anterior IPv4, à saber,
} 
protocolo IP não garante uma entrega assegurada dos pacotes, não possui controle do fluxo de dados, não tem um mecanismo para de recuperação de erros (frequentes, principalmente em links de rádio) e não é orientado a conexão, em outras palavras, sem controle de estabelecimento e persistência da conexão. A figura 3.2 representa um cabeçalho IP.

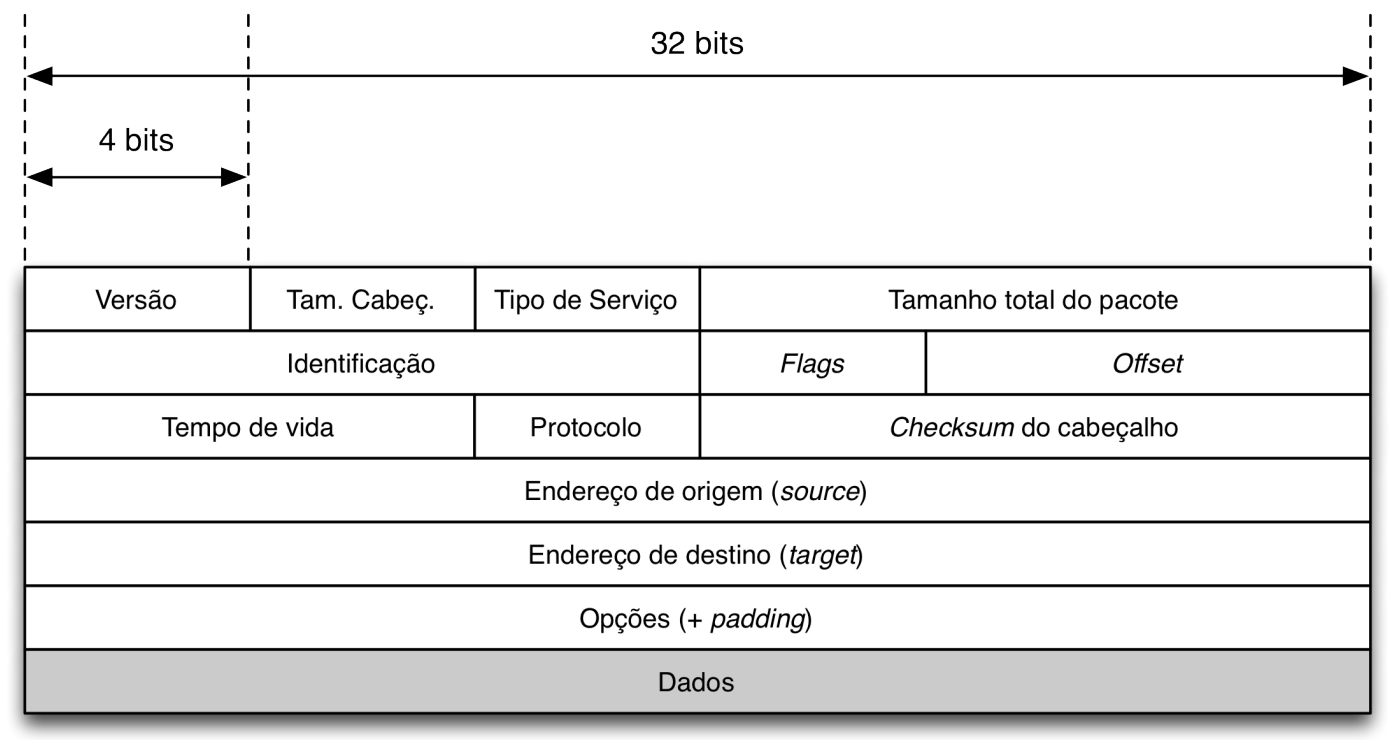

Figura 3.2: Representação do cabeçalho IP.

\subsubsection{O protocolo TCP}

O TCP (Transmission Control Protocol, RFC - Request For Comments 793) como o nome sugere refere-se a um protocolo de controle da transmissão, isso implica na garantia de entrega dos pacotes (confiança), de forma ordenada e íntegra, garantindo que não há erros nos dados transmitidos (verificação e correção de erros). O TCP é um protocolo de transporte orientado a conexão, uma característica complementar ao IP, que traz robustez ao esquema (TCP/IP), e além disso funciona como um serviço intermediário entre a aplicação e o protocolo IP, pois este último, trabalha com tamanhos de dados específicos de 32 bits, o TCP, quando na transmissão de dados maiores, encapsula as operações de divisão de dados para o encaixe nos pacotes IP. A figura 3.3 representa um cabeçalho TCP.

A cifra multicanal proposta a seguir, utiliza múltiplos canais TCP/IP. A maioria das linguagens de programação modernas provê acesso fácil para a criação desses canais. Cada canal estabelecido é um socket (soquete, encaixe, conexão).

Para que ocorra uma comunicação é necessário duas pontas, normalmente programas distintos, um cliente e um servidor.

No desenvolvimento normal do servidor abre-se uma porta de comunicação (socket), estado conhecido como listening (escuta), esperando que um cliente nela conecte, quando há uma conexão, uma nova thread (processo leve, uma nova corrente de processamento) é aberta e o socket é transferido para essa thread, enquanto servidor volta a ficar em listening. Dessa maneira o programa servidor consegue tratar múltiplas conexões. A figura 3.4 ilustra o processo de conexão de múltiplos clientes ao servidor.

O termo multicanal utilizado é justamente por essa característica, trabalha com conexões TCP/IP múltiplas, simultâneas e homogêneas; estabelecidas da maneira descrita acima. O programa cliente mantém normalmente uma só comunicação com o servidor, mas nada impede de haver um programa que controle vários clientes conectados com o servidor.

o número aproximado de 4,3 bilhões de endereços. 


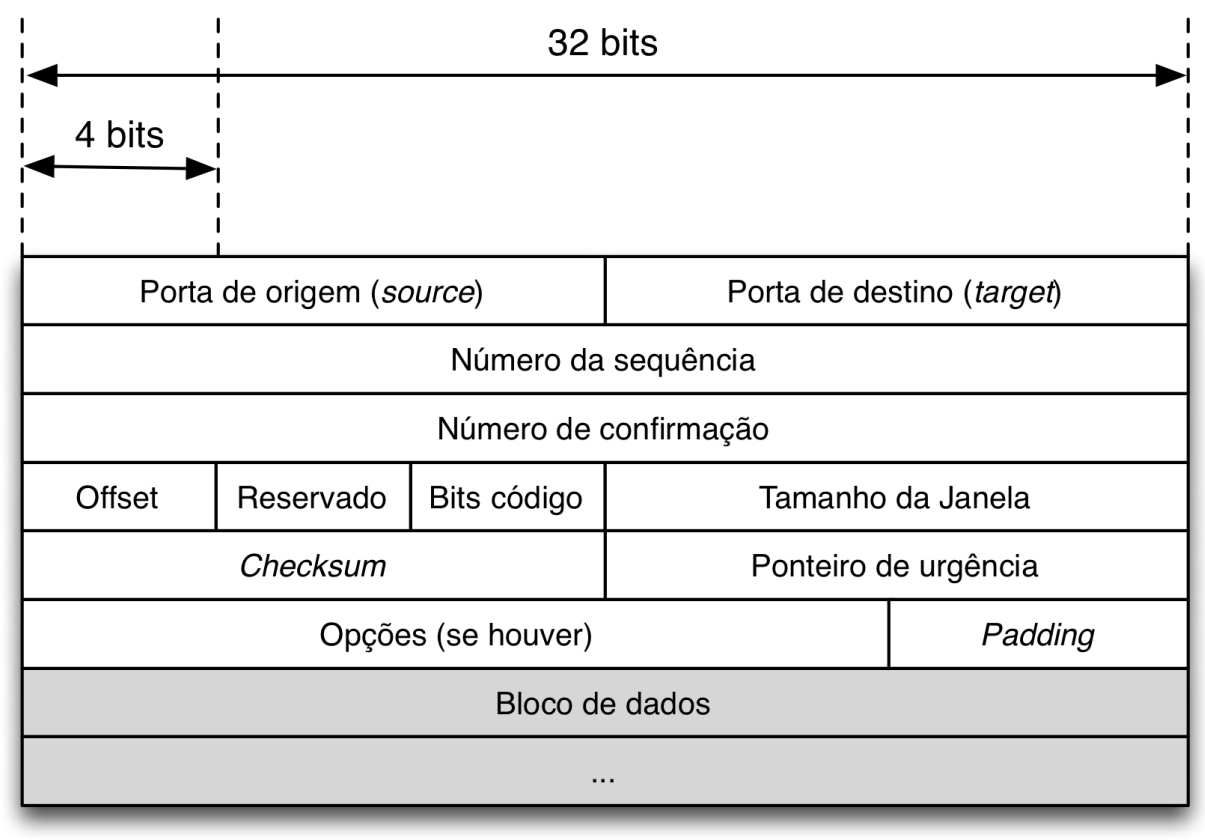

Figura 3.3: Representação do cabeçalho TCP.

Nos protocolos de segurança multicanais verificados, onde um exemplo bem concreto é o proposto por Wong e Stajano (2005), normalmente trabalha-se com poucos canais e que são heterogêneos, onde o objetivo é transmitir partes da chave secreta em meios diferentes, de modo a dificultar a obtenção integral dela, por parte de um adversário.

\subsection{Criptanálise diferencial}

A criptanálise diferencial foi apresentada pela primeira vez por Biham e Shamir na CRYPTO 90 para atacar a cifra DES (Data Encryption Standard) que posteriormente virou um livro Biham e Shamir (1991), embora originalmente apresentado para o DES, juntamente com a criptanálise linear, é hoje uma das principais ferramentas de criptanálise para a cifra de bloco. Alguns artigos a apresentam de forma mais genérica, não relacionada uma cifra de bloco em particular, é o caso do tutorial Heys (2001), no qual nos basearemos para explicar esse ataque.

A criptanálise diferencial explora a alta probabilidade de ocorrência de que certas diferenças do texto-legível gerem certas diferenças no texto-ilegível.

Por exemplo, considerando um sistema que tenha como entrada $x=\left\{x_{1}, x_{2}, \ldots x_{n}\right\}$, onde $x_{i}$ é um bit na posição $i$ de $x$, e uma saída $y=\left\{y_{1}, y_{2}, \ldots, y_{n}\right\}$, onde $y_{j}$ é um bit na posição $j$ de $y$. Considerando duas entradas $x^{\prime}$ e $x^{\prime \prime}$ e duas respectivas saídas $y^{\prime}$ e $y^{\prime \prime}$. A diferença de entrada é dada por $\Delta x=x^{\prime} \oplus x^{\prime \prime}$, assim $\Delta x=\left\{\Delta x_{1}, \Delta x_{2}, \ldots, \Delta x_{n}\right\}$, onde cada $\Delta x_{i}=x_{i}^{\prime} \oplus x_{i}^{\prime \prime}$, representa a diferença de cada bit de $x^{\prime}$ e $x^{\prime \prime}$. De mesmo modo, $\Delta y=y^{\prime} \oplus y^{\prime \prime}$ é a diferença de saída, sendo $\Delta y=\left\{\Delta y_{1}, \Delta y_{2}, \ldots, \Delta y_{n}\right\}$, onde $\Delta y_{i}=y_{i}^{\prime} \oplus y_{i}^{\prime \prime}$, representa a diferença binária das saídas.

Em uma cifra aleatória ideal, a probabilidade que uma diferença de saída particular $\Delta y$ aconteça dado uma particular diferença de entrada $\Delta x$ é de $\frac{1}{2^{n}}$, onde $n$ é o número de bits de $x$. A criptanálise diferencial procura explorar um cenário onde um particular $\Delta y$ ocorre para uma particular diferença de entrada $\Delta x$ com probabilidade $P_{d} \frac{1}{2^{n}}$.

O par de diferenças $(\Delta x, \Delta y)$ é definido como diferencial (differential).

A criptanálise diferencial é um tipo de ataque de somente texto-legível escolhido, porque supõe que o adversário (criptanalista Carlos) consegue selecionar as entradas e examinar as saídas na tentativa de derivar (encontrar) a chave secreta $k$. O adversário seleciona dois pares $x^{\prime}$ e $x^{\prime \prime}$, para satisfazer uma particular diferença $\Delta x$, sabendo que para aquele $\Delta x$, uma $\Delta y$ ocorre com grande 
a)
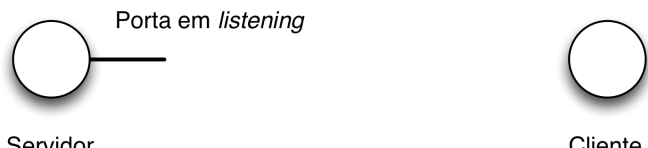

Servidor

Cliente

b)
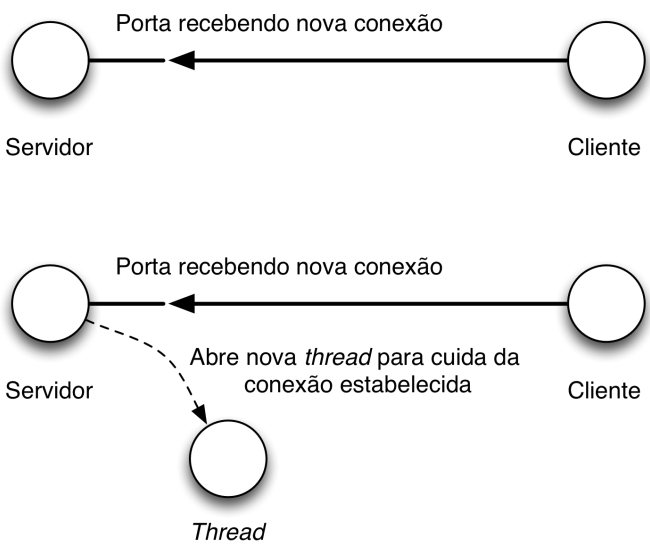

d)
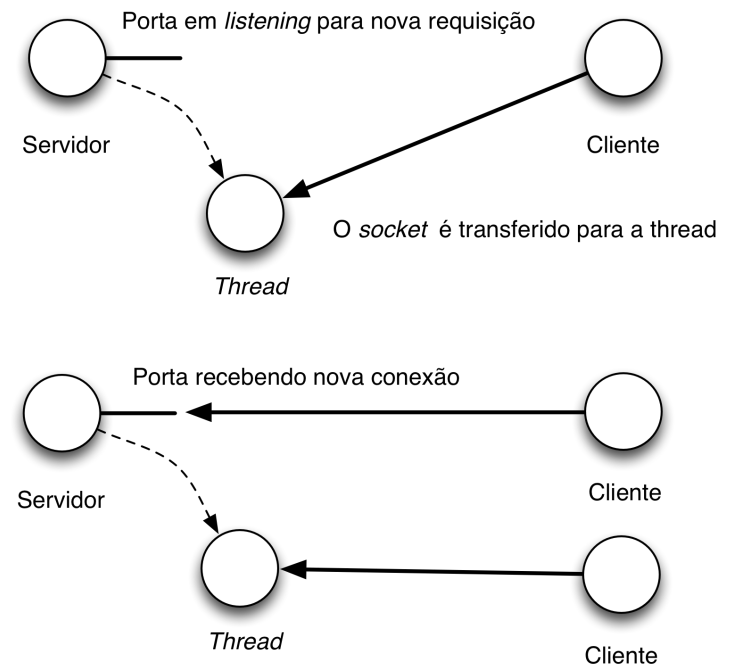

Figura 3.4: Ilustração do processo de abertura de múltiplas conexões socket $T C P / I P$.

probabilidade. Eventualmente, montando-se uma tabela de relações entre $\Delta x$, uma certa quantidade de chaves $k$ e $\Delta y$ e fazendo essa análise várias vezes é possível inferir a chave secreta $k$, que foi utilizada na criptografia, realizando-se muito menos tentativas que a força bruta. A criptanálise diferencial é um procedimento estatístico que procura maximizar a probabilidade de que a chaves escolhidas pelo criptanalista seja a correta.

A força contra a criptanálise diferencial é medida pela relação de números de bits alterados entre $\Delta x$ e $\Delta y$. No nosso caso, 4 bits $^{4}$ são alterados na entrada $(\Delta x)$ quer se descobrir quantos bits são alterados na saída $\Delta y$ e em quais posições em relação a $y^{\prime}$. Se o $\Delta y$ for baixo, e se os bits alterados, mostrarem algum viés, há uma vantagem probabilística para o adversário. Queremos, portanto, que $\Delta y$ seja tão grande quanto possível.

O trabalho de Biham e Shamir (1991) mostra que aplicado ao DES, o tempo médio necessário para o ataque usando essa cifra é da ordem de $2^{47}$, onde pela força bruta o tempo necessário é da ordem de $2^{56}$, uma redução considerável.

Testamos a cifra multicanal contra a criptanálise diferencial, onde mostrou-se extremamente frágil, no capítulo 6 apresentaremos os detalhes dessa fragilidade e a forma proposta para superá-la.

\footnotetext{
${ }^{4}$ Todas as combinações possíveis dos 4 bits.
} 


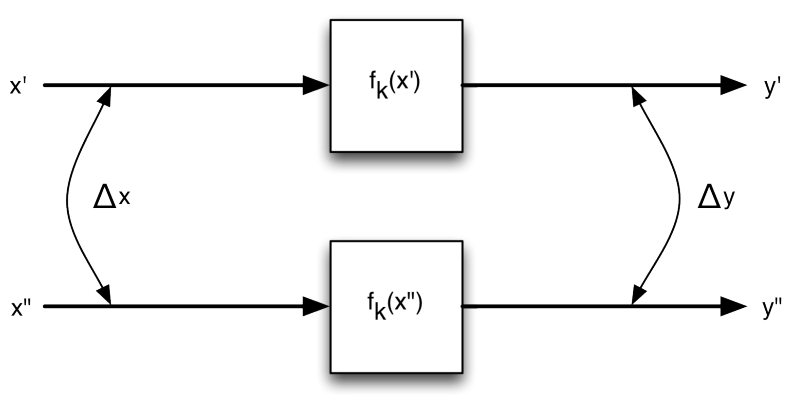

Figura 3.5: Representação da obtenção dos deltas ( $\Delta x$ e $\Delta y$ ) para a criptanálise diferencial.

\subsection{A cifra multicanal proposta}

Uma comunicação TCP/IP segura normalmente é estabelecida criptografando-se um fluxo de dados $x$ (data stream) por um algoritmo criptográfico $f_{k}(x)$, utilizando-se uma chave $k$, gerando um fluxo de dados criptografado y (texto ilegível, ou cifrado) que irá trafegar em um canal socket entre o transmissor (Alice - A) e o receptor (Beto - B). O trabalho do criptanalista (Carlos - C) consiste em capturar esse fluxo de dados criptografado y e, aplicando técnicas de criptanálise, tentar encontrar maneiras de decifrá-lo ${ }^{5}$ (figura 3.6).

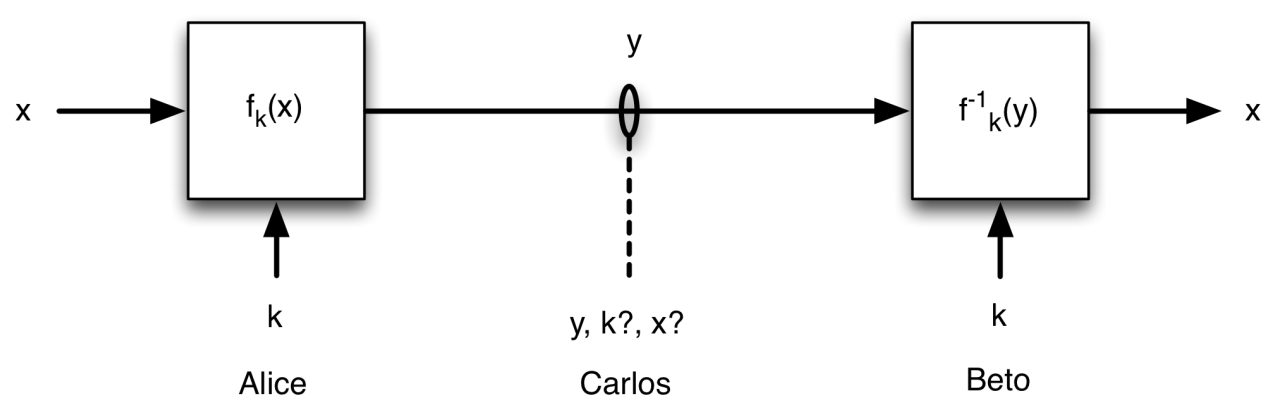

Figura 3.6: Representação da interceptação normal de um canal seguro.

O modelo proposto é criar uma comunicação segura com múltiplos canais, $n$, estabelecidos entre Alice e Beto, enviando nesses canais os blocos criptografados, $p$, do fluxo de dados, o textoilegível $y$, onde $p_{c}=y / n$, para $1 \leq c \leq n$. Cada um dos blocos é enviado seguindo uma sequência aleatória $i$, combinada anteriormente entre Alice e Beto, na figura 3.7 temos uma representação dessa comunicação.

Podemos notar que a dificuldade do criptanalista aumenta, pois agora, além de ter que quebrar o fluxo cifrado $y$, tem que "adivinhar" a sequência aleatória utilizada na transmissão para a remontagem à forma original dos blocos $y$ interceptados ${ }^{6}$.

É esse embaralhamento dos blocos de $y$ enviados por múltiplos canais que estamos chamando de cifra multicanal.

Evidentemente, se pensarmos na cifra de forma serializada, ou seja, após a recuperação do textoilegível "y", podemos pensar na sequência $i$ empregada como a aplicação de uma segunda chave, em uma composição de funções. Sendo $g_{i}(y)=z$ a cifra multicanal e $f_{k}(x)=y$ uma cifra criptográfica qualquer (vide página 28, Terada (2008)). Nesse caso a cifra $g_{i}(y)$ representando uma permutação dos blocos $y$.

Para a realização dos experimentos, na implementação do mecanismo proposto, consideramos ainda a inclusão de um canal seguro TLS (Transport Layer Security) ${ }^{7}$, para a troca de uma chave

\footnotetext{
${ }^{5}$ Em Terada (2008) há uma relação dos tipos de ataques possíveis

${ }^{6} \mathrm{~A}$ interceptação de pacotes é trivial em redes TCP/IP, utilizando-se um sniffer.

${ }^{7}$ Para maiores informações acesse a descrição do protocolo no caminho: http://tools.ietf.org/html/rfc5246.
} 


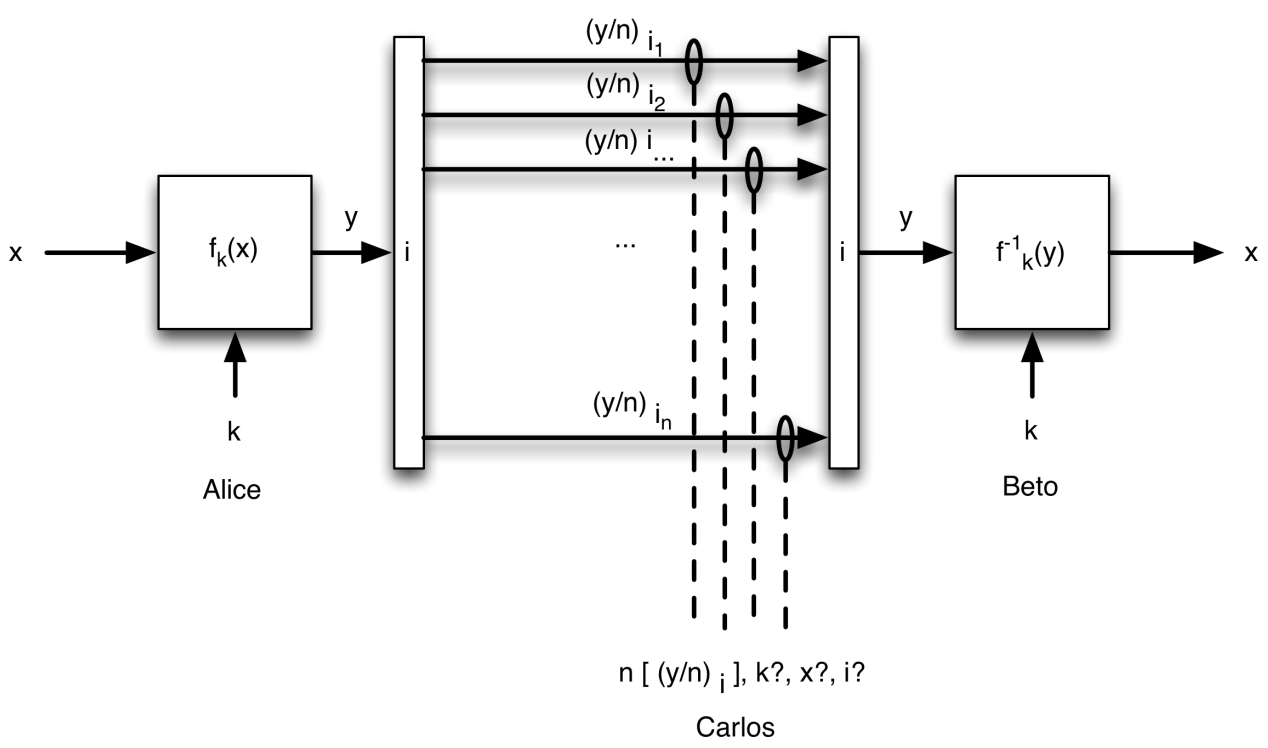

Figura 3.7: Representação da comunicação pela cifra multicanal, interceptada por um criptanalista.

de sessão $k$ e a sequência aleatória $i$, conforme a figura 3.8 .

Eventualmente, essa troca de chaves poderia ser concebida e realizada pela própria comunicação multicanal, não foi o caso aqui para facilitar os experimentos.

O esquema mais simples para a implementação de uma comunicação multicanal é o envio direto e sequencial dos blocos $p_{c}$ do texto ilegível $y$, a medida que vão sendo criadas.

$\mathrm{Na}$ sequência detalhamos o funcionamento, através da sequência de operações e comunicações realizadas pelos agentes Alice e Beto.

\subsubsection{Geração e troca da chave de sessão $k$ e da sequência aleatória $i$}

A primeira etapa é a de geração e troca das chave de sessão $k$ e da sequência aleatória $i$ utilizada no envio dos blocos $p_{n}$. Aqui utilizamos o canal seguro TLS para enviar as chaves, normalmente essa operação é realizada através de um protocolo de acordo de chaves específico, mas tal como protocolo não é foco desse trabalho, apenas supomos que a transferência foi feita de forma segura e que Alice é capaz de identificar Beto de forma inequívoca.

Abaixo a sequência detalhada dessa etapa:

1. Alice gera uma chave de sessão $k$, através de uma função geradora SessionKey(), com tamanho necessário ao uso da cifra criptográfica $f_{k}(x)$;

2. Beto conecta-se à Alice através de $n$ canais e envia através do canal TLS seu código de identificação único $(U U I D)$;

3. Considerando que haja repetição de canais, a partir das $n$ conexões estabelecidas com Beto, Alice gera através da função RandomSequence(), uma sequência aleatória, $i=X_{1}, \ldots, X_{n}$ onde $X$ é uma variável aleatória de distribuição uniforme e independente (IID) com valores representando a identificação dos canais no intervalo de $\{0,1, \ldots, n-1\}$. Se considerarmos a não repetição de canais, a sequência aleatória $i$ gerada pela função RandomSequence(), deve ser composta de $n$ valores aleatórios $v$ distintos, onde $1 \leq v \leq n$ e uniformemente prováveis. A geração dessa sequência pode ser feita através do seguinte algoritmo: 


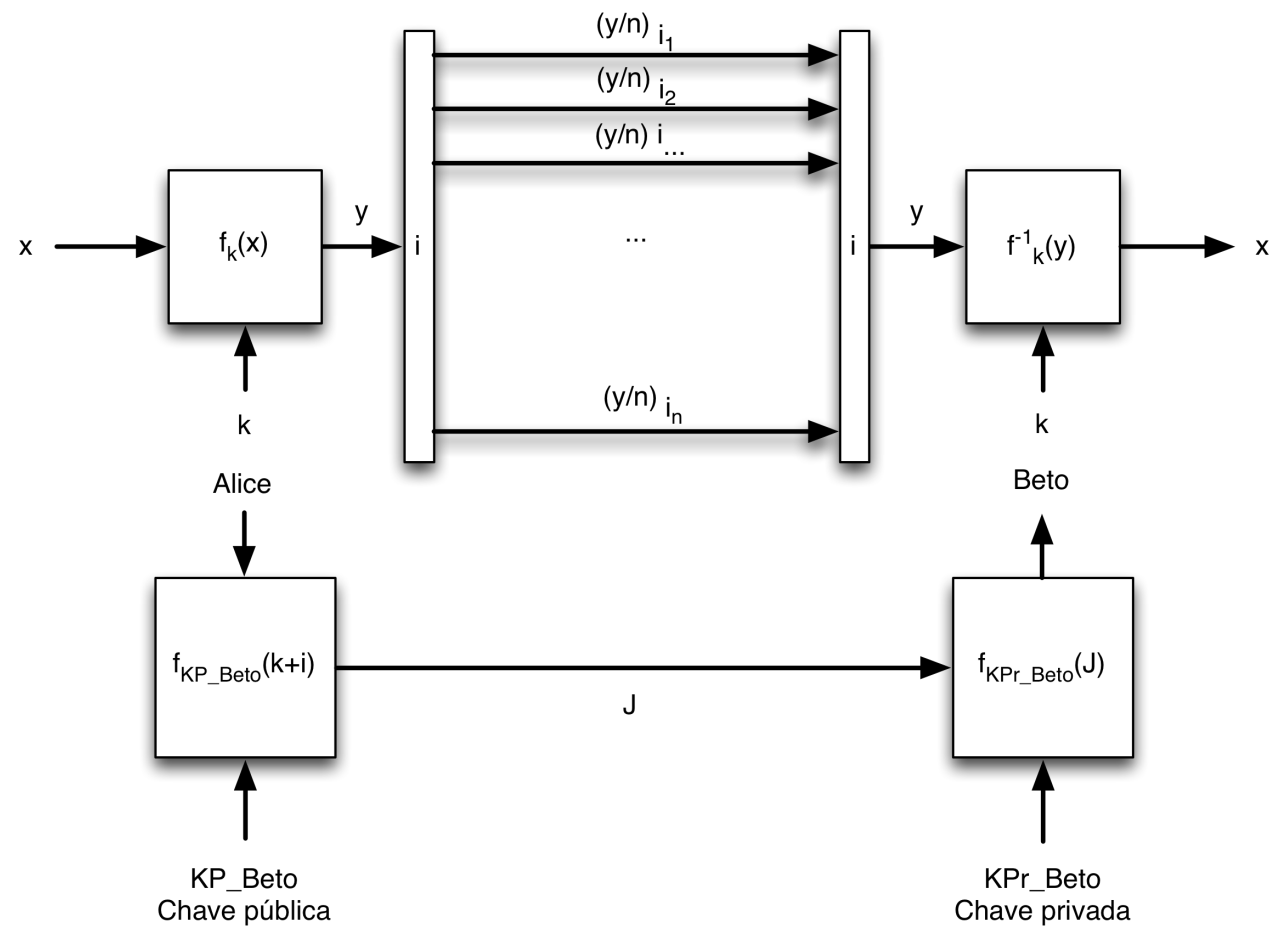

Figura 3.8: Comunicação multicanal, com um canal específico para a troca de chaves.

\section{RandomSequence(n)}

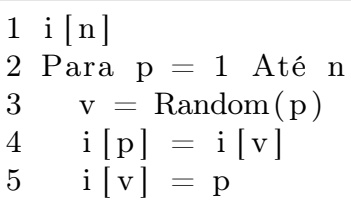

A função RandomSequence( $n$ ) retorna um valor aleatório $v$ de 1 até $n$. Provar que esse algoritmo gera uma sequência aleatória uniforme não é trivial, mas ele é baseado em um algoritmo conhecido na literatura como PermuteInPlace detalhado em Cormen et al. (2009), onde está definido o lema 5.5. que prova que o algoritmo realiza uma permutação aleatória uniforme. No algoritmo RandomSequence somente acrescentamos ao PermuteInPlace a inserção de valores $v$ no vetor de saída $i$, ao invés de só permutarmos o vetor.

4. Alice então envia a chave de sessão e a sequência aleatória $i^{8}$ gerada para Beto.

A figura 3.9 ilustra essa etapa.

\subsubsection{A demultiplexação e envio de dados através dos múltiplos canais}

Com os canais estabelecidos e chaves trocadas é possível realizar a transmissão dos dados. A transferência é iniciada por Beto que informa a Alice a informação que deseja. Alice, então, com a chave $k$, criptografa o texto-legível (informação) $x$ requerido por Beto, divide o tamanho do texto ilegível $y$ resultante a ser transmitido pelo número de canais estabelecidos $n$, e então, envia os blocos $p_{c}$ para Beto.

Abaixo a sequência detalhada dessa etapa:

1. Beto faz a requisição de dados $($ DataRequest ()$)$ a Alice, no canal SSL;

\footnotetext{
${ }^{8}$ Podemos pensar nessa sequência como uma segunda chave criptográfica. Supondo que haja 256 canais estabelecidos, o tamanho dessa chave seria de 256 bytes, ou 2048 bits.
} 
2. Alice criptografa os dados requeridos com uma função criptográfica $f_{k}(x)=y$;

3. Alice envia então, sequencialmente, em cada um dos canais estabelecidos $C_{n}$ com Beto, um dos blocos do texto-ilegível $p_{d}$, onde $d$ é a identificação de uma parte de $y$ escolhida segundo a sequência aleatória estabelecida $i$;

4. No final da transmissão, Alice sinaliza Beto do término (EndOfData()), no canal SSL.

A figura 3.10 ilustra essa etapa.

\subsubsection{Multiplexação (montagem) dos dados recebidos}

Uma vez recebidos todos os blocos, o papel de Alice na comunicação encerra-se. Beto com a sequência aleatória $i$ e com os blocos obtidos $p_{n}$, reordena os blocos no texto-ilegível $y$, e com a chave $k$, o decriptografa em $x$.

Neste ponto todas as conexões podem ser terminadas, aí depende somente o uso que se queira dar à aplicação.

Abaixo a sequência detalhada dessa etapa:

1. Beto serializa a informação recuperando os dados dos canais utilizando a sequência aleatória $i$ estabelecida em conjunto com Alice;

2. Beto utiliza a função inversa do algoritmo criptográfico $f_{k}^{-1}(y)=x$, e assim, recupera os dados originais requeridos $x$.

A figura 3.11 ilustra essa etapa.

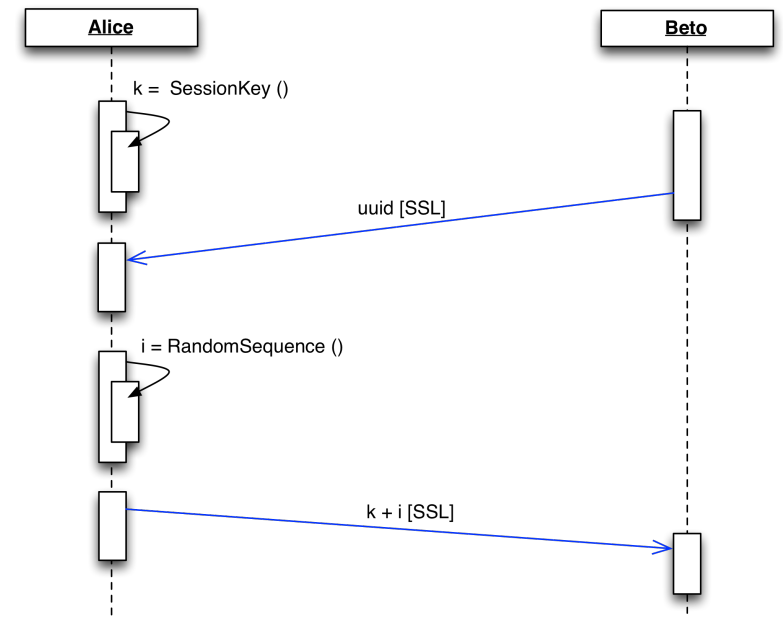

Figura 3.9: Geração e troca da chave de sessão $k$ e da sequência aleatória $i$.

Neste capítulo fizemos uma introdução dos conceitos necessários para o entendimento da cifra multicanal e apresentamos suas características, principalmente o esquema básico de funcionamento entre os agentes de comunicação Alice e Beto. 


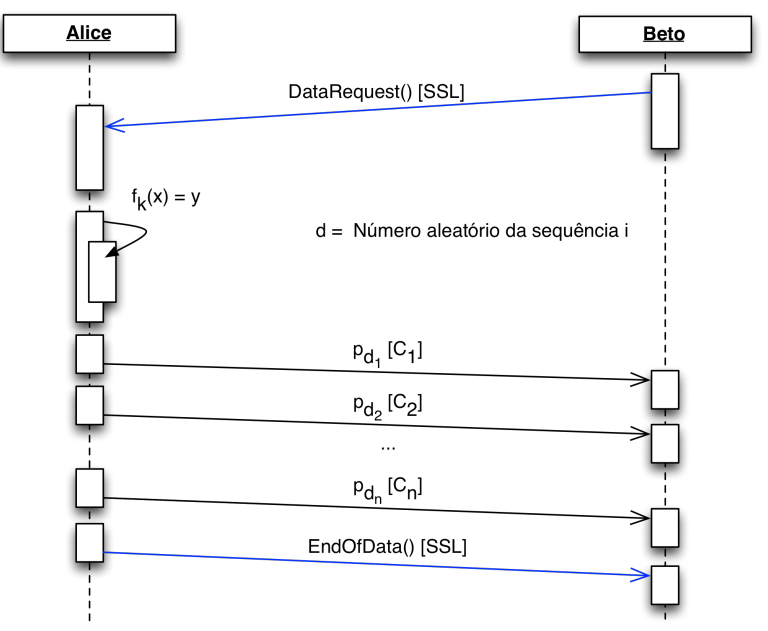

Figura 3.10: Envio de dados em esquema multicanal.

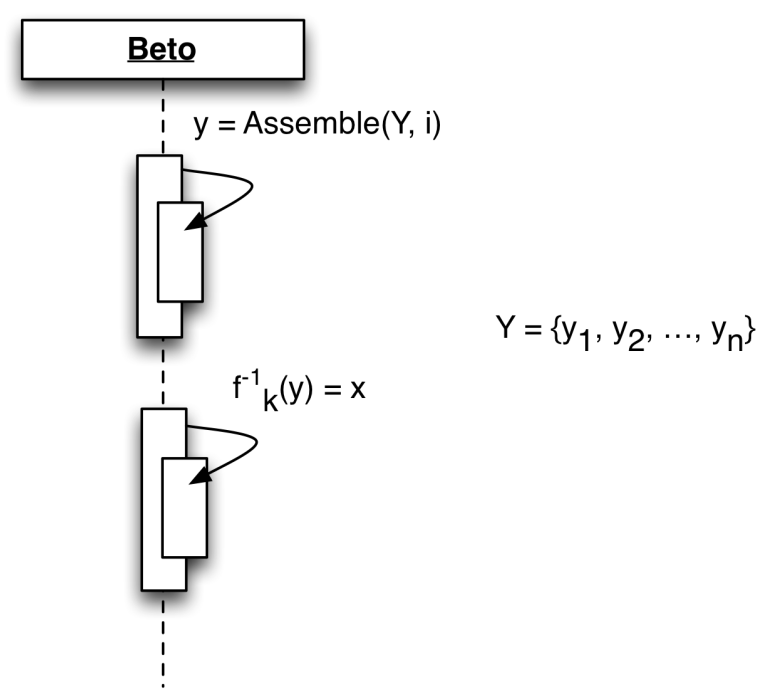

Figura 3.11: Remontagem dos dados. 


\section{Capítulo 4}

\section{Características da cifra multicanal}

Após a apresentação da cifra no capítulo anterior, apresentamos aqui as suas características e propriedades, mostramos que pode ser considerada como uma permutação aleatória, onde o número de combinações é razoavelmente grande, de forma que há considerável ganho de segurança em sua utilização.

Se removida a parte da comunicação, a cifra multicanal pode ser reduzida em uma segunda função, em uma composição de funções criptográficas, a aplicação de uma segunda chave, a sequência aleatória. A aplicação dessa segunda chave é meramente uma operação de permutação aleatória que apesar de sua simplicidade permite aumentar a segurança de todo os sistema, e com uma pequena alteração pode aumentar relativamente a segurança contra a criptanálise diferencial conforme estabelecido por Biham e Shamir (1991) (detalhado no capítulo 3).

Supondo que o criptanalista Carlos consiga todas os blocos $p$ do texto-ilegível $y$ transmitidos, o que em uma rede TCP/IP é relativamente fácil, principalmente se considerarmos apenas uma única interface de rede ${ }^{1}$ entre Alice e Beto, é trivial que a segurança da cifra multicanal seja toda relacionada com a sequência aleatória $i$ combinada entre as partes (Alice e Beto), pois Carlos teria que verificar cada uma das combinações possíveis dos blocos que obteve até encontrar a correta que representa o texto-ilegível $y$ antes que possa, enfim, analisar para tentar descobrir o texto-original.

Assim, é importante que o gerador da sequência aleatória gere realmente números aleatórios em uma distribuição uniforme. Do contrário, Carlos, poderia ter alguma vantagem estatística para obter a sequência aleatória $i$.

Supondo que o gerador é realmente aleatório, o número de combinações que o criptanalista Carlos precisa analisar, no pior caso, é de $n$ !, se não considerarmos a repetição dos canais envolvidos na comunicação. E $n^{n}$, se houver repetição dos canais. Evidentemente a probabilidade de Carlos encontrar a sequencia certa é de $1 / n$ ! e $1 / n^{n}$, respectivamente, à questão da repetição de canais.

Para o número de 100 canais Carlos tem $7,15.10^{-150 \%}$ (considerando a não repetição de canais) como probabilidade de acerto ao acaso da sequência correta de montagem do texto-ilegível.

Desde o início de 2012, já podemos contar com um gerador realmente aleatório em chips convencionais da Intel, através da instrução RdRand, nos chips da plataforma ivy-bridge, segundo Hofemeier (2012), portanto podemos considerar a hipótese do gerador de sequência aleatória como verdadeira e funcional. Neste trabalho não tivemos acesso a um chip com essa instrução (RdRand), trabalhamos que essa hipótese seja verdadeira e nas implementações dos experimentos utilizamos um gerador relativamente seguro da linguagem Java, implementado pela classe, java.security.SecureRandom ${ }^{2}$, esse gerador aleatório atende as especificações estatísticas do NIST (National Institute of Standards and Technology) estabelecidas pela FIPS 140-2, Security Requirements for Cryptographic Modules ${ }^{3}$, na sessão 4.9.1.

\footnotetext{
${ }^{1}$ Para tal basta utilizar um programa para capturar todos os pacote de comunicação que passam na interface de rede (um sniffer, o Wireshark (http://www.wireshark.org/) é um do mais conhecidos programas para tal).

${ }^{2} \mathrm{~A}$ documentação sobre esse gerador está disponível no javadoc, através do endereço: http://docs.oracle.com/ javase/7/docs/api/java/security/SecureRandom.html

${ }^{3}$ Disponível em csrc.nist.gov/cryptval/140-2.htm
} 
Sendo $T_{\text {quebra }}$ o tempo total de quebra da chave de sessão $k$ utilizado por um algoritmo criptográfico qualquer $f_{k}(x)=y$, no melhor caso, o adversário tem sorte, e consegue, ao acaso, escolher a sequência correta $i$ com a qual os blocos foram permutados, utilizando a cifra multicanal. Nesse caso, o tempo total de quebra é exatamente o tempo de quebra do algoritmo criptográfico utilizado, $T_{\text {total }}=T_{\text {quebra }}$. A chance do adversário conseguir tal façanha é dada pela probabilidade $P(q u e b r a)=\frac{1}{n !}$ no caso da não repetição de canais e $P(q u e b r a)=\frac{1}{n^{n}}$, caso haja repetição, ou seja, bem baixa, para um número razoável de canais.

No pior caso, o adversário tem azar, e tem que avaliar cada uma das combinações possíveis para a sequência $i$. Nesse caso, $T_{\text {total }}$ pode ser escrito como $T_{\text {total }}=T_{\text {quebra }} . n$ !, sem repetição de canais, ou $T_{\text {total }}=T_{\text {quebra }} . n^{n}$, caso haja reutilização dos canais.

Considerando a probabilidade de quebra $P(q u e b r a)=\frac{1}{n !}$ (sem repetição de canais), podemos realizar uma análise de tempo médio, $T_{\text {medio }}$ para a quebra da cifra multicanal, da seguinte forma ${ }^{4}$ :

$$
\begin{aligned}
& T_{\text {medio }}=\frac{1}{n !} \cdot T_{\text {quebra }}+\frac{2}{n !} \cdot T_{\text {quebra }}+\ldots+\frac{n !}{n !} \cdot T_{\text {quebra }} \\
& T_{\text {medio }}=\frac{1}{n !} \cdot(1+2+\ldots+n !) \cdot T_{\text {quebra }} \\
& T_{\text {medio }}=\frac{T_{\text {quebra }}}{n !} \cdot \sum_{i=1}^{n !} i \\
& T_{\text {medio }}=\frac{T_{\text {quebra }}}{n !} \cdot\left(\frac{n ! .(n !+1)}{2}\right) \\
& T_{\text {medio }}=T_{\text {quebra }} \cdot\left(\frac{(n !+1)}{2}\right)
\end{aligned}
$$

Assintoticamente para um número grande de $n$, percebemos que o tempo médio $T_{\text {medio }}$ é igualmente explosivo, como no pior caso.

$$
\lim _{n \rightarrow \infty} T_{\text {medio }}=\infty
$$

Portanto, podemos observar que como o crescimento das combinações é no mínimo fatorial, com poucos canais estabelecidos aumenta-se consideravelmente o esforço da criptanálise.

Ainda no caso da obtenção total dos blocos do texto-ilegível pelo adversário (Carlos), se serializarmos os blocos $p$ obtidos na mesma ordem da obtenção, notamos que a operação resultante tratase, na realidade, de uma permutação aleatória em blocos do texto-ilegível $y$, definidos pelo emprego de uma segunda chave, a sequência aleatória $i$. Conforme já mencionado (capítulo 3) trata-se uma composição de funções, onde a função composição $c$ pode ser definida como $c_{k 1 k 2}(x)=g_{k 2}\left(g_{k 1}(x)\right)$. A demonstração que $c_{k, i}(x)$, no nosso caso a cifra multicanal, é mais forte (mais seguro), que uma outra cifra qualquer, $f_{k}(x)$, em termos assintóticos é razoavelmente difícil, no entanto, podemos testar o aumento de segurança para alguns casos de criptanálise mais utilizados, é o caso, em relação a criptanálise diferencial que apresentamos no capítulo 3.

Neste capítulo apresentamos as características da cifra multicanal e suas propriedades. Mostramos que podemos considerar um gerador aleatório real e disponível nas próximas gerações de computadores, através da instrução RdRand dos novos chips da Intel. Mostramos que as combinações geradas pela cifra multicanal são grandes o suficiente para um aumento considerável de segurança.

\footnotetext{
${ }^{4}$ Consideramos na demonstração o caso sem repetição de canais, para o caso da repetição de canais, basta trocar o $n$ !, por $n^{n}$
} 


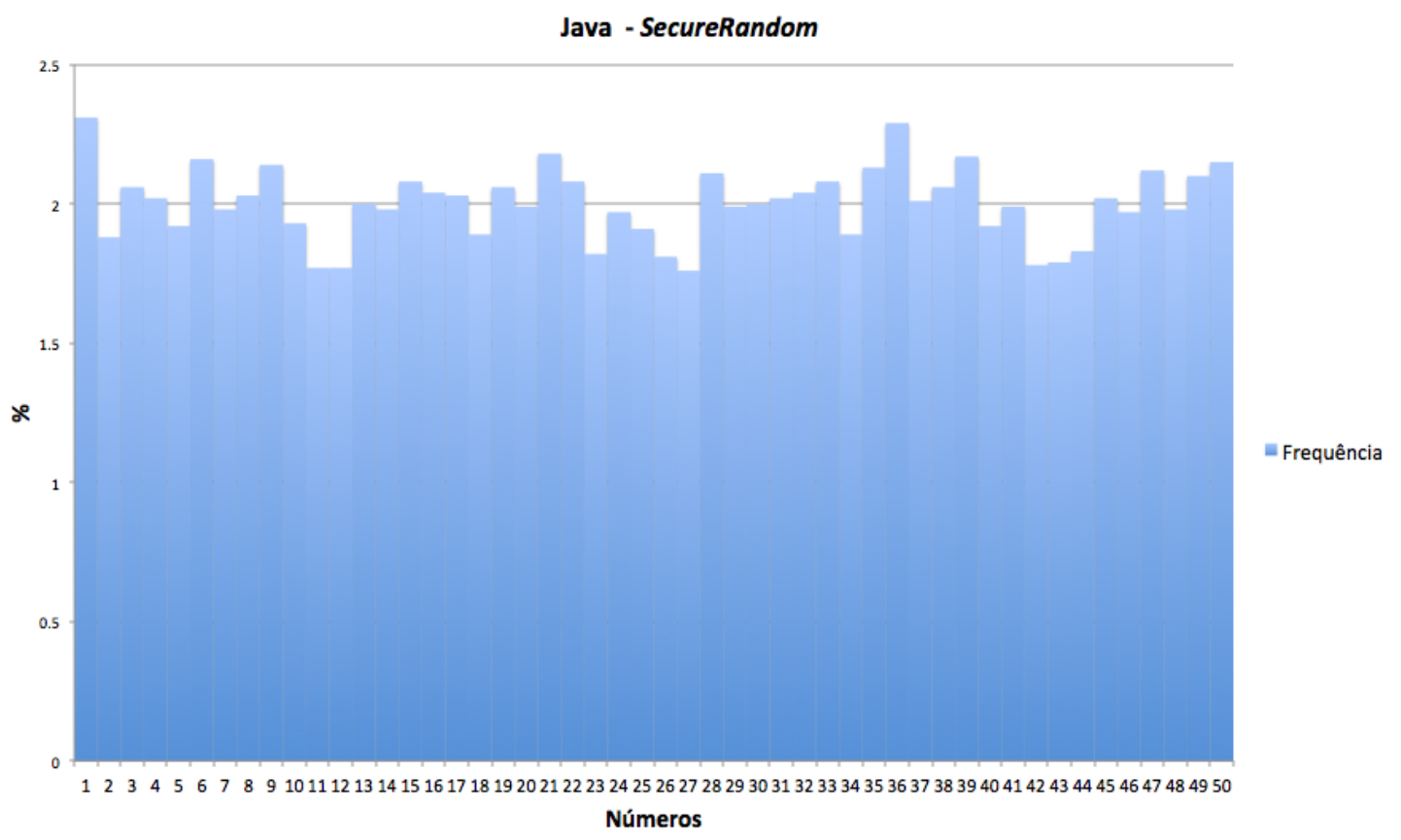

Figura 4.1: Distribuição de números aleatórios de 1 a 50, pela classe [java.security.SecureRandom] da plataforma Java.

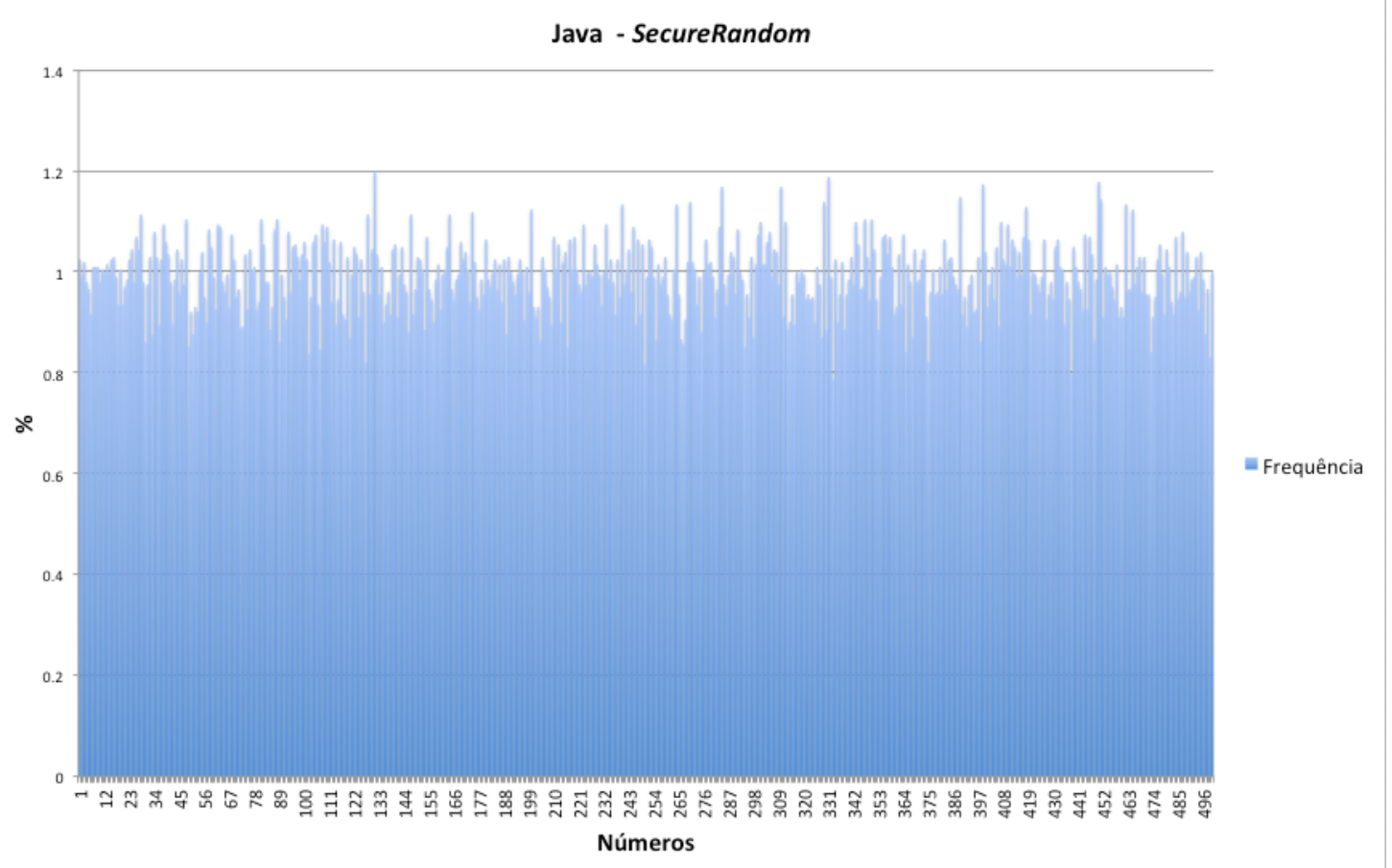

Figura 4.2: Distribuição de números aleatórios de 1 a 500, pela classe [java.security.SecureRandom] da plataforma Java. 
Fatorial

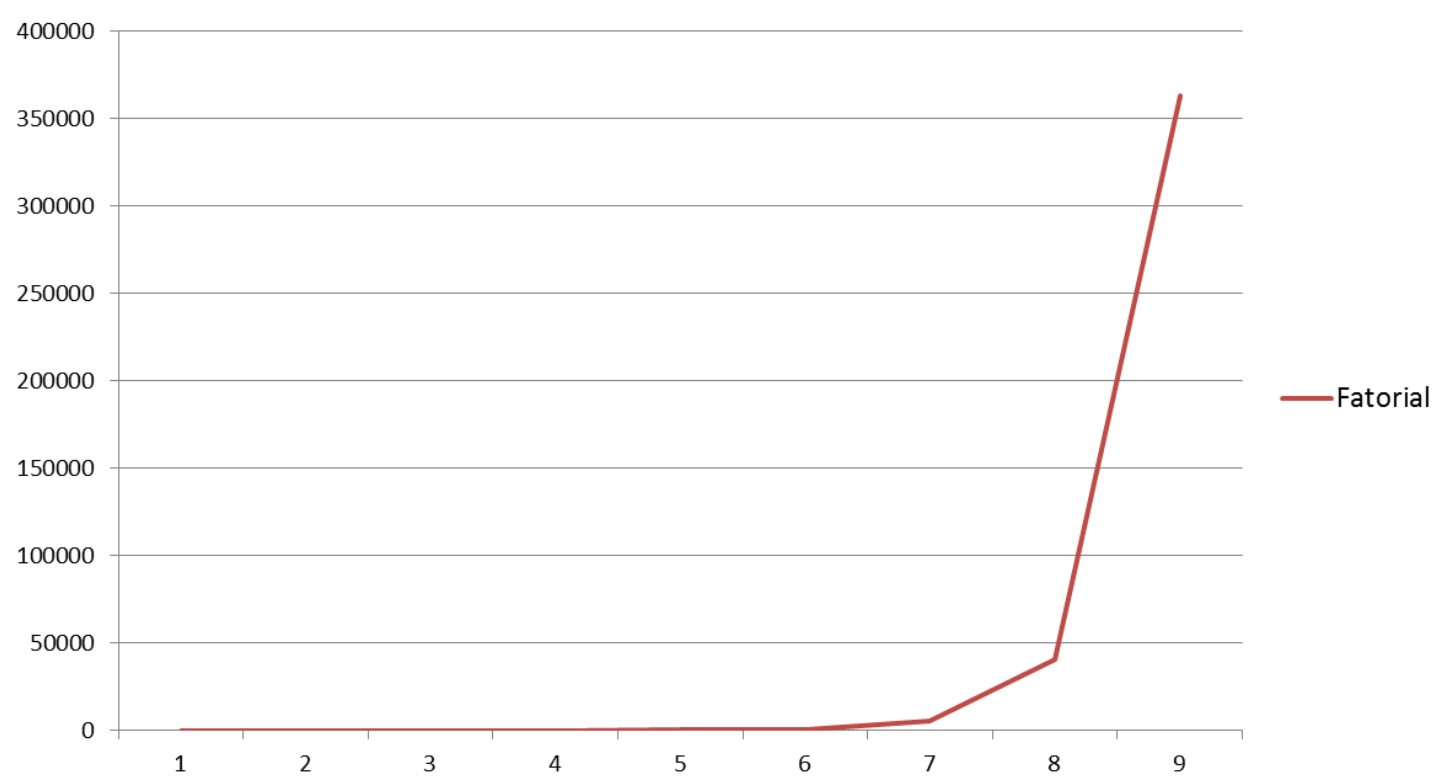

Figura 4.3: Crescimento de uma função fatorial. 


\section{Capítulo 5}

\section{Metodologia}

Neste capítulo apresentamos a metodologia utilizada nesse trabalho para aferir a viabilidade da cifra multicanal como uma alternativa de uso prático, e, também, como medir a segurança da cifra em relação à criptanálise diferencial, através do cálculo dos valores $\Delta x$ e $\Delta y$.

Para validar a cifra multicanal proposta, foi desenvolvido um sistema "cliente-servidor", inspirado na técnica FHSS, com agentes comunicando-se entre si através de múltiplos canais TCP/I que simulando computacionalmente uma comunicação real, nos permitiu gerar dados empíricos de análise.

Sobre a transferência de dados da cifra, nessa implementação, temos os seguintes pontos de avaliação:

1. Como múltiplos canais são estabelecidos, o tempo de administração desses canais, inviabilizam a transmissão?

2. Qual é relação entre o tempo de administração e o tempo total da comunicação?

3. Qual é a sua evolução em função do número de canais estabelecidos?

4. Em uma comunicação serial os dados são empacotados pelo protocolo TCP uma única vez, no caso da cifra multicanal, por conta da divisão da informação em vários blocos, qual é o tempo a mais (overhead) gasto pelo TCP para a transmissão de cada um desses blocos?

5. Qual a relação do tempo gasto com a cifra multicanal e em relação a apenas um canal seguro estabelecido, o meio normal de comunicação?

Para responder a tais pontos, os tempos da comunicação foram aferidos com precisão de milissegundos e segregados por função: inicialização, estabelecimento dos múltiplos canais de comunicação, divisão da informação, transmissão e tempo de remontagem da informação.

Para a relação do tempo com o número de canais, foram efetuados vários experimentos com diferentes números de canais.

E para o estudo da relação entre a cifra multicanal e uma comunicação segura normal (com apenas um canal estabelecido). Uma nova implementação foi realizada, com apenas um canal seguro (TLS), e os mesmos dados utilizados nos experimentos com a cifra multicanal foram utilizados na transmissão nesse único canal, os tempos foram aferidos e comparados ao tempos obtidos com a transmissão multicanal.

A respeito da segurança da cifra, sabemos que há uma relação fatorial, ou exponencial ${ }^{1}$, entre o número de canais e o número combinações com a qual o adversário terá que lidar. Um ponto importante é saber o número máximo de canais que é possível ser estabelecido, evidentemente, essa informação define o máximo da complexidade obtida no sistema. Para obter essa informação,

\footnotetext{
${ }^{1}$ Por conta da combinações possíveis na permutação, fatorial, sempre que não houver repetição de canal, e exponencial, caso o canal possa se repetir.
} 
elevamos progressivamente o número de canais até o momento que o sistema se torna inviável, ou seja, não realiza mais a transmissão dos dados.

Quanto ao ganho de segurança dessa cifra em relação às demais, é uma questão muito difícil de ser respondida e depende de diversos fatores, neste trabalho consideramos a segurança da cifra em relação a criptanálise diferencial (capítulo 3), para essa avaliação um outro experimento foi criado, uma outra implementação, dessa vez tratando a cifra multicanal apenas como a aplicação de uma segunda chave criptográfica, como um algoritmo aleatório de permutação.

Para aferir os diferenciais, os experimentos foram realizados com um texto-legível $x$ gerado aleatoriamente com um tamanho de 64 bits (8 bytes). A cifra multicanal (como permutação) foi utilizada com diferentes tamanhos de bloco, $p=\{1,4,8,16,32\}$.

Para a análise dos deltas de entrada $(\Delta x)$ e saída $(\Delta y)$ foi utilizada a medida da Distância de Hamming, Hamming (1950), que mede a quantidade de bits alterados entre dois vetores binários ${ }^{2}$. Para gerar o $\Delta x$ um bloco de 64 bits $x^{\prime}$ é gerado aleatoriamente e duplicado, gerando o bloco $x$ ", neste último, são utilizados somente os primeiros 4 bits, onde em um laço são trocados os bits, varrendo todas as possibilidades possíveis, primeiramente em 1 bit de cada vez, depois em grupos de dois bits, em grupos de 3 e por fim um grupo de 4 bits. O número de combinações possíveis de cada passo do experimento pode ser calculado através do binômio de Newton. Cada passo através da equação:

$$
\left(\begin{array}{l}
n \\
k
\end{array}\right)=\frac{n !}{k !(n-k) !}
$$

Onde $n$ é o tamanho do conjunto e $k$ é agrupamento utilizado. No caso da geração de $x ", n=4$, e $1 \leq k \leq 4$.

Para o cálculo de combinações totais do experimento, basta seguir:

$$
C_{\text {total }}=\left(\begin{array}{l}
4 \\
1
\end{array}\right)+\left(\begin{array}{l}
4 \\
2
\end{array}\right)+\ldots+\left(\begin{array}{l}
4 \\
4
\end{array}\right)
$$

A figura 5.1 ilustra o processo de geração do $x^{\prime \prime}$ em relação a um $x^{\prime}$.

A função de troca de bits é bem genérica, poderia ser utilizada com qualquer valor $n$, mas para a criptanálise diferencial, interessa valores baixos de $n$ (no nosso caso igual a 4), porque não se deseja uma mapeamento muito de grande $\Delta x$, chaves k e $\Delta y$.

Para o $\Delta y$ medimos a diferença de saída após a permutação (de diferentes tamanhos de blocos) entre o texto-ilegível $y^{\prime}$ gerado pelo texto-legível original $x^{\prime}$ (sem a troca de bits) e o texto ilegível $y "$ gerado pelo texto legível alterado $x "$.

Os diversos resultados dos $\Delta x$ e $\Delta y$ foram tabulados e os dados organizados graficamente para melhor visualização e são apresentados no capítulo 6. Com tais valores, $\Delta x$ e $\Delta y$, é possível afirmar a segurança da cifra em relação à criptanálise diferencial, onde para a consideração de forte e seguro, $\Delta y$ deve ser relativamente "grande" em relação a $\Delta x$.

Neste capítulo propomos duas implementações, a primeira para responder as questões de viabilidade prática da cifra multicanal e a segunda para testar a segurança da cifra em relação à criptanálise diferencial. Detalhamos o processo de geração dos $\Delta x$ e $\Delta y$, variáveis necessárias para a verificação de segurança, mostrando como obter tais valores, a partir da alteração de binária das combinações possíveis dos quatro primeiros bits do bloco de entrada.

\footnotetext{
${ }^{2}$ A medida é bem genérica, pode ser utilizada em outros tipos de vetores, como strings, por exemplo. O algoritmo utilizado para o cálculo da Distância de Hamming binário foi o publicado por Wegner (1960), muito elegante por sinal.
} 


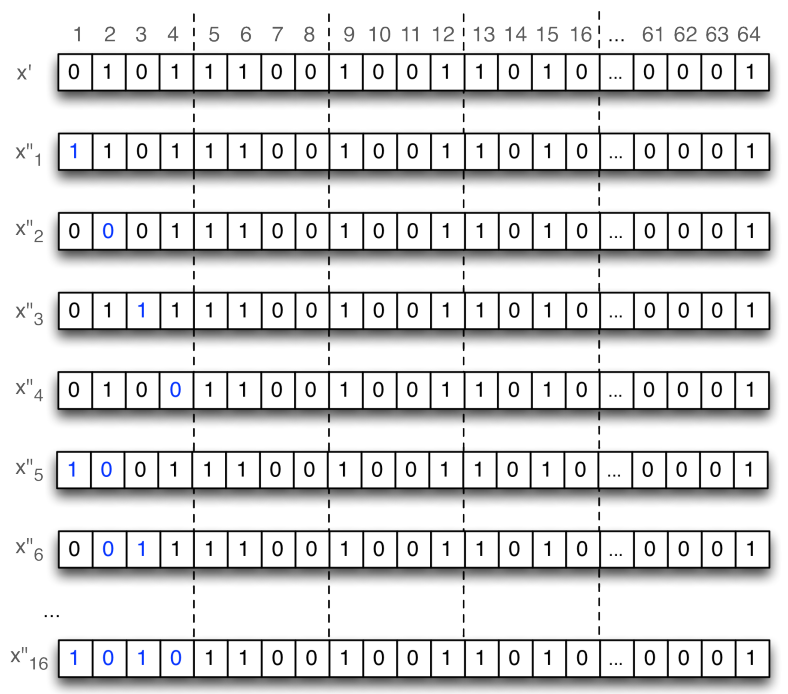

Figura 5.1: Alteração de bits seguindo a combinação através dos $k$ agrupamentos. O valores mais claros na ilustração representam os bits alterados. 


\section{Capítulo 6}

\section{Implementação}

Neste capítulo detalhamos as duas implementações nos quais se baseiam os experimentos realizados, apresentamos os resultados e fazemos uma análise do significado dos dados obtidos.

Duas aplicações distintas foram desenvolvidas, conforme descrito no capítulo 5. A primeira que detalhamos é um experimento de transferência de dados e a segunda um experimento para a verificação da segurança em relação a criptanálise diferencial.

Todos os programas foram desenvolvidos na plataforma Java (J2SE - Java 2 Standard Edition), versão JDK 1.7. Duas máquinas foram utilizadas no desenvolvimento e execução. A primeira máquina, a ponta cliente da comunicação, o Beto, um Macbook Pro, com CPU Intel Core 2 Duo, de $2.53 \mathrm{GHz}$, e 8 GBytes de memória RAM, rodando o MacOSX, versão 10.8.4, com HD de 250 GBytes. E a segunda, a ponta servidora da comunicação, a Alice, um desktop, com CPU Intel Core i7, de 2.8Ghz, e 8 Gbytes de memória, rodando o Windows 7, com HD de 128 GBytes SSD (Solid-State Drive). Ambas máquinas de 64 bits, com interface de rede giga bit. A comunicação entre as máquina foi realizada por cabo através de um roteador TP-Link, modelo TL-WR841ND.

O código-fonte está disponível no seguinte endereço do github ${ }^{1}:$ https://github.com/sylvioazevedo/ multichannel-security, é um repositório privado, para ter acesso, envie um e-mail para: sylvio@ime .usp.br.

\subsection{Aplicação de transferência de arquivos}

A cifra multicanal foi testada em uma aplicação simples de transferência de arquivos no modelo cliente-servidor clássico. Seguimos exatamente a descrição da cifra apresentada no capítulo 3.

Para detalharmos a aplicação desenvolvida, trataremos o agente da comunicação Beto como o cliente, e a agente Alice, como servidor.

O cliente inicia a comunicação, estabelece primeiramente as conexões no canal seguro (TLS) e nos múltiplos canais de comunicação, após, com o servidor troca a chave de sessão e a sequência aleatória da transmissão de dados.

O cliente informa o arquivo que quer receber através do canal TLS, o servidor localiza o arquivo em seu diretório, o abre, lê e criptografa os dados do arquivo utilizando a chave de sessão, divide os dados em pacotes de transmissão, usando o tamanho do arquivo pelo número de canais estabelecidos (em bytes), e então, envia os pacotes através dos canais, utilizando-os sequencialmente e selecionando os pacotes com a sequência aleatória. Após a transmissão de todos os blocos do arquivo o servidor envia uma sinalização de término de arquivo (EOF - End of File).

O cliente vai recebendo através dos canais cada um dos blocos de dados do arquivo requerido, na ordem em que estão sendo enviados, após o recebimento de todos os blocos e a sinalização de término de arquivo (EOF), ordena os dados utilizando a sequência aleatória. Com os dados ordenados, decriptografa os dados utilizando a chave de sessão, cria um arquivo e escreve os dados decriptografados nele.

\footnotetext{
${ }^{1}$ Sistema web de controle de projetos versionados pelo git, uma ferramenta moderna de controle de versão (http://git-scm.com).
} 
Os tamanhos de arquivos utilizados no experimento foram: 100 bytes, 44 Kbytes, 100 Kbytes e 1,7 MBytes. Os dados dos arquivos são mantidos em memória nesta implementação, por isso arquivos maiores não foram testados, entretanto nada impede que uma outra aplicação seja criada para trabalhar com arquivos gigantescos.

Para realizar as conexões TCP/IP foi utilizado o framework de infraestrutura de rede Apache $\mathrm{Mina}^{2}$, versão 2.0.7. O projeto Apache Mina facilita muito o desenvolvimento de aplicações de rede, restando para o desenvolvedor, somente a definição do esquema de serialização ${ }^{3}$ e o protocolo da comunicação a ser utilizado. O método de serialização escolhido foi o BSON $^{4}$ (Binary JSON), um método de serialização binário baseado no $\mathrm{JSON}^{5}$ (Javascript Object Notation), uma representação de objetos javascript em um mapa de texto (chave-valor). O método de serialização é desenvolvido através da criação de codecs (acrônimo de "codificador" e "decodificador") implementando interfaces do Mina (à saber, ProtocolEncoder e ProtocolDecoder) e o protocolo estendendo uma classe padrão (IoHandlerAdapater), duas dessas classes foram desenvolvidas, uma para o protocolo do canal seguro (TLS) e outra para o protocolo os múltiplos canais de comunicação. No detalhamento da cifra multicanal (capítulo 3) os dois foram apresentados juntos.

\subsubsection{Resultados da aplicação de transferência de arquivos}

Apresentamos nessa sessão os resultados da aplicação de transferência de arquivos. Para esse experimento foram utilizados tamanhos de arquivos típicos ${ }^{6}$ de 100 Bytes, representando uma linha texto; 40 kBytes, uma página html normal; 500 kBytes, um arquivo de texto Microsoft Word com 5 páginas ou um arquivo PDF (Portable Document Format); 1,1 MBytes, uma foto em alta definição ou 1 minuto de música em MP3 (MPEG-1/2, Audio Layer 3); e 6,6 MBytes, 3 minutos de MP3 em um taxa de bits muito altas (256 kbps) ou um 1 minuto de fluxo de video.

Foram utilizados diferentes números de canais conectados simultaneamente, à saber, $n_{\text {canais }}=$ $\{1,3,6,12,25,50,100,200,500\}$ (repare que o número de canais é dobrado em cada experimento, propositalmente quadrático, para verificar se há explosão de tempo em função a um número expressivo de canais simultâneos estabelecidos). Na figura 6.1, temos os tempos de inicialização, o tempo necessário para levantar a infraestrutura da comunicação com o estabelecimento dos $n_{\text {canais }}$, entre o cliente e o servidor, apesar de estarem no gráfico relacionado com os diferentes arquivos, o estabelecimento dos canais de comunicação é um processo independente, e por isso as curvas apresentam um mesmo comportamento. O tempo necessário para inicializar os canais teve um comportamento explosivo, principalmente depois de 50 canais, onde o tempo passa a praticamente dobrar. O tempo de inicialização é fator determinante para o número de canais que se deseja utilizar na cifra multicanal, no entanto, dependendo da aplicação, esse tempo pode ser gasto apenas uma vez se as conexões forem mantidas não apenas uma transferência de dados, mas várias.

A seguir, apresentaremos os experimento com o tempo da comunicação para a transferência de dados dos múltiplos arquivos, começando pelo menor de 100 Bytes até o maior de 6,6 MBytes.

Nas tabelas apresentamos o número de canais utilizados (No. canais), o tempo de estabelecimento das conexões dos canais (Inicialização), o tempo de transferência dos dados pelos múltiplos canais (Transferência), o tempo da administração dos canais e manipulação dos arquivos (inclui, a abertura, leitura e escrita) que é o tempo de overhead ${ }^{7}$ (Overhead), e o tempo total da comunicação (Total).

Como apresentamos em um gráfico só o tempos de inicialização dos canais, nos gráficos dos tempos da comunicação dos arquivos subtraímos essa informação, nestes, portanto, estão as informações

\footnotetext{
${ }^{2}$ Para maiores informações a respeito da tecnologia, acesse: http://mina.apache.org

${ }^{3}$ Termo utilizado para a definição de como os dados de um determinado objeto (no modelo de programação orientado a objetos) será transformado em um sequência binária para a transmissão em um canal de comunicação. Já a deserialização é a operação inversa, que transforma uma sequência binária novamente em um objeto.

${ }^{4}$ Para saber mais sobre o BSON, acesse: http://bsonspec.org/

${ }^{5}$ Para saber mais sobre o JSON, acesse: http://www.json.org/

${ }^{6} \mathrm{Na}$ internet existem algumas referências de quais são os arquivos típicos e mais utilizados, para referência, utilizamos, http://www.gn.apc.org/support/understanding-file-sizes

${ }^{7}$ Esse tempo foi calculado subtraindo do tempo total o tempo de transferência de dados
} 


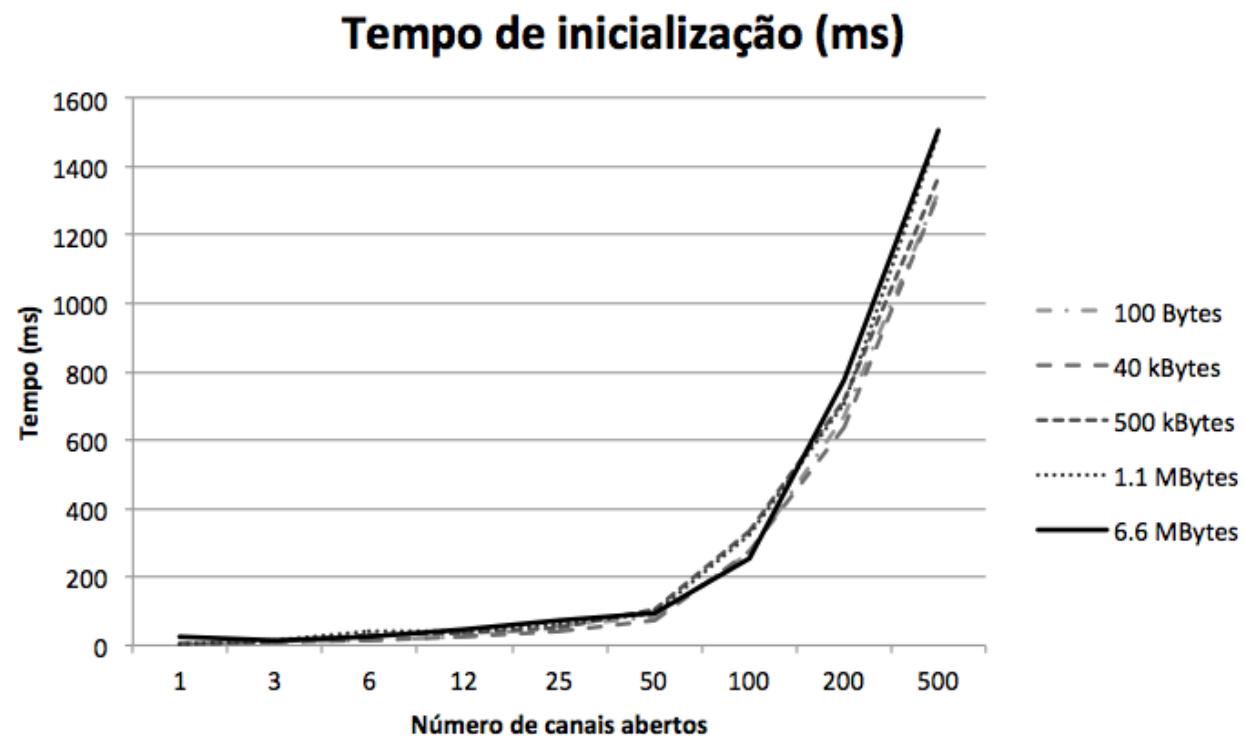

Figura 6.1: Tempos de inicialização para diferentes números de canais.

dos canais (nas abscissas) e os tempo de transferência, overhead e total da comunicação.

Na tabela 6.1 temos os tempos obtidos para a transmissão de dados de um arquivo de 100 Bytes:

\begin{tabular}{|r|r|r|r|r|}
\hline No. canais & Inicialização $(\mathrm{ms})$ & Transferência $(\mathrm{ms})$ & Overhead $(\mathrm{ms})$ & Total $(\mathrm{ms})$ \\
\hline \hline 1 & 3 & 32 & 13 & 45 \\
\hline 3 & 8 & 34 & 9 & 43 \\
\hline 6 & 16 & 33 & 12 & 45 \\
\hline 12 & 27 & 30 & 22 & 52 \\
\hline 25 & 56 & 33 & 40 & 73 \\
\hline 50 & 85 & 25 & 31 & 56 \\
\hline 100 & 269 & 18 & 41 & 59 \\
\hline 200 & 671 & 21 & 35 & 56 \\
\hline 500 & 1325 & 35 & 45 & 80 \\
\hline
\end{tabular}

Tabela 6.1: Tempos de transmissão de dados de um arquivo de 100 Bytes (ms).

Na figura 6.2 temos a representação gráfica para os dados da tabela 6.1.

Na tabela 6.2 temos os tempos obtidos para a transmissão de dados de um arquivo de 40 kBytes:

\begin{tabular}{|r|r|r|r|r|}
\hline No. canais & Inicialização $(\mathrm{ms})$ & Transferência $(\mathrm{ms})$ & Overhead $(\mathrm{ms})$ & Total $(\mathrm{ms})$ \\
\hline \hline 1 & 2 & 483 & 7212 & 7695 \\
\hline 3 & 10 & 704 & 871 & 1575 \\
\hline 6 & 13 & 813 & 650 & 1463 \\
\hline 12 & 25 & 817 & 788 & 1605 \\
\hline 25 & 39 & 857 & 777 & 1634 \\
\hline 50 & 75 & 790 & 876 & 1666 \\
\hline 100 & 278 & 662 & 1118 & 1780 \\
\hline 200 & 640 & 692 & 1585 & 2277 \\
\hline 500 & 1319 & 790 & 1302 & 2092 \\
\hline
\end{tabular}

Tabela 6.2: Tempos de transmissão de dados de um arquivo de $40 \mathrm{kBytes}$ (ms). 
Tempos da transferência de arquivo de 100 Bytes (ms)

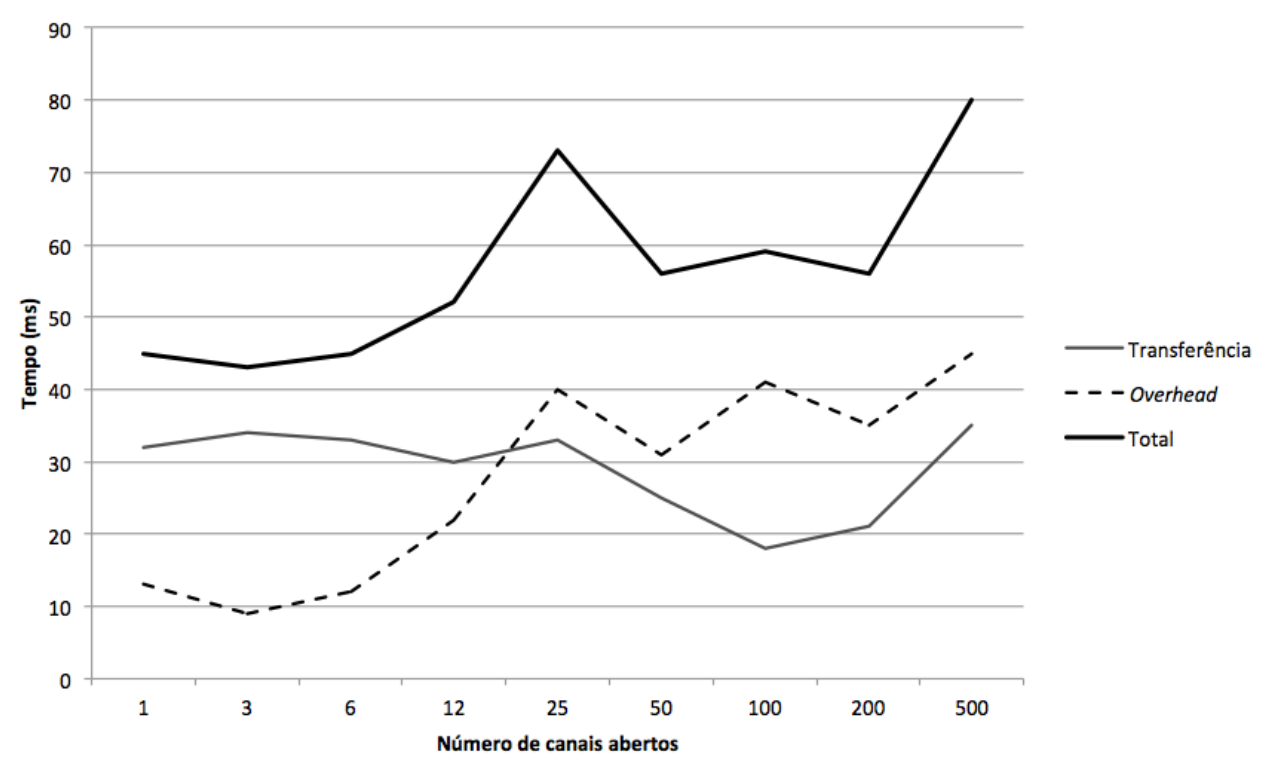

Figura 6.2: Tempos de transferência, overhead e total da comunicação para um arquivo de 100 Bytes.

Na figura 6.3 temos a representação gráfica para os dados da tabela 6.2.

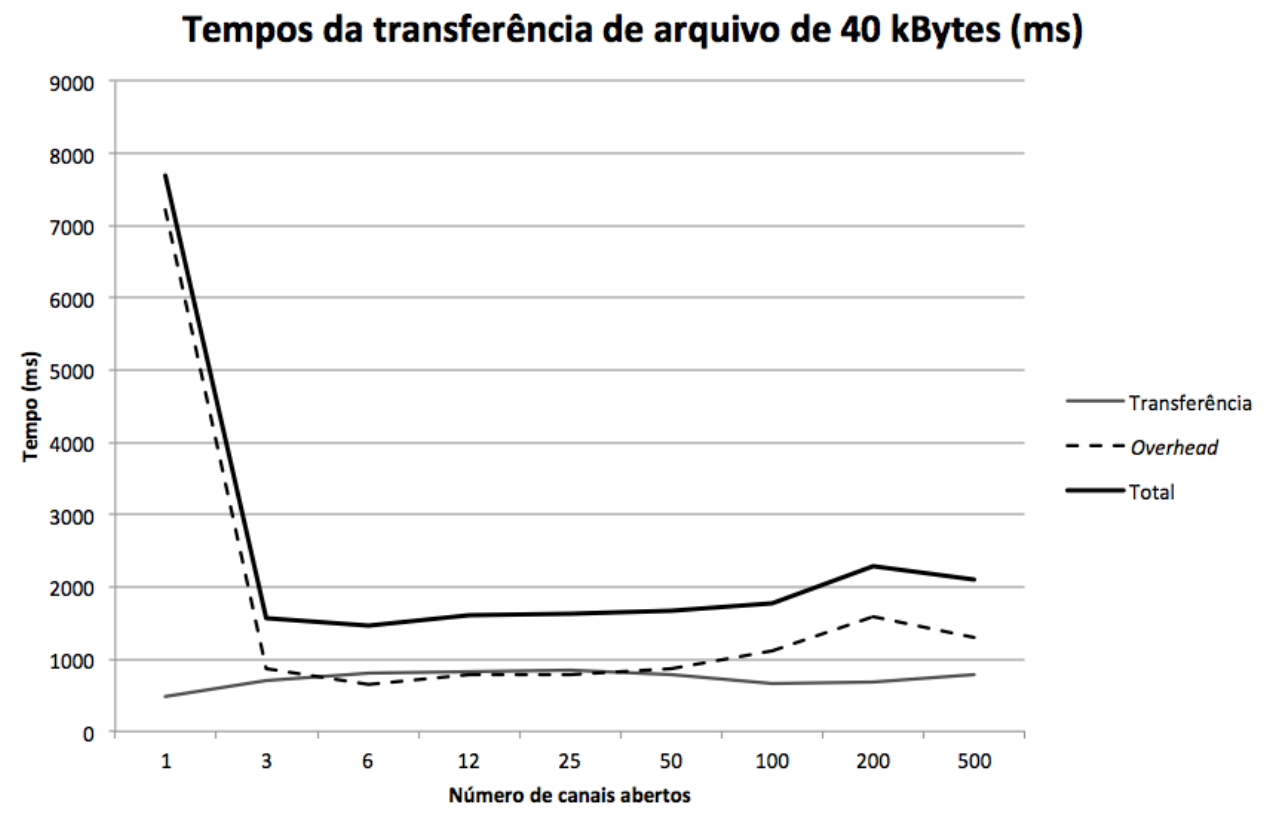

Figura 6.3: Tempos de transferência, overhead e total da comunicação para um arquivo de 40 kBytes.

Na tabela 6.3 temos os tempos obtidos para a transmissão de dados de um arquivo de 500 kBytes:

Na figura 6.4 temos a representação gráfica para os dados da tabela 6.3.

Na tabela 6.4 temos os tempos obtidos para a transmissão de dados de um arquivo de 1,1 MBytes:

Na figura 6.5 temos a representação gráfica para os dados da tabela 6.4.

Na tabela 6.5 temos os tempos obtidos para a transmissão de dados de um arquivo de 6,6 MBytes:

Na figura 6.6 temos a representação gráfica para os dados da tabela 6.5. 


\begin{tabular}{|r|r|r|r|r|}
\hline No. canais & Inicialização $(\mathrm{ms})$ & Transferência $(\mathrm{ms})$ & Overhead $(\mathrm{ms})$ & Total $(\mathrm{ms})$ \\
\hline \hline 1 & 4 & 48927 & 75096 & 124023 \\
\hline 3 & 11 & 6309 & 15892 & 22201 \\
\hline 6 & 28 & 7655 & 12769 & 20424 \\
\hline 12 & 36 & 7377 & 10992 & 18369 \\
\hline 25 & 54 & 6771 & 13200 & 19971 \\
\hline 50 & 106 & 8003 & 13865 & 21868 \\
\hline 100 & 332 & 8132 & 19815 & 27947 \\
\hline 200 & 718 & 7744 & 24779 & 32523 \\
\hline 500 & 1369 & 11683 & 29064 & 40747 \\
\hline
\end{tabular}

Tabela 6.3: Tempos de transmissão de dados de um arquivo de 500 kBytes (ms).

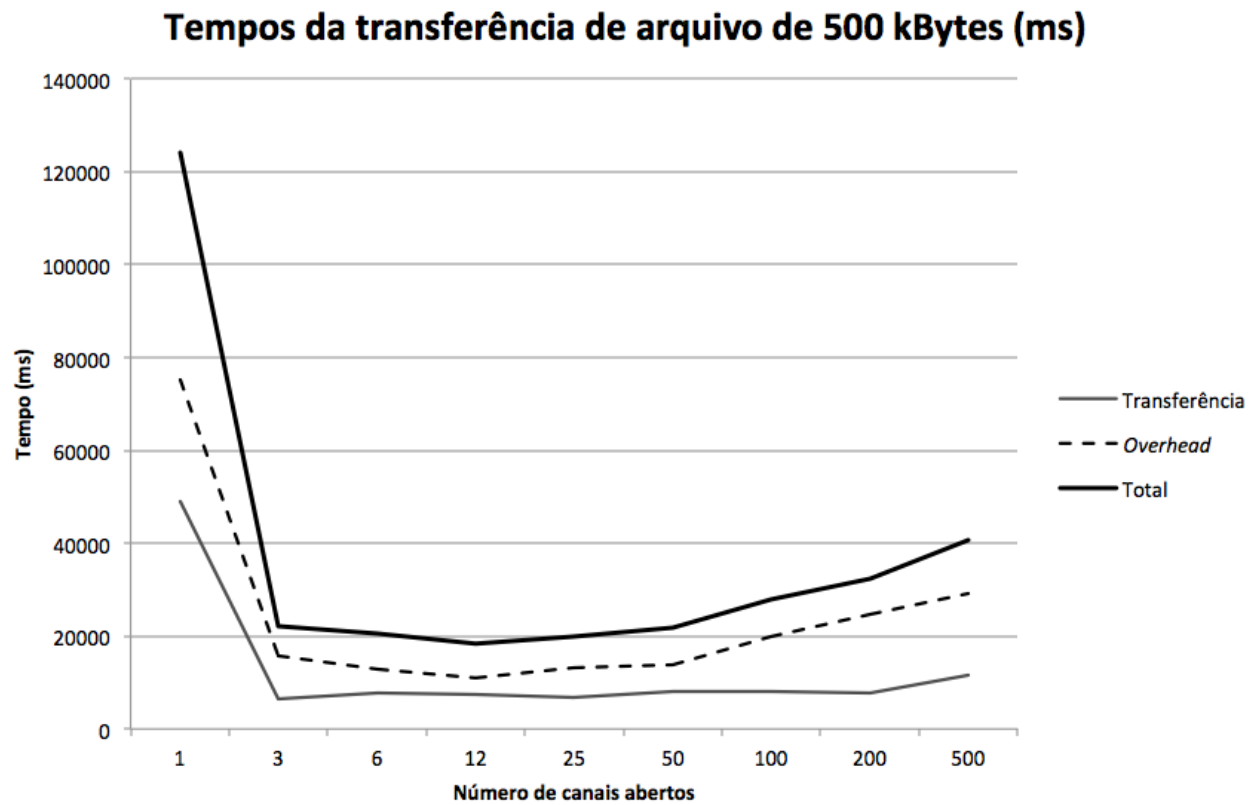

Figura 6.4: Tempos de transferência, overhead e total da comunicação para um arquivo de $500 \mathrm{kBytes.}$

\begin{tabular}{|r|r|r|r|r|}
\hline No. canais & Inicialização $(\mathrm{ms})$ & Transferência $(\mathrm{ms})$ & Overhead $(\mathrm{ms})$ & Total $(\mathrm{ms})$ \\
\hline \hline 1 & 2 & 161212 & 63938 & 225150 \\
\hline 3 & 16 & 18753 & 19394 & 38147 \\
\hline 6 & 41 & 11233 & 21906 & 33139 \\
\hline 12 & 42 & 12188 & 25279 & 37467 \\
\hline 25 & 65 & 9522 & 28453 & 37975 \\
\hline 50 & 92 & 12607 & 28610 & 41217 \\
\hline 100 & 326 & 14733 & 40804 & 55537 \\
\hline 200 & 708 & 15062 & 45152 & 60214 \\
\hline 500 & 1499 & 23826 & 52763 & 76589 \\
\hline
\end{tabular}

Tabela 6.4: Tempos de transmissão de dados de um arquivo de 1,1 MBytes (ms).

Os tempos apresentados, foram obtidos da média de 100 execuções com cada um dos arquivos, com cada número de canais. Podemos reparar nesse experimento, que uma característica importante nesses gráficos se sobressai, não há um crescimento explosivo do tempo em função do número de 
Tempos da transferência de arquivo de 1.1 MBytes (ms)

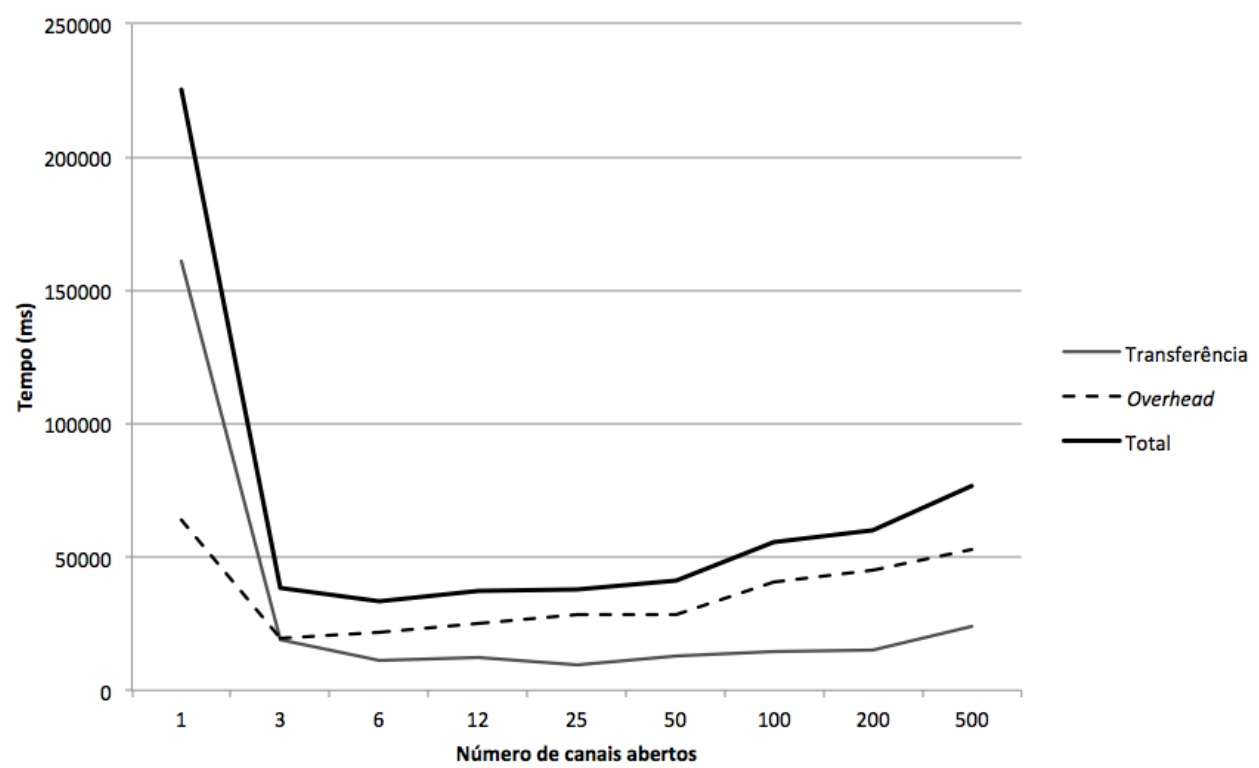

Figura 6.5: Tempos de transferência, overhead e total da comunicação para um arquivo de 1.1 MBytes.

\begin{tabular}{|r|r|r|r|r|}
\hline No. canais & Inicialização $(\mathrm{ms})$ & Transferência $(\mathrm{ms})$ & Overhead $(\mathrm{ms})$ & Total $(\mathrm{ms})$ \\
\hline \hline 1 & 27 & 1526952 & 56639 & 1583591 \\
\hline 3 & 13 & 295801 & 47389 & 343190 \\
\hline 6 & 25 & 225736 & 44290 & 270026 \\
\hline 12 & 47 & 176473 & 81579 & 258052 \\
\hline 25 & 75 & 144215 & 100876 & 245091 \\
\hline 50 & 93 & 134894 & 127277 & 262171 \\
\hline 100 & 252 & 145801 & 6595 & 152396 \\
\hline 200 & 775 & 156481 & 249484 & 405965 \\
\hline 500 & 1507 & 197712 & 323110 & 520822 \\
\hline
\end{tabular}

Tabela 6.5: Tempos de transmissão de dados de um arquivo de 6,6 MBytes (ms).

canais antes dos 200 canais, e essa é a informação que mais nos interessa. Quanto maior o número de canais, maior é a segurança, pois com um valor relativamente grande de canais, sabendo que a sequência de transmissão dos pacotes é aleatória (a chave da cifra multicanal) e seu efeito final é uma permutação, podemos considerar que temos uma alta entropia na chave, o que garante a segurança contra o ataque do homem-do-meio, conforme a sessão 2.3.2, em Terada (2008). No contexto TCP/IP essa propriedade é desejável. Os gráficos mostram que na comunicação com as máquina envolvidas, 100 canais poderiam ser utilizados sem problemas.

O expressivo aumento de tempo a partir de 200 canais os altos tempos pode ser explicado pela necessidade de maior tempo para administrar os canais, portanto, um possível trade off que deve ser avaliado pelo projetista do sistema.

Outras implementações podem ser realizadas para aproveitar melhor os limites da máquina, mas não é o foco neste trabalho. Aqui é suficiente saber que podemos ter um número razoável de canais para aumentar a segurança da comunicação.

Os tempos para a transmissão em geral são significativamente maiores do que uma transmissão em série normal em um canal TLS seguro, algo em torno de 10 vezes mais lento. Em uma implementação de referência de transferência de arquivos temos os tempos relacionados na tabela 6.6. Não chega a ser impeditivo, mas fica claro que o estabelecimento e administração dos canais tem 
Tempos da transferência de arquivo de 6.6 MBytes (ms)

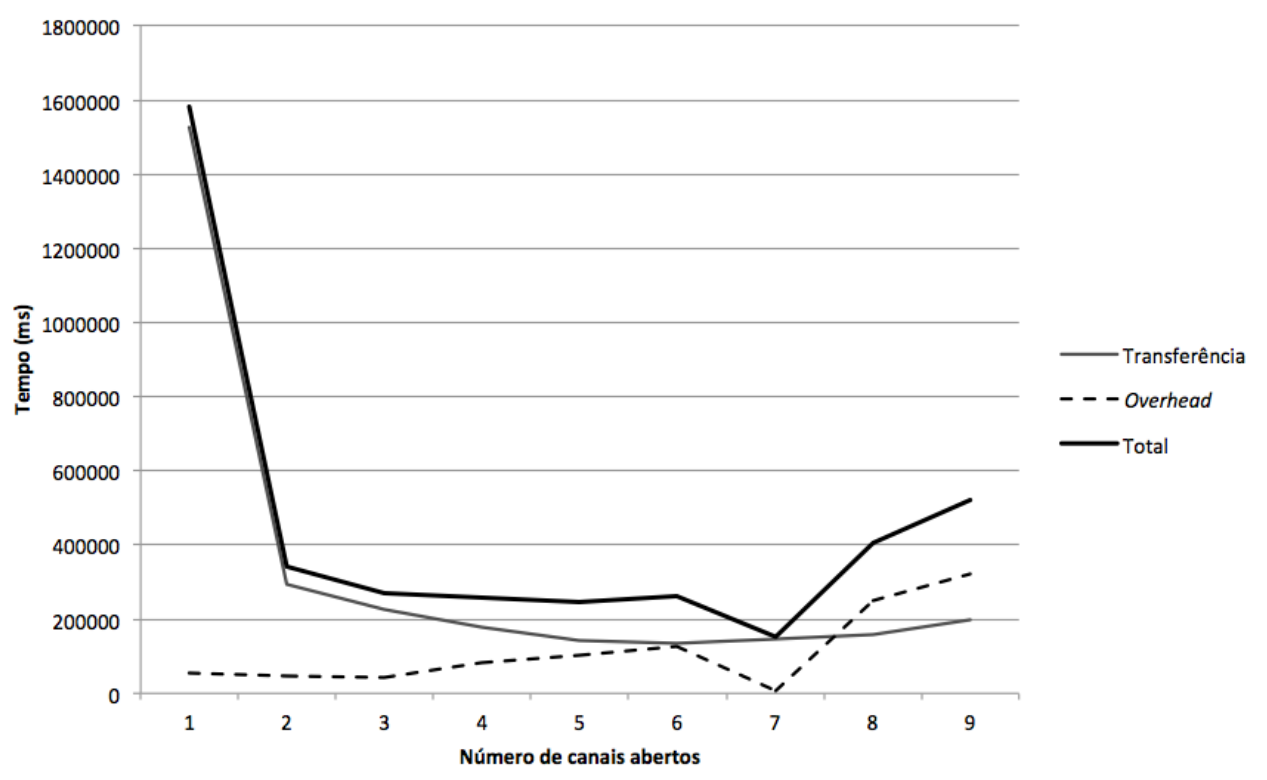

Figura 6.6: Tempos de transferência, overhead e total da comunicação para um arquivo de 6.6 MBytes.

um custo que deve ser considerado.

\begin{tabular}{|r|r|}
\hline Tamanho do arquivo & Transferência de dados $(\mathrm{ms})$ \\
\hline \hline 100 Bytes & 12 \\
\hline 40 kBytes & 73 \\
\hline 500 kBytes & 179 \\
\hline 1.1 MBytes & 186 \\
\hline 6.6 MBytes & 1201 \\
\hline
\end{tabular}

Tabela 6.6: Tempos de transmissão de dados em um abordagem serializada normal (ms).

A cifra multicanal não estabelece número máximo de canais que possam ser utilizados, entretanto além do overhead da administração dos canais, nos experimentos, ao ir aumentando o número de canais, encontramos uma outra limitação, dessa vez, em relação ao sistema de arquivos dos sistemas operacionais. Nos sistemas Unix uma conexão de rede é mapeada em um arquivo temporário no sistema de controle de arquivos e há um limite máximo de arquivos abertos concorrentemente. No MacOSX esse limite é de 710, nas distribuições Linux normalmente está configurado em 1024 e encontramos que o sistema operacional Windows trabalha com no máximo em torno de 8.000 conexões simultâneas, embora esse último não tenha relação direta com o sistema de arquivos. Apesar dessa restrição, nos sistemas Unix, é possível configurar o número máximo de arquivos aberto simultaneamente, normalmente através do comando "ulimit". Para a construção de servidores esse ponto merece especial atenção e a consulta do manual da distribuição do sistema operacional é necessária para a correta configuração desse limite. 


\subsection{Segurança em relação à criptanálise diferencial}

A cifra multicanal foi transformada em uma função de permutação aleatória, dessa forma removemos totalmente a características de comunicação e damos a atenção somente as propriedades da cifra, que nesse caso, tem somente o efeito da permutação.

O resultado do cálculo da distância de Hamming é justamente o valor da diferença binária, logo, se calculado para duas entradas da cifra de permutação, é o $\Delta x$, e se calculado para as respectivas saídas, é o $\Delta y$, necessários para mensurar a força contra a análise diferencial, capítulo 3.

Os experimentos utilizando a distância de Hamming foram realizados para diversos tamanhos de blocos para a permutação, $\operatorname{Tam}_{\text {bloco }}=\{1,4,8,16,32,64\}$, nesse conjunto, o primeiro elemento representando uma permutação binária e o último, o próprio tamanho do buffer aleatório, representando nenhuma permutação, esse último foi só mantido como referência.

A operação do experimento, possui as seguintes etapas:

1. Geração de um buffer de 8 Bytes (64 bits) com valores aleatórios. Para tal, foi utilizada a classe java Random, uma vez que retorna inteiros, foi limitada para gerar valores de 0 a 255 , os bits não utilizados, já que um inteiro tem 4 bytes e só utilizamos 1, são descartadas com uma operação de casting ${ }^{8}$. Esse buffer gerado representa o $x^{\prime}$;

2. Geração de uma sequência aleatória em função do tamanho de bloco da permutação. Por exemplo, se o tamanho do bloco for 1 (binário), a sequência aleatória terá 64 valores distintos. Se o tamanho for 4, terá 16 valores, e assim por diante;

3. Um looping é estabelecido para varrer todas as combinações dos 4 primeiros bits do buffer $x^{\prime}$, conforme explicado no capítulo 5;

4. Clonagem do buffer aleatório gerado e alteração dos quatro primeiros bits seguindo a combinação corrente (muda a cada passo do laço). O buffer clonado com os bits alterados representa о $x^{\prime \prime}$

5. Permutação do buffer de dados $x^{\prime}$ com a sequência aleatória, obtendo-se assim o $y^{\prime}$;

6. Permutação do buffer de dados clonado e com bits alterados $x^{\prime \prime}$ com a sequência aleatória, obtendo-se assim o $y^{\prime \prime}$;

7. Realização do cálculo da distância de Hamming para $x^{\prime}$ e $x^{\prime \prime}$, obtendo-se assim o $\Delta x$;

8. Realização do cálculo da distância de Hamming para $y^{\prime}$ e $y^{\prime \prime}$, obtendo-se assim o $\Delta y$;

9. Contabilização dos $\Delta x$ e $\Delta y$, conforme o agrupamento da combinação corrente.

Ao realizar esse experimento nas primeiras vezes, encontramos um resultado não previsto inicialmente. A operação de permutação não provoca um número maior de bits trocados na saída em relação a entrada, ou seja, não protege estatisticamente o texto elegível, pois um bit alterado na entrada corresponde diretamente em função da chave um bit na saída, em outras palavras, em qualquer combinação das entradas $x^{\prime}$ e $x^{\prime \prime}$, se a chave $k$ for a mesma, o $\Delta x$ será sempre igual ao $\Delta y$. E essa característica é válida inclusive para qualquer tamanho de bloco utilizado na permutação.

$\mathrm{Na}$ figura 6.7 representamos a operação de permutação em duas entradas $x^{\prime}$ e $x^{\prime \prime}$, repare que embora $y^{\prime}$ e $y^{\prime \prime}$ sejam diferentes, o número de bits alterados continua o mesmo.

Essa característica da permutação a invalida totalmente em relação a criptanálise diferencial pois avaliando as diferenças (operação xor) das entradas e saídas é possível inferir diretamente a chave. Verificando novamente a figura 6.7 onde alterou-se o primeiro bit da entrada $x^{\prime}$ em $x^{\prime \prime}$, olhando a diferença, é possível ver claramente que essa mudança foi permutada para o último bloco em $y^{\prime \prime}, \operatorname{logo}$ o valor da sequência aleatória correspondente aquele bloco é 1 .

\footnotetext{
${ }^{8}$ Herança da linguagem, é a determinação de tipo de uma determinada instância de valor ou objeto.
} 


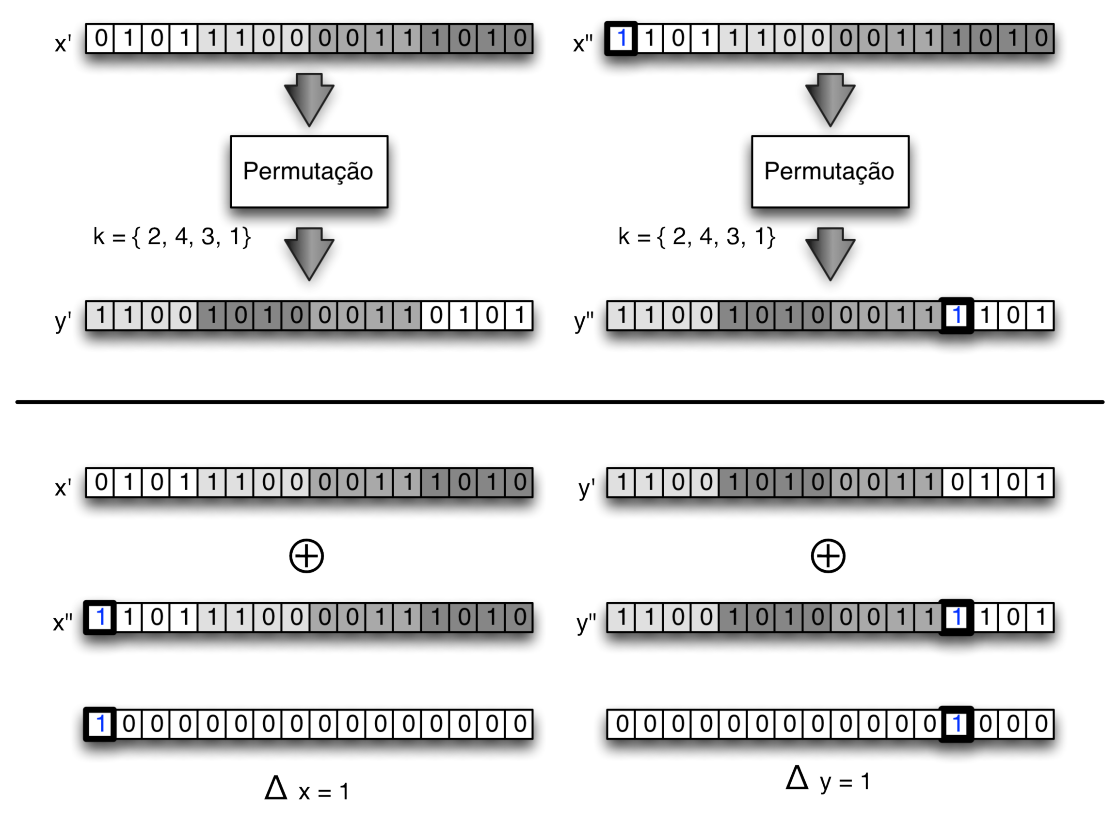

Figura 6.7: Exemplo mostrando que a operação de permutação não causa difusão binária.

Algumas maneiras foram pensadas para fortalecer a cifra multicanal em relação à criptanálise diferencial, uma delas era colocar um componente aleatório de offset, provocando um deslocamento dos bits, isso iria descaracterizar a cifra com um aumento de uma outra chave. Preferiu-se então, utilizar o mesmo mecanismo do AES para realizar o aumento de difusão dos bits de saída, que naturalmente realiza o trabalho de maneira segura, testada ao longo de vários anos, sem alterar o tamanho da chave.

A função principal do AES responsável pela difusão binária é a chamada de MixColumns, onde a entrada é transformada em uma matriz de bytes e multiplicada com uma outra matriz com valores dentro do $G F\left(2^{8}\right)$ (Galois Field - Corpo de Galois). E é ao misturar as linhas e colunas (na multiplicação matricial) que encontramos o efeito de difusão desejado, onde diversos bits são alterados em função de uma alteração na entrada.

O número de bits alterados em função da alteração de cada bit da entrada é no caso desejável a metade do tamanho do bloco da cifra, para a máxima entropia, onde a probabilidade de qualquer valor (0 ou 1) em qualquer bit do bloco é de $50 \%$. No nosso caso o tamanho do bloco é 64 , e o valor desejável é 32, portanto.

Experimentalmente em conjunto com a função S-Box (Substitution Box - Caixa de Substituição) do AES, onde valores são trocados por outros, também dentro do $G F\left(2^{8}\right)$; e com a função de deslocamento (ShiftBytes - Deslocamento de bytes), os números de bits alterados na saída a ficaram muito próximo do desejável.

A função SubBytes, consiste em dois passos, o primeiro, a inversão de cada um dos bytes por uma função $f(x)$. Sejam $t, u \in G F\left(2^{8}\right), f: u \rightarrow t=u^{-1} \bmod m(x)$ Terada (2008). E a segunda etapa, uma multiplicação matricial da seguinte forma, sendo $b$ os bits de entrada e $y$ bits de saída: 


$$
\left[\begin{array}{l}
y_{0} \\
y_{1} \\
y_{2} \\
y_{3} \\
y_{4} \\
y_{5} \\
y_{6} \\
y_{7}
\end{array}\right]=\left[\begin{array}{llllllll}
1 & 0 & 0 & 0 & 1 & 1 & 1 & 1 \\
1 & 1 & 0 & 0 & 0 & 1 & 1 & 1 \\
1 & 1 & 1 & 0 & 0 & 0 & 1 & 1 \\
1 & 1 & 1 & 1 & 0 & 0 & 0 & 1 \\
1 & 1 & 1 & 1 & 1 & 0 & 0 & 0 \\
0 & 1 & 1 & 1 & 1 & 1 & 0 & 0 \\
0 & 0 & 1 & 1 & 1 & 1 & 1 & 0 \\
0 & 0 & 0 & 1 & 1 & 1 & 1 & 1
\end{array}\right]\left[\begin{array}{l}
b_{0} \\
b_{1} \\
b_{2} \\
b_{3} \\
b_{4} \\
b_{5} \\
b_{6} \\
b_{7}
\end{array}\right] \oplus\left[\begin{array}{l}
1 \\
1 \\
0 \\
0 \\
0 \\
1 \\
1 \\
0
\end{array}\right]
$$

De igual maneira a função inversa da função SubBytes, possui duas etapas, a aplicação da inversa dentro do $G F\left(2^{8}\right)$. Sendo $t, u \in G F\left(2^{8}\right)$, temos $f^{-1}: t \rightarrow u=t^{-1} \bmod m(x)$.

E a segunda a etapa, uma multiplicação matricial da seguinte forma:

$$
\left[\begin{array}{l}
b_{0} \\
b_{1} \\
b_{2} \\
b_{3} \\
b_{4} \\
b_{5} \\
b_{6} \\
b_{7}
\end{array}\right]=\left[\begin{array}{llllllll}
0 & 0 & 1 & 0 & 0 & 1 & 0 & 1 \\
1 & 0 & 0 & 1 & 0 & 0 & 1 & 0 \\
0 & 1 & 0 & 0 & 1 & 0 & 0 & 1 \\
1 & 0 & 1 & 0 & 0 & 1 & 0 & 0 \\
0 & 1 & 0 & 1 & 0 & 0 & 1 & 0 \\
0 & 0 & 1 & 0 & 1 & 0 & 0 & 1 \\
1 & 0 & 0 & 1 & 0 & 1 & 0 & 0 \\
0 & 1 & 0 & 0 & 1 & 0 & 1 & 0
\end{array}\right]\left[\begin{array}{l}
y_{0} \\
y_{1} \\
y_{2} \\
y_{3} \\
y_{4} \\
y_{5} \\
y_{6} \\
y_{7}
\end{array}\right] \oplus\left[\begin{array}{l}
1 \\
0 \\
1 \\
0 \\
0 \\
0 \\
0 \\
0
\end{array}\right]
$$

Na operação ShiftRows, o bloco a ser codificado é representado em uma matriz $M$ de 4 linhas e $N_{b}$ colunas. A operação ocorre da seguinte maneira:

- A linha 0 da matriz $M$ não é alterada;

- A linha 1 da matriz $M$ é deslocada circularmente para a esquerda em $C_{1}$ bytes;

- A linha 2 da matriz $M$ é deslocada circularmente para a esquerda em $C_{2}$ bytes;

- A linha 3 da matriz $M$ é deslocada circularmente para a esquerda em $C_{3}$ bytes;

Os valores constantes de $C_{1}, C_{2}$ e $C_{3}$ dependem do valor $N_{b}$, conforme a tabela 6.7.

\begin{tabular}{|r|r|r|r|}
\hline$N_{b}$ & $C_{1}$ & $C_{2}$ & $C_{3}$ \\
\hline \hline 4 & 1 & 2 & 3 \\
\hline 6 & 1 & 2 & 3 \\
\hline 8 & 1 & 2 & 3 \\
\hline
\end{tabular}

Tabela 6.7: Tabela de constantes de deslocamento em função do tamanho do bloco de entrada do AES.

A operação inversa da função ShiftRows é realizada no deslocamento ao contrário, do seguinte modo:

- A linha 0 da matriz $M$ não é alterada;

- A linha 1 da matriz $M$ é deslocada circularmente para a esquerda em $N_{b}-C_{1}$ bytes;

- A linha 2 da matriz $M$ é deslocada circularmente para a esquerda em $N_{b}-C_{2}$ bytes;

- A linha 3 da matriz $M$ é deslocada circularmente para a esquerda em $N_{b}-C_{3}$ bytes; 
A seguir, detalhamos a função MixColumns, uma multiplicação matricial da seguinte forma:

$$
\left[\begin{array}{l}
b_{0} \\
b_{1} \\
b_{2} \\
b_{3}
\end{array}\right]=\left[\begin{array}{llll}
02 & 03 & 01 & 01 \\
01 & 02 & 03 & 01 \\
01 & 01 & 02 & 03 \\
03 & 01 & 01 & 02
\end{array}\right]\left[\begin{array}{l}
a_{0} \\
a_{1} \\
a_{2} \\
a_{3}
\end{array}\right]
$$

Detalhe da operação inversa da função MixColumns:

$$
\left[\begin{array}{l}
a_{0} \\
a_{1} \\
a_{2} \\
a_{3}
\end{array}\right]=\left[\begin{array}{cccc}
0 E & 0 B & 0 D & 09 \\
09 & 0 E & 0 B & 0 D \\
0 D & 09 & 0 E & 0 B \\
0 B & 0 D & 09 & 0 E
\end{array}\right]\left[\begin{array}{l}
b_{0} \\
b_{1} \\
b_{2} \\
b_{3}
\end{array}\right]
$$

A cifra multicanal (uma permutação) associada ao mecanismo de difusão do AES, foi batizada de SMP (S-Box/ShiftBytes, a MixColumns, acrônimos das funções que a compõem e a permutação aleatória).

As figuras 6.8 e 6.9, representam as operações da cifra SMP. Repare que as operações importadas do AES não sofrem interferência da chave (sequência aleatória $i$ ), portanto, juntas formam apenas uma função de codificação.

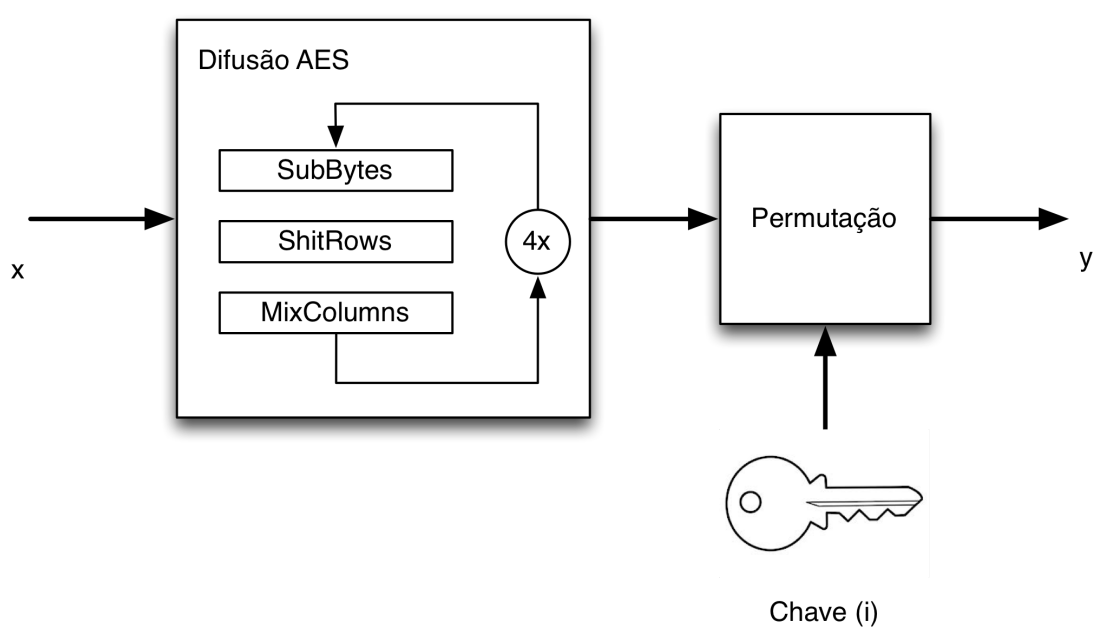

Figura 6.8: Representação da cifra SMP para a operação criptográfica.

\subsubsection{Resultados dos experimentos em relação à criptanálise diferencial}

Os dados contabilizados por $\Delta x$ e $\Delta y$ são apresentados a seguir para a SMP, estão representados graficamente e organizados por valores diferentes do tamanho de bloco de permutação, começando com a permutação binária (bit a bit), bloco de 4 bits, bloco de 8 bits, bloco de 16 bits, bloco de 32 bits e, por último, o bloco de 64 que coincide com o tamanho do bloco de entrada, nesse caso não há permutação.

Quatro gráficos são apresentados para cada tamanho de bloco, o primeiro, o total de bits alterados na saída $(\Delta y)$ em função do número de combinações de um determinado agrupamento. O segundo, uma estatística do número médio de bits alterados, o desvio padrão e os valores de máximos e mínimos encontrados. E o último, o coeficiente de variação, dado pelo desvio padrão dividido pela média.

Os resultados obtidos do SMP não apresentam grande variação em qualquer tamanho de bloco, isso mostra claramente que a cifra de permutação não colabora com a difusão. Isso pode ser confir- 


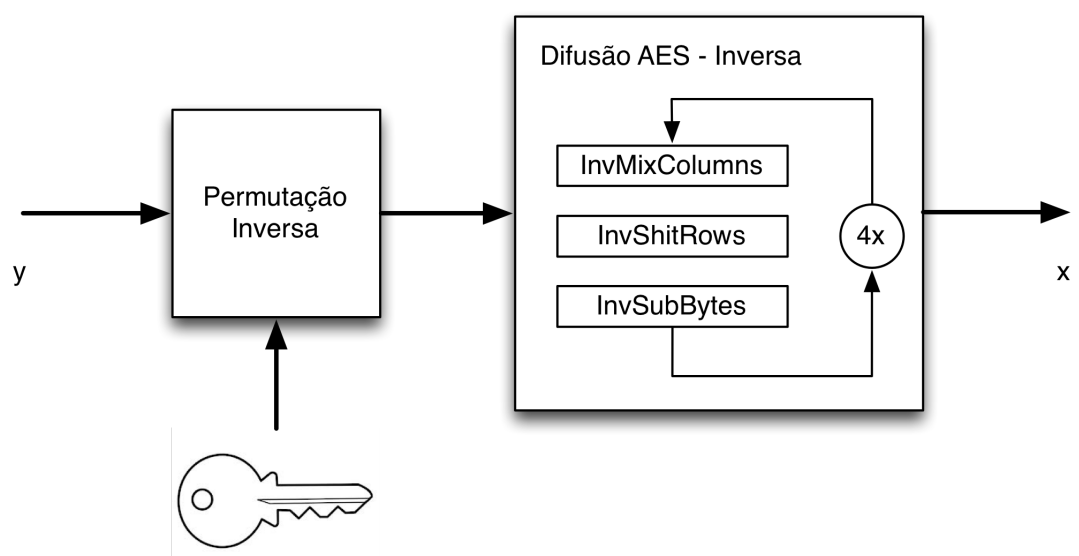

Chave (i)

Figura 6.9: Representação da operação inversa da cifra SMP.

mado no último gráfico, o de controle, com o bloco de 64 bits, onde não há permutação, há ainda grande difusão dos bits na saída.

Total de bits alterados pela operação SMP

A seguir mostramos os gráficos de números de bits alterados pela cifra SMP tanto na entrada como na saída.

n: 4, k: 1-4 - Permutação de 1 bit

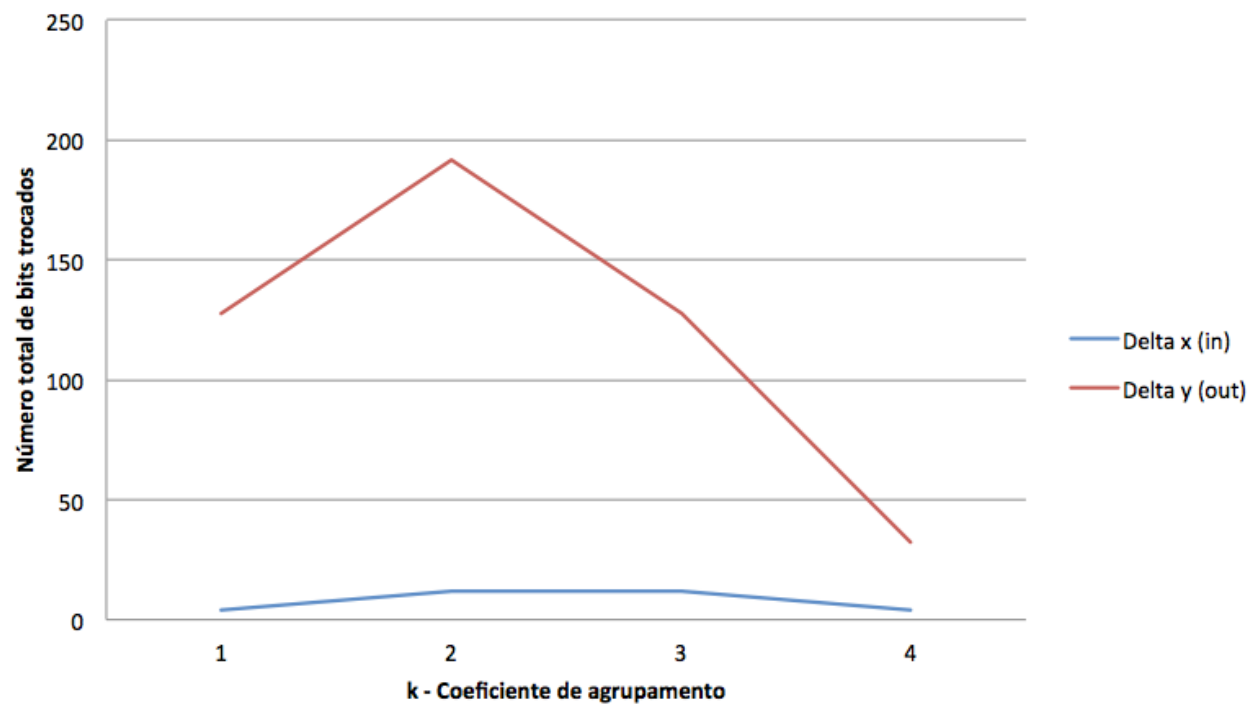

Figura 6.10: Total de bits alterados para a permutação binária. 
n: 4, k: 1-4 - Permutação de 4 bits

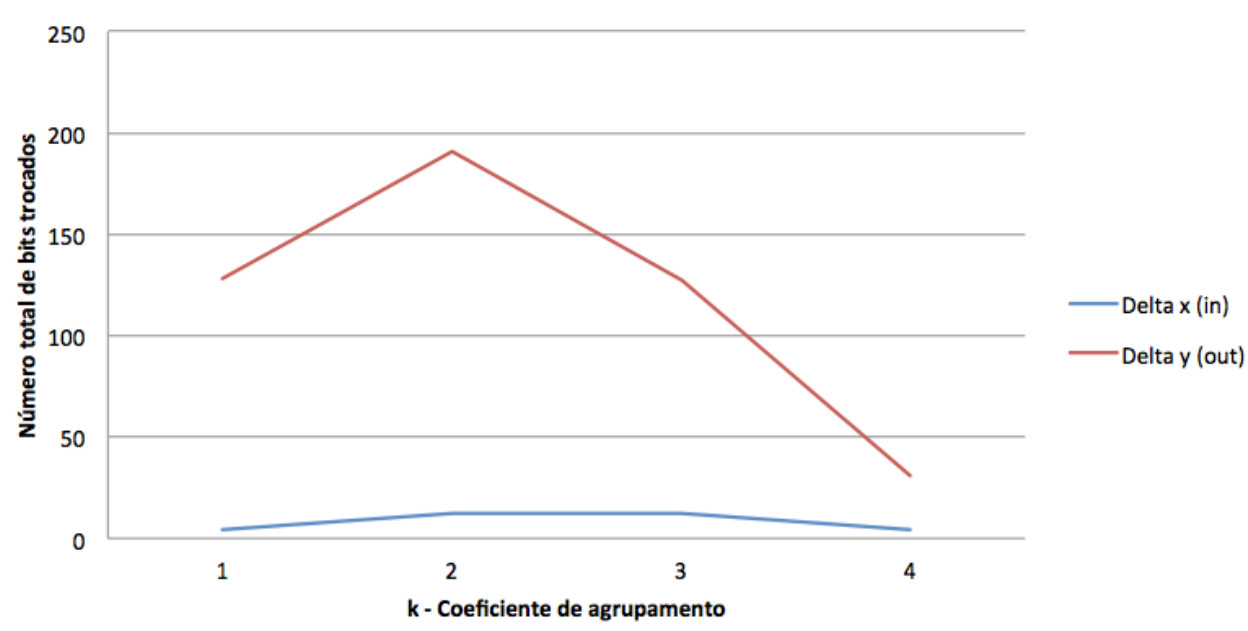

Figura 6.11: Total de bits alterados para a permutação de blocos de 4 bits.

n: 4, k: 1-4 - Permutação de 8 bits

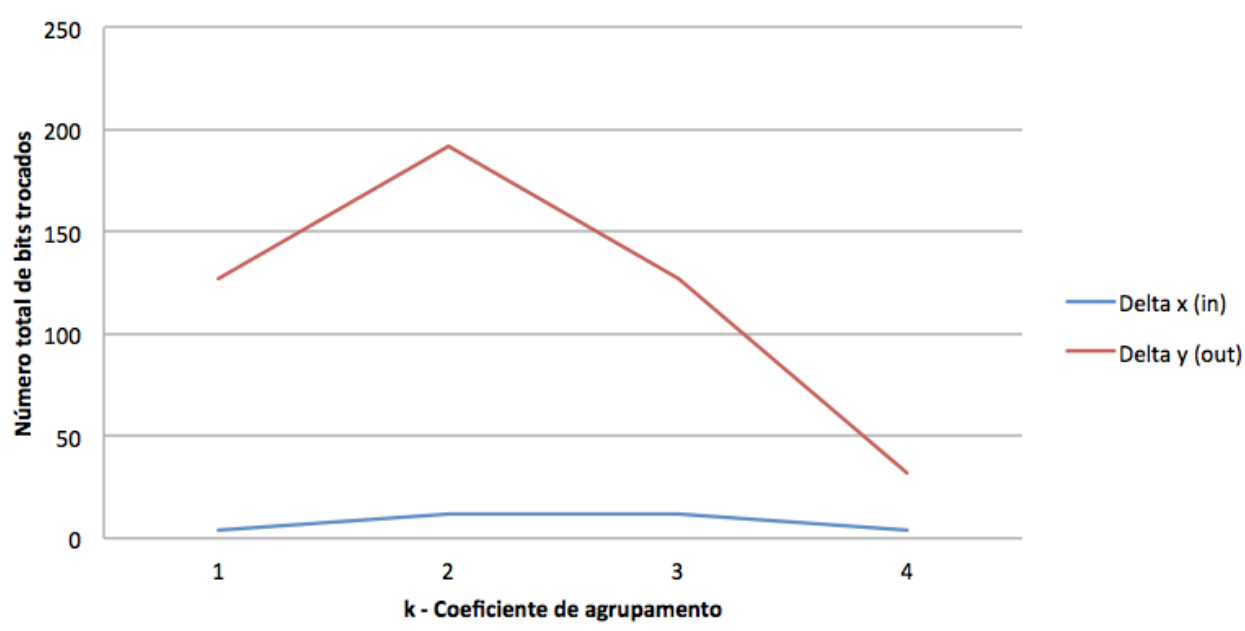

Figura 6.12: Total de bits alterados para a permutação de blocos de 8 bits. 


\section{n: 4, k: 1-4 - Permutação de 16 bits}

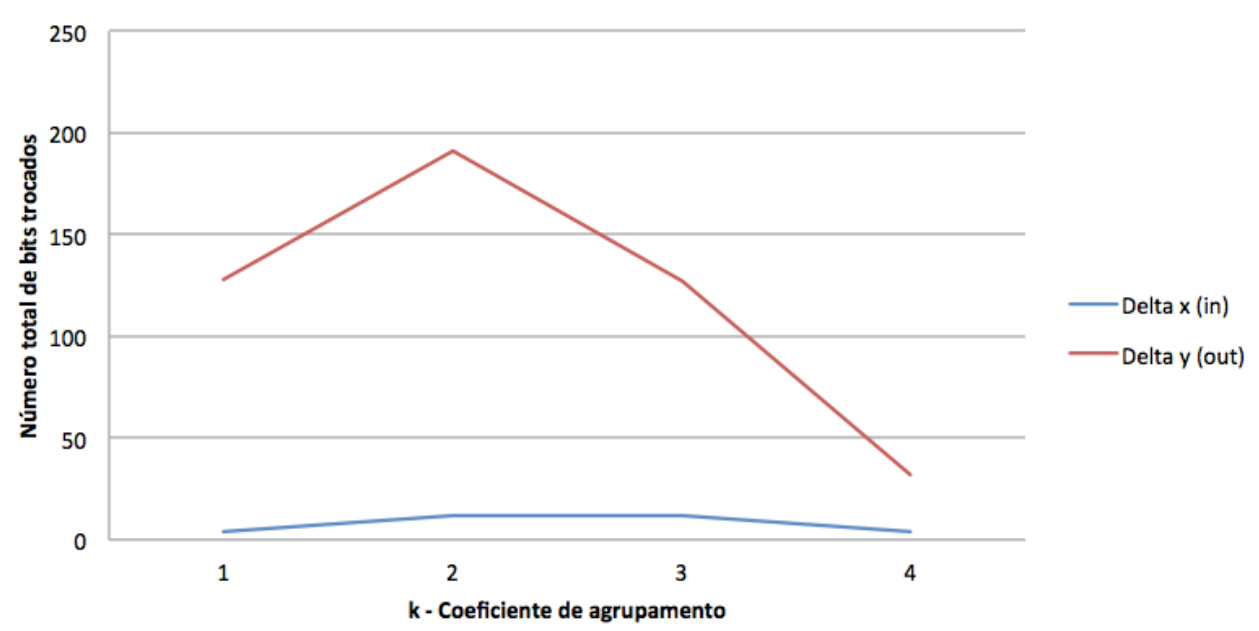

Figura 6.13: Total de bits alterados para a permutação de blocos de 16 bits.

\section{n: 4, k: 1-4 - Permutação de 32 bits}

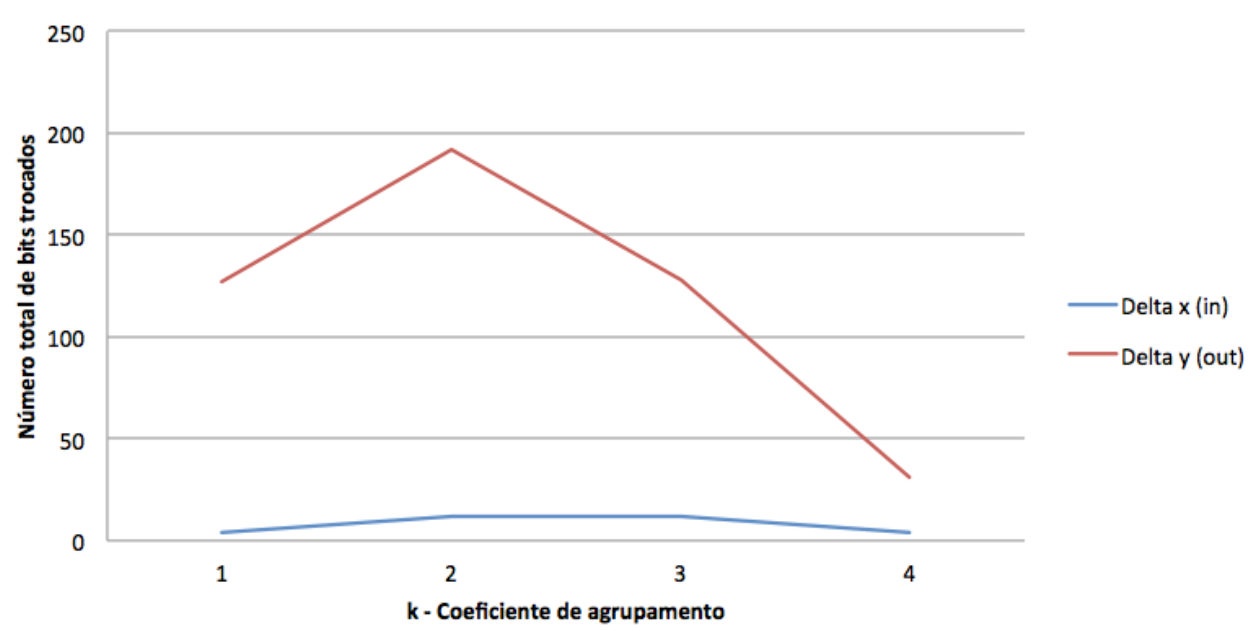

Figura 6.14: Total de bits alterados para a permutação de blocos de 32 bits. 
n: 4, k: 1-4 - Permutação de 64 bits

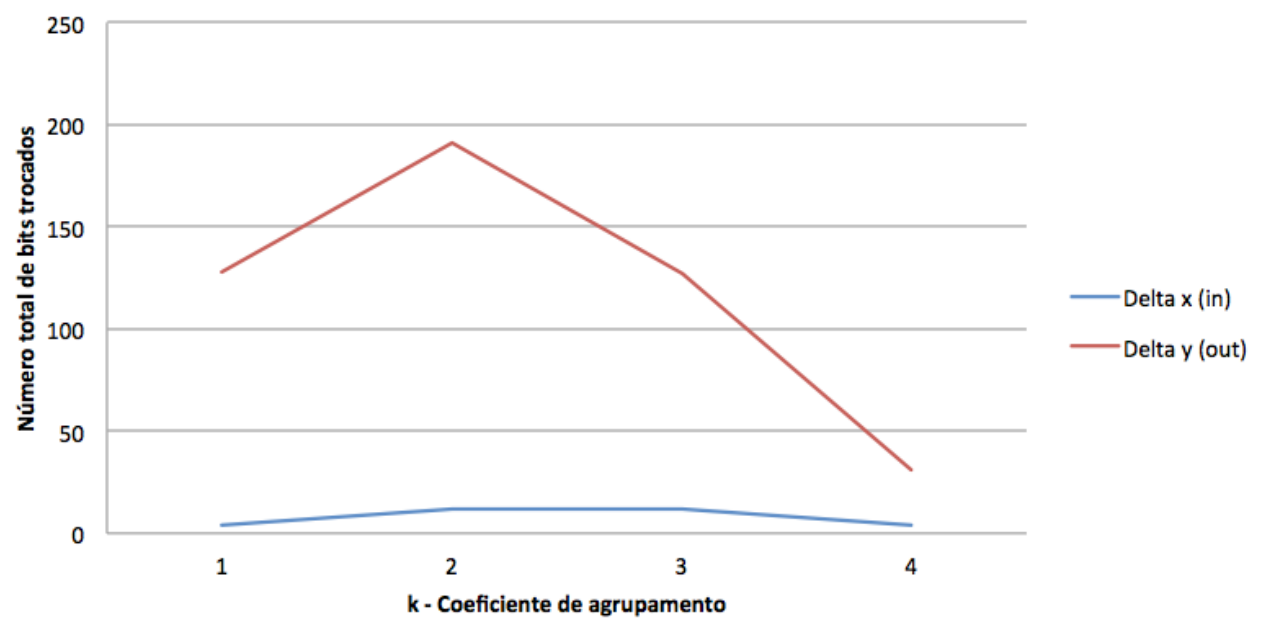

Figura 6.15: Total de bits alterados para a permutação de blocos de 64 bits. 
Estatística dos bits alterados na operação SMP

Apresentamos aqui as médias, mínimos, máximos e os desvios padrão dos bits alterados pela cifra SMP.

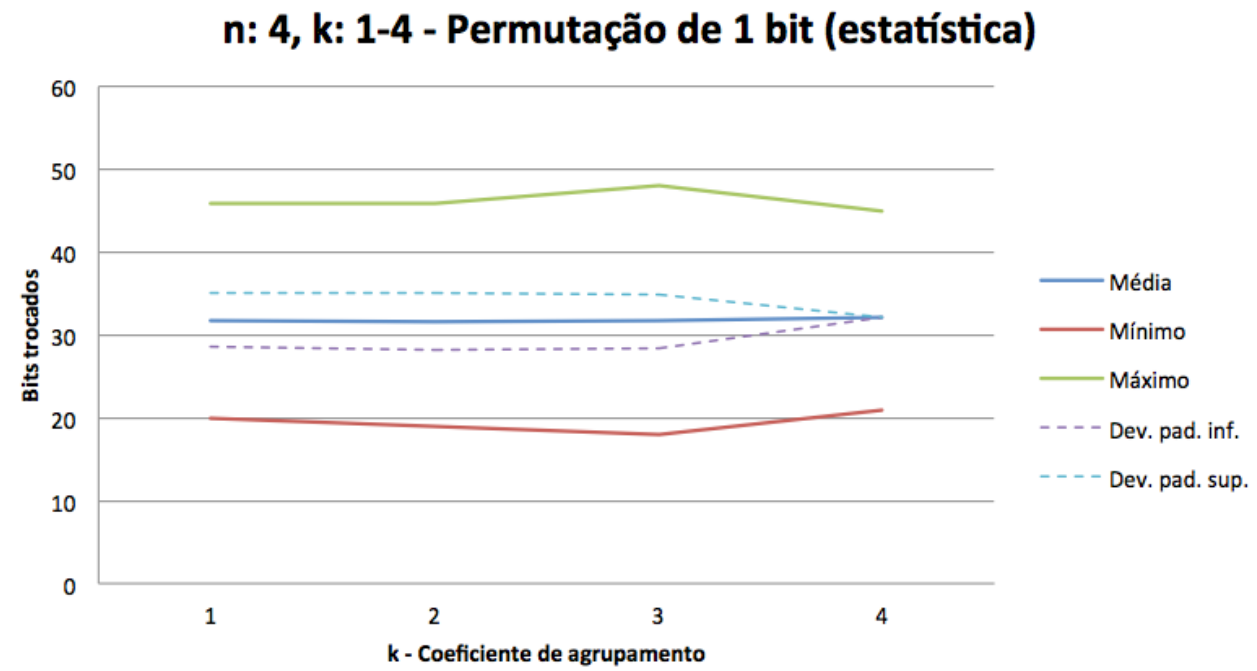

Figura 6.16: Estatística dos bits alterados para a permutação binária.

n: 4, k: 1-4 - Permutação de 4 bits (estatística)

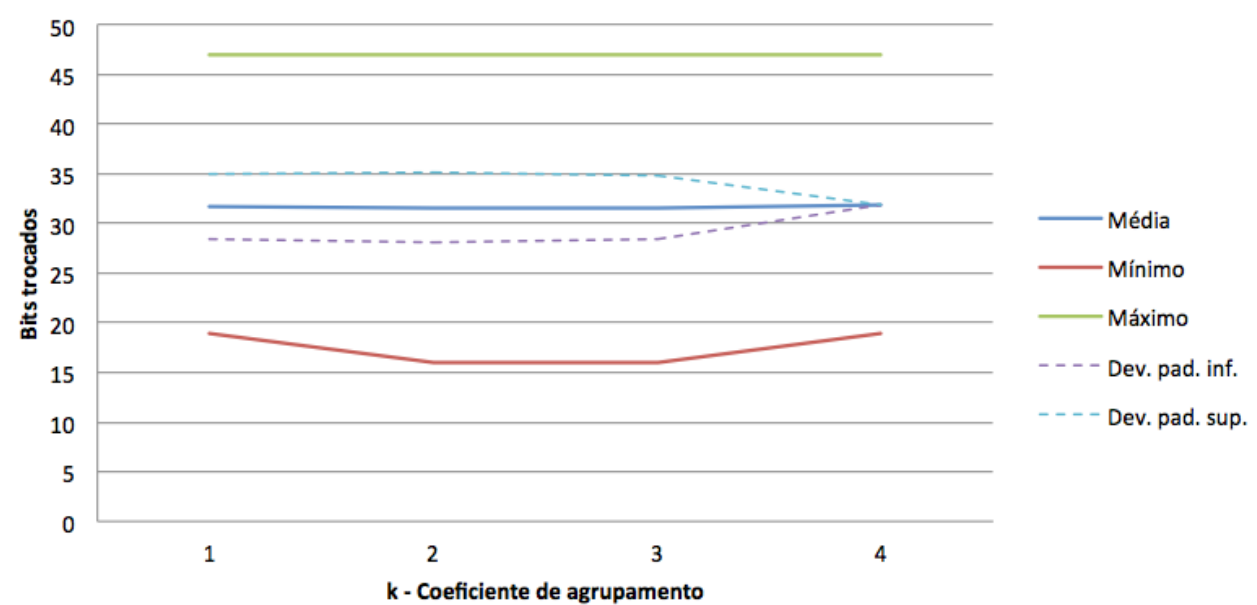

Figura 6.17: Estatística dos bits alterados para a permutação de blocos de 4 bits. 
n: 4, k: 1-4 - Permutação de 8 bits (estatística)

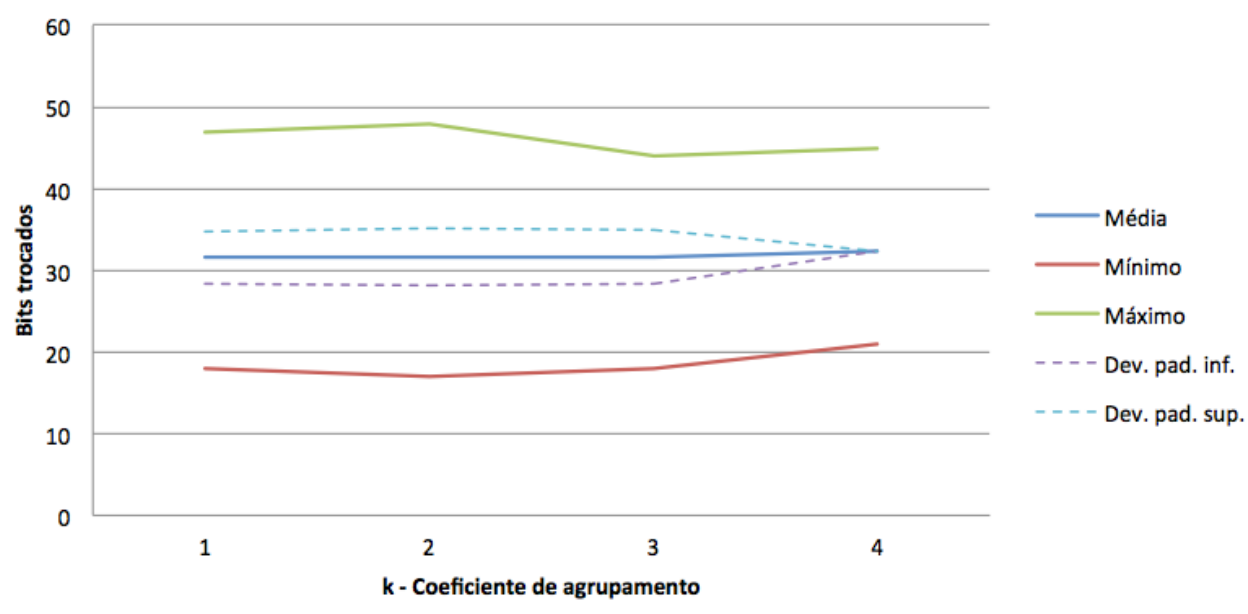

Figura 6.18: Estatística dos bits alterados para a permutação de blocos de 8 bits.

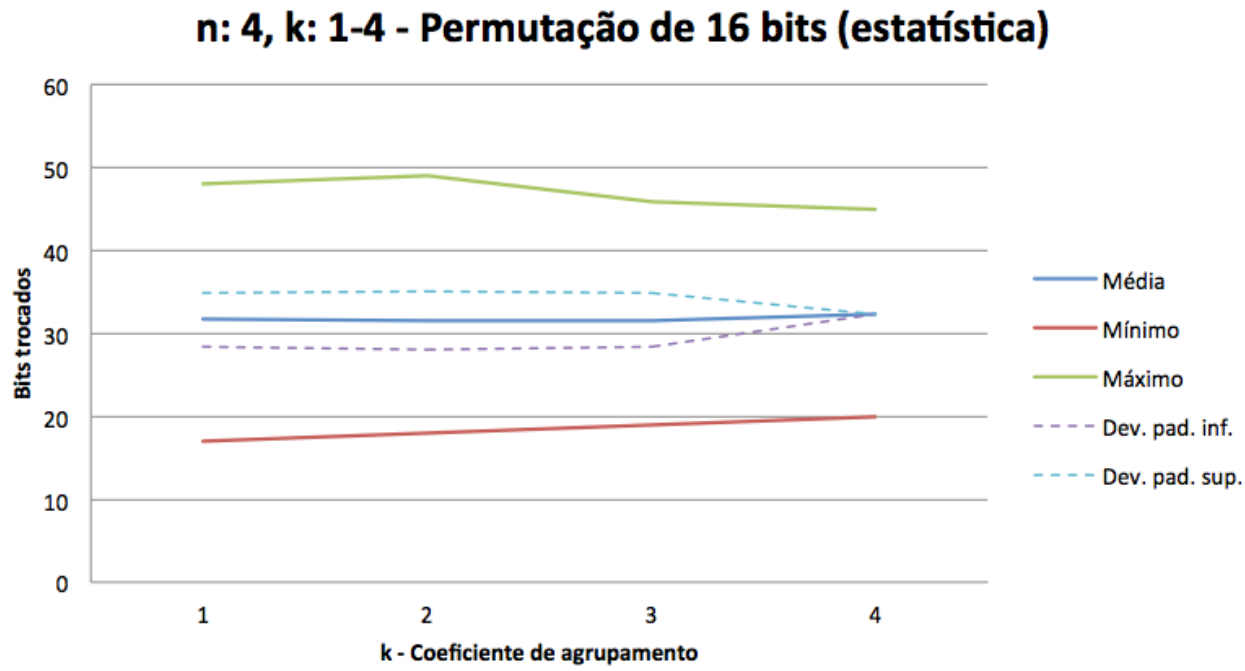

Figura 6.19: Estatística dos bits alterados para a permutação de blocos de 16 bits.

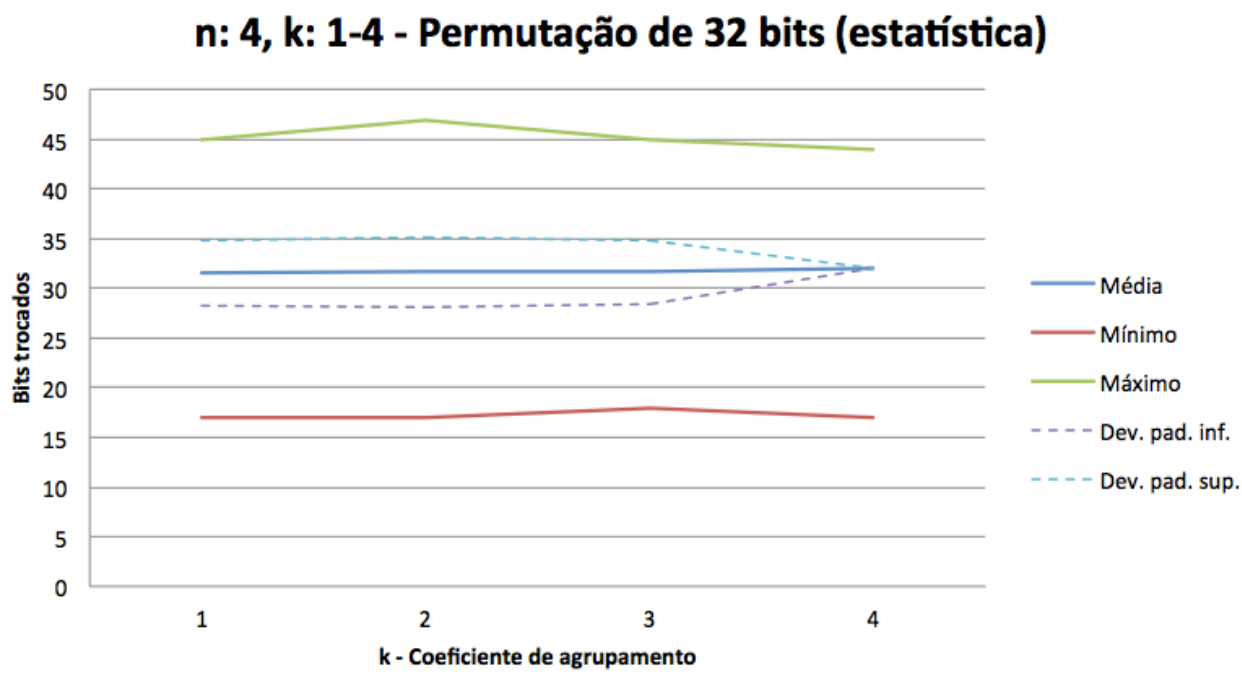

Figura 6.20: Estatística dos bits alterados para a permutação de blocos de 32 bits. 
n: 4, k: 1-4 - Permutação de 64 bits (estatística)

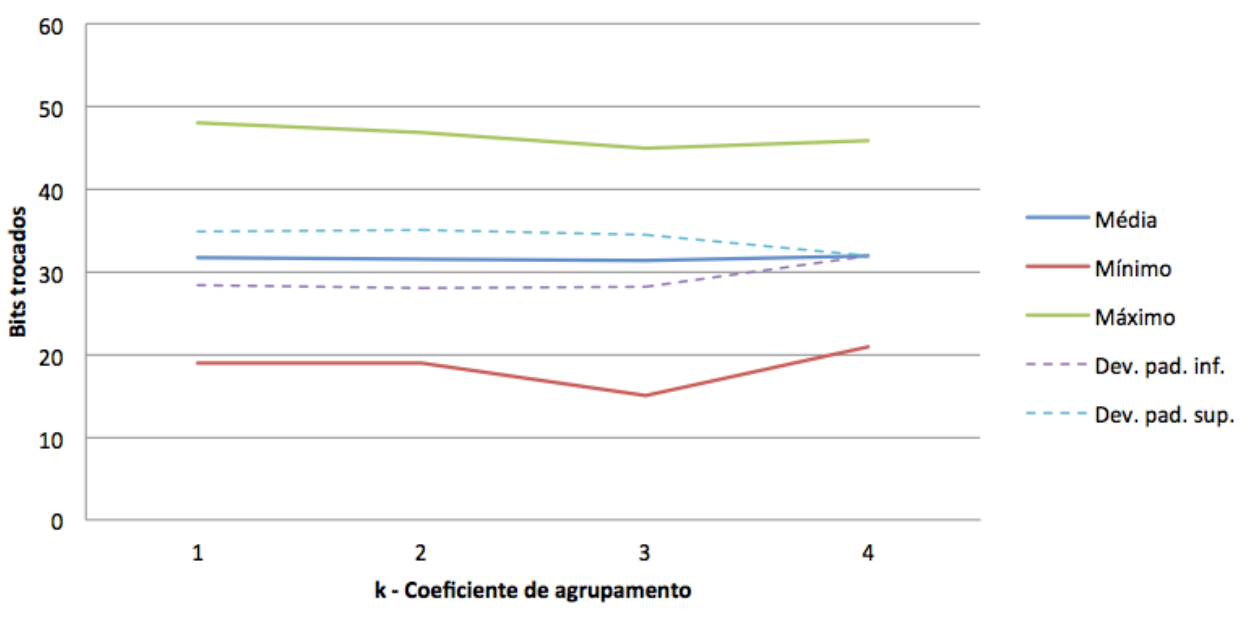

Figura 6.21: Estatística dos bits alterados para a permutação de blocos de 64 bits. 


\section{Coeficientes de variação}

Mostramos agora o coeficiente de variação (devio padrão pela média) de cada uma das estatísticas realizadas.

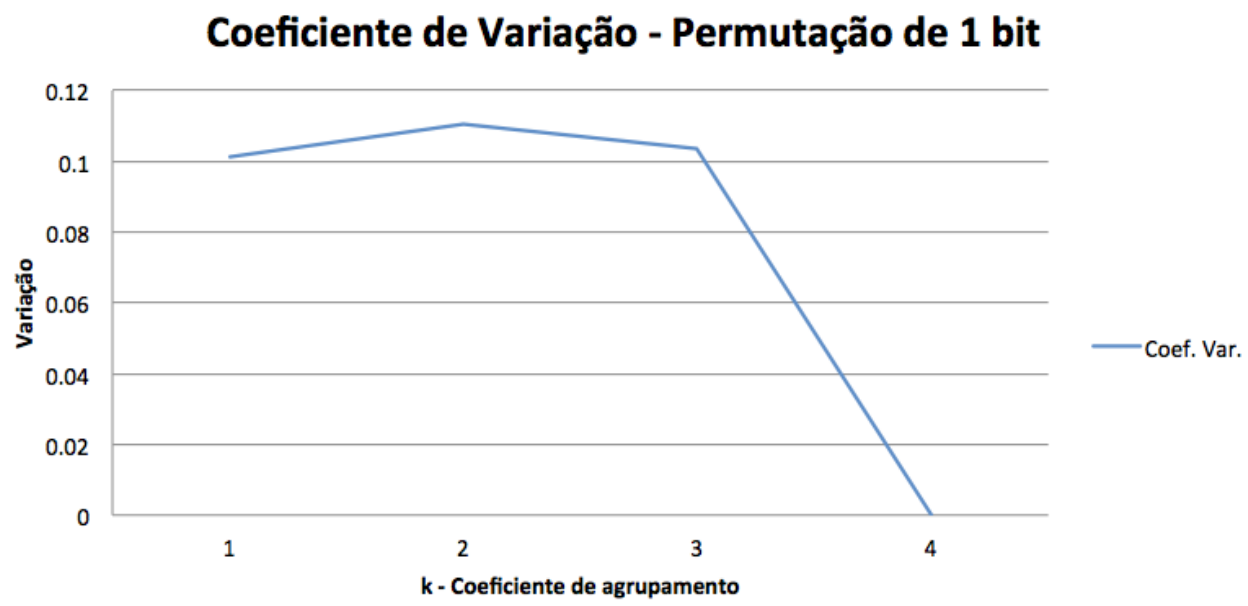

Figura 6.22: Coeficiente de variação (desvio padrão pela média) para a permutação binária.

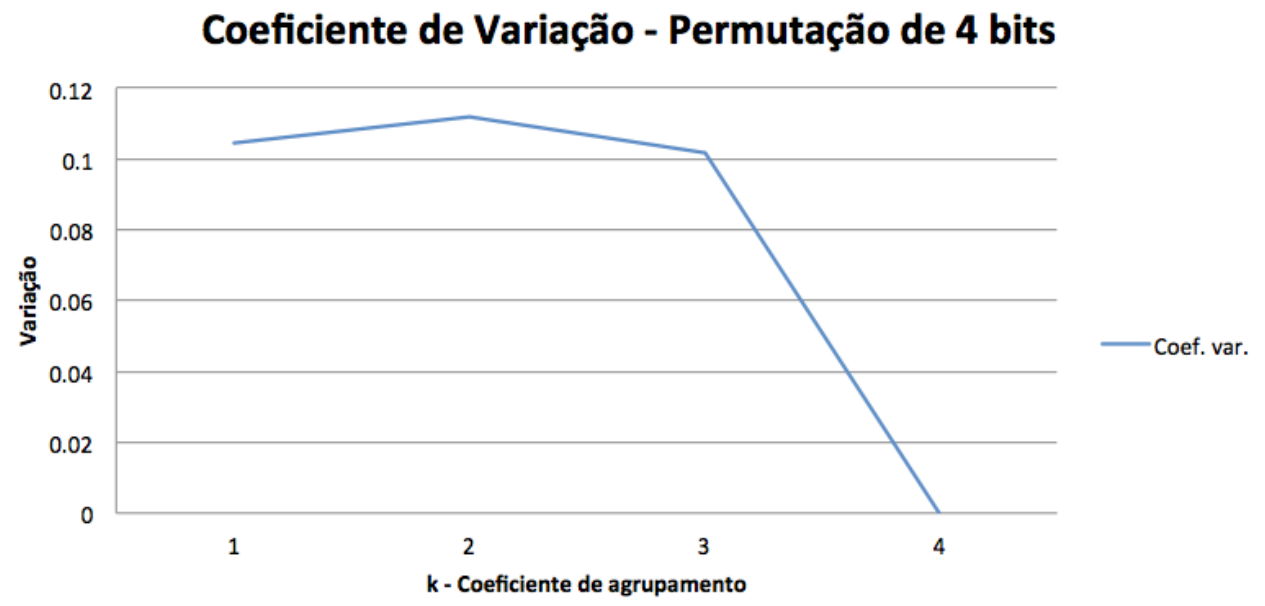

Figura 6.23: Coeficiente de variação (desvio padrão pela média) para a permutação de blocos de 4 bits.

Observe que o último ponto em todos os gráficos vai a zero, isso ocorre porque só um único valor, dada combinação binomial de 4 a 4 . Portanto, não há média, nem devio padrão. 


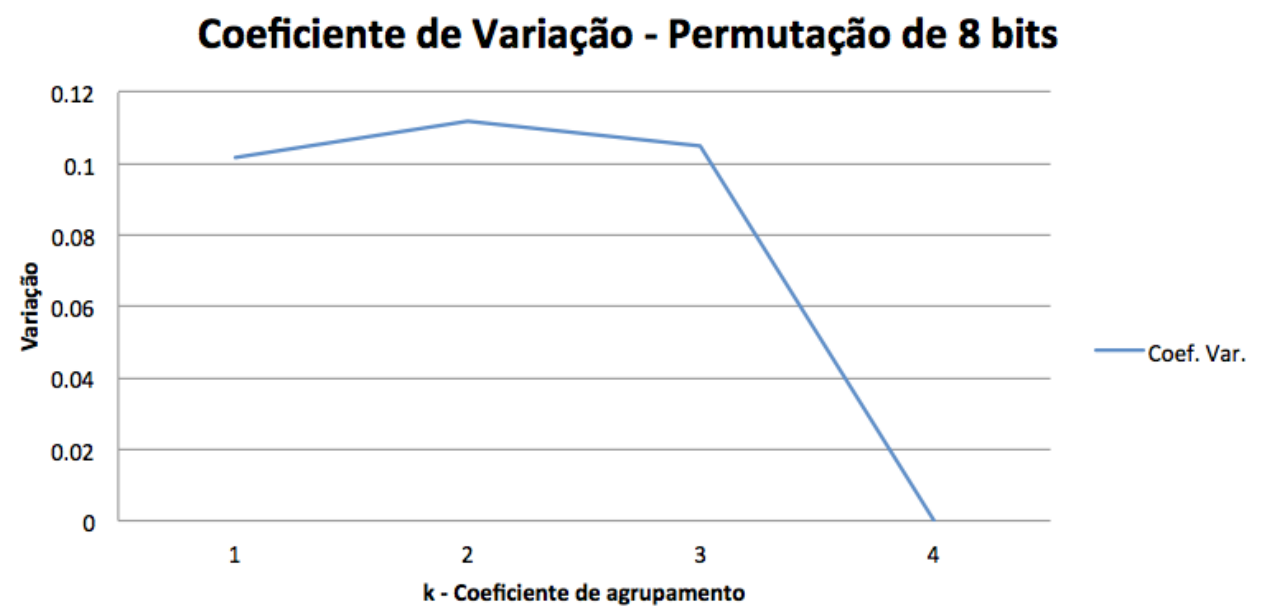

Figura 6.24: Coeficiente de variação (desvio padrão pela média) para a permutação de blocos de 8 bits.

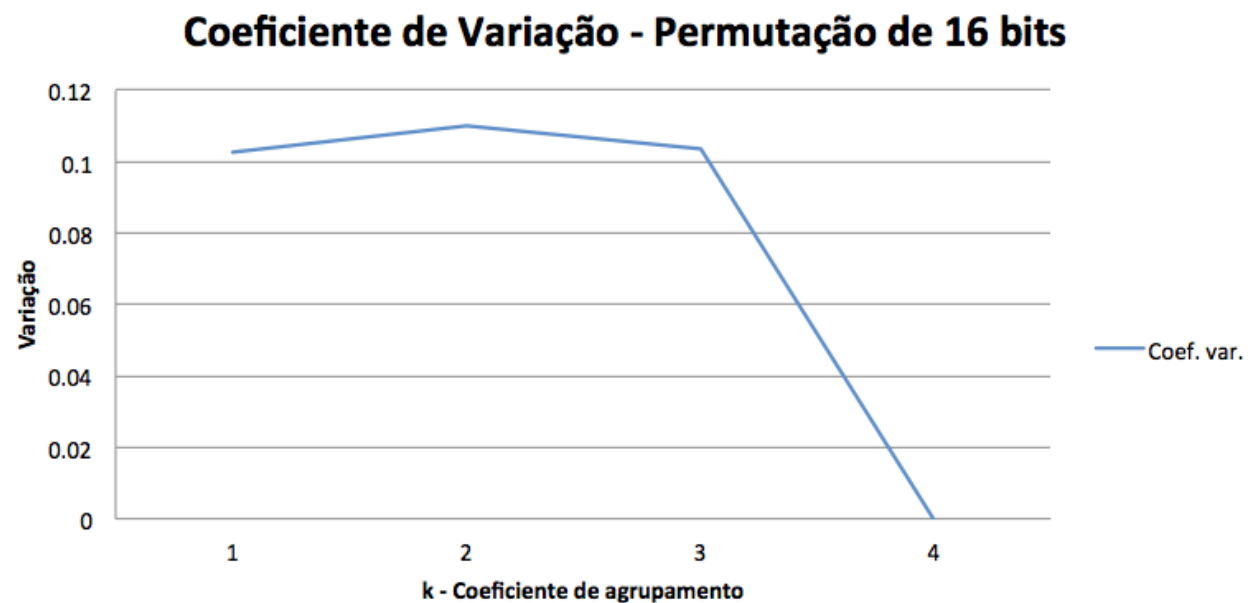

Figura 6.25: Coeficiente de variação (desvio padrão pela média) para a permutação de blocos de 16 bits.

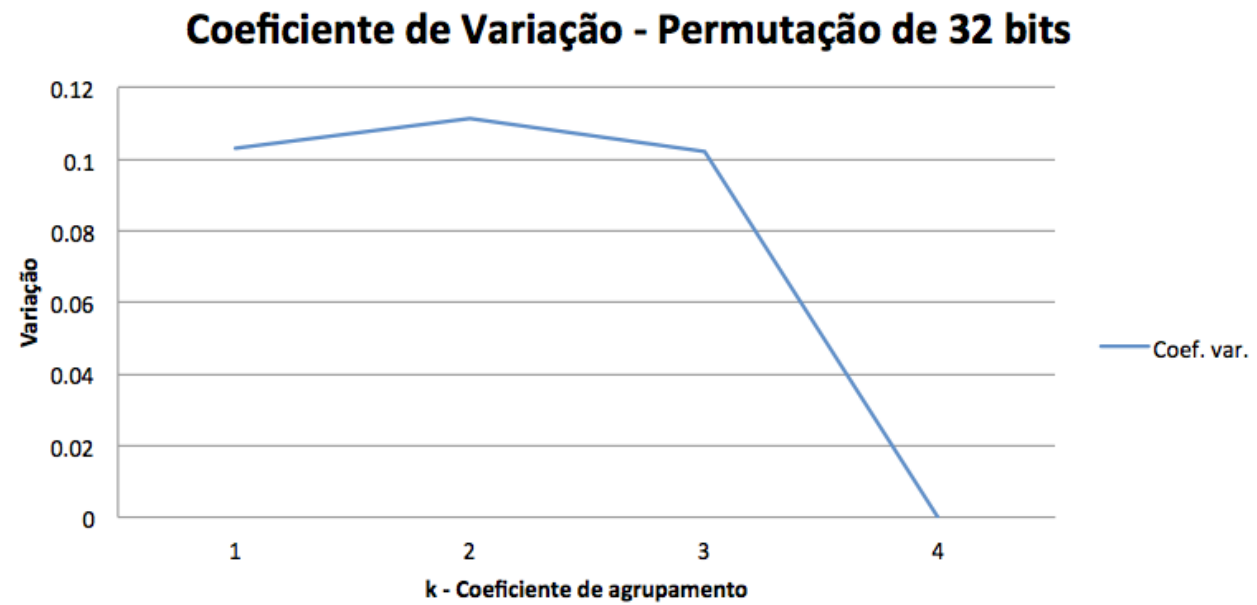

Figura 6.26: Coeficiente de variação (desvio padrão pela média) para a permutação de blocos de 32 bits. 


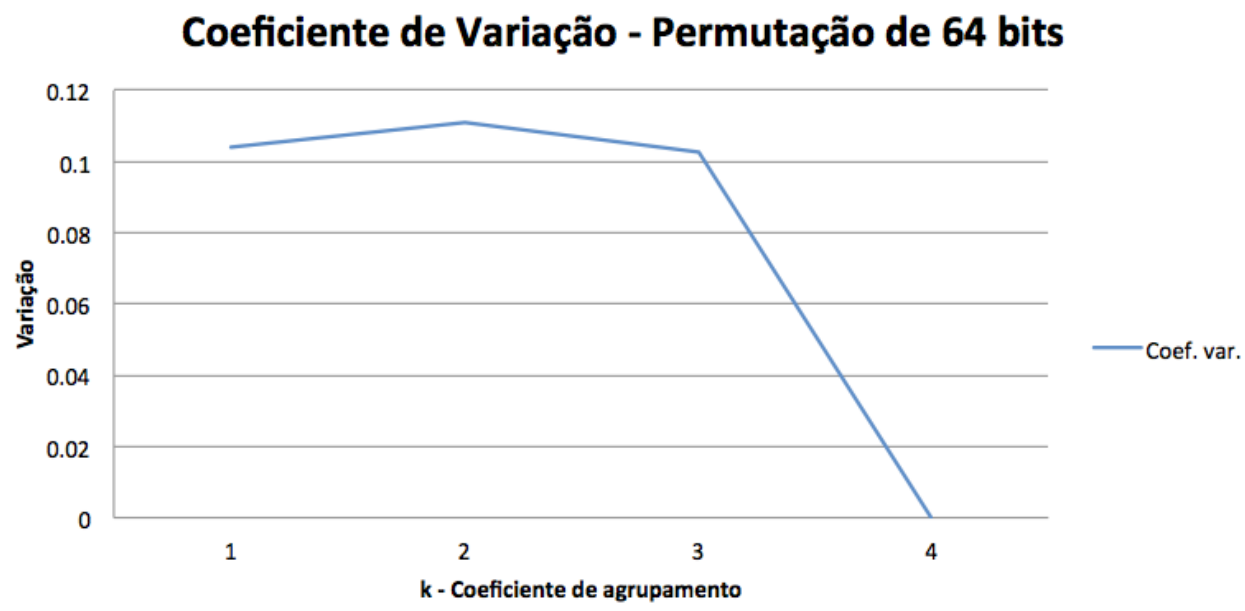

Figura 6.27: Coeficiente de variação (desvio padrão pela média) para a permutação de blocos de 64 bits. 
Média de bits trocados na operação SMP

Apresentamos aqui a média de bits trocados na operação SMP.

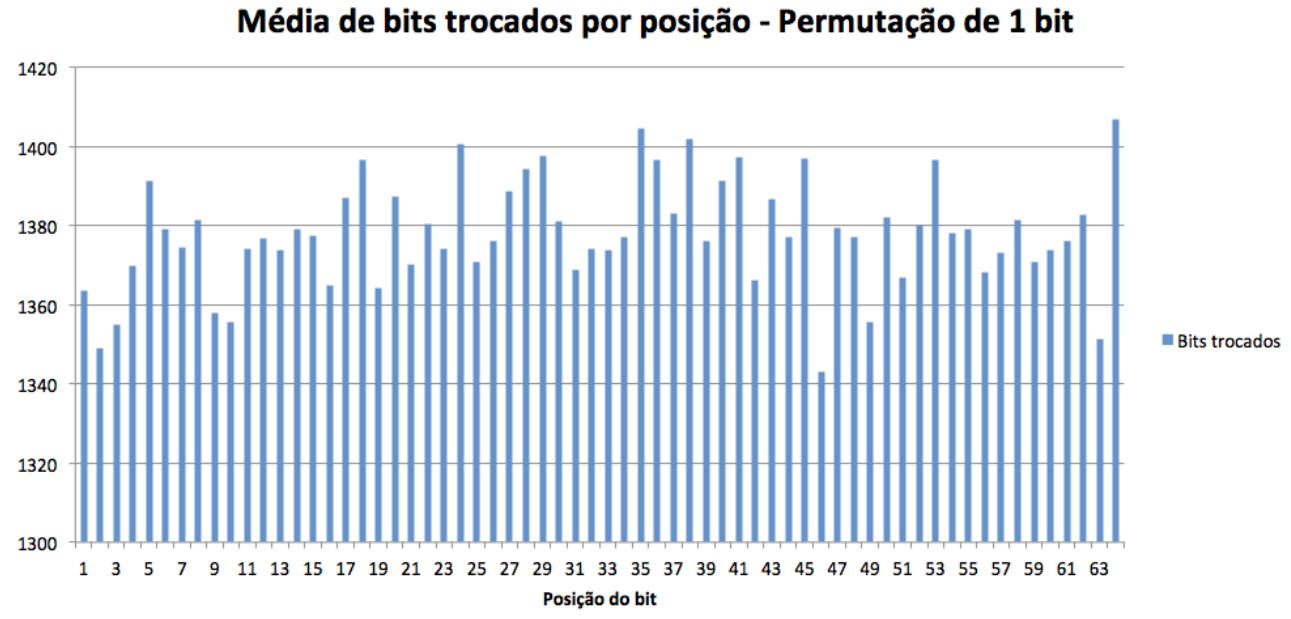

Figura 6.28: Média de bits trocados por posição em permutação binária.

Média de bits trocados por posição - Permutação de 4 bits

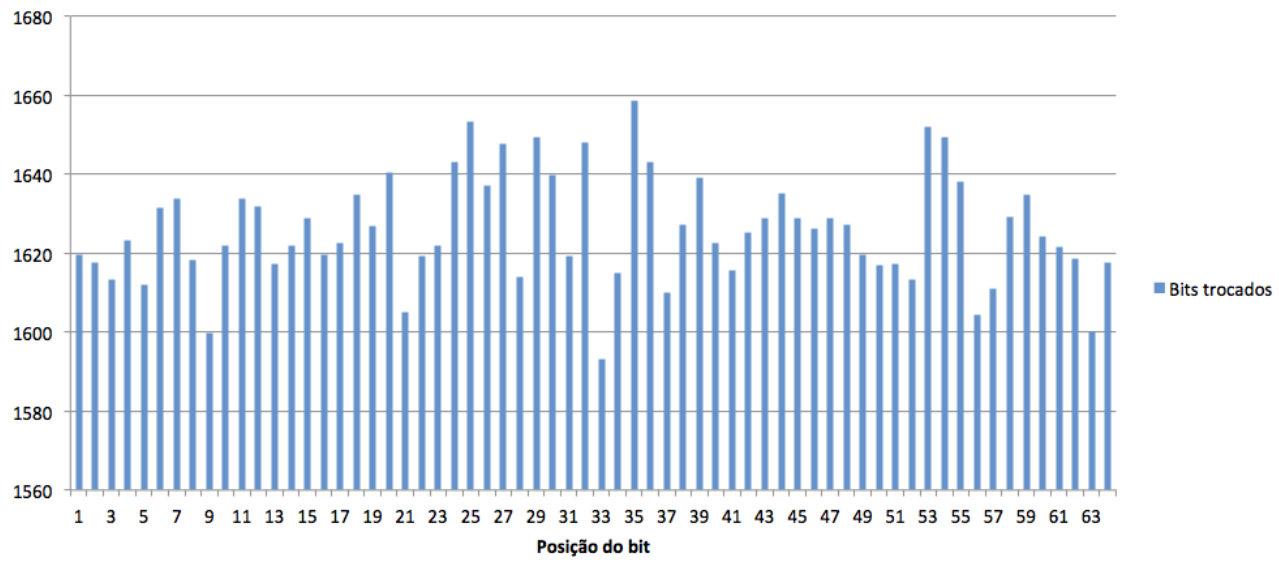

Figura 6.29: Média de bits trocados por posição em permutação de blocos de 4 bits.

Neste capítulo, após o detalhamento das duas implementações e apresentação dos dados, podemos verificar que a cifra multicanal é viável na prática, onde o crescimento do número de canais não representa necessariamente um crescimento explosivo do tempo de processamento necessário para sua execução, mas que um projetista tem que ficar atento com o overhead da infraestrutura e considerar algumas limitações tecnológicas.

Em relação a criptanálise diferencial, vimos que a função de permutação é totalmente ineficiente, um atacante pode facilmente recuperar a chave secreta utilizada. Mas que a cifra modificada, SMP, tem as propriedades requeridas contra a criptanálise diferencial e de fato fortalece um sistema onde seja utilizada. 


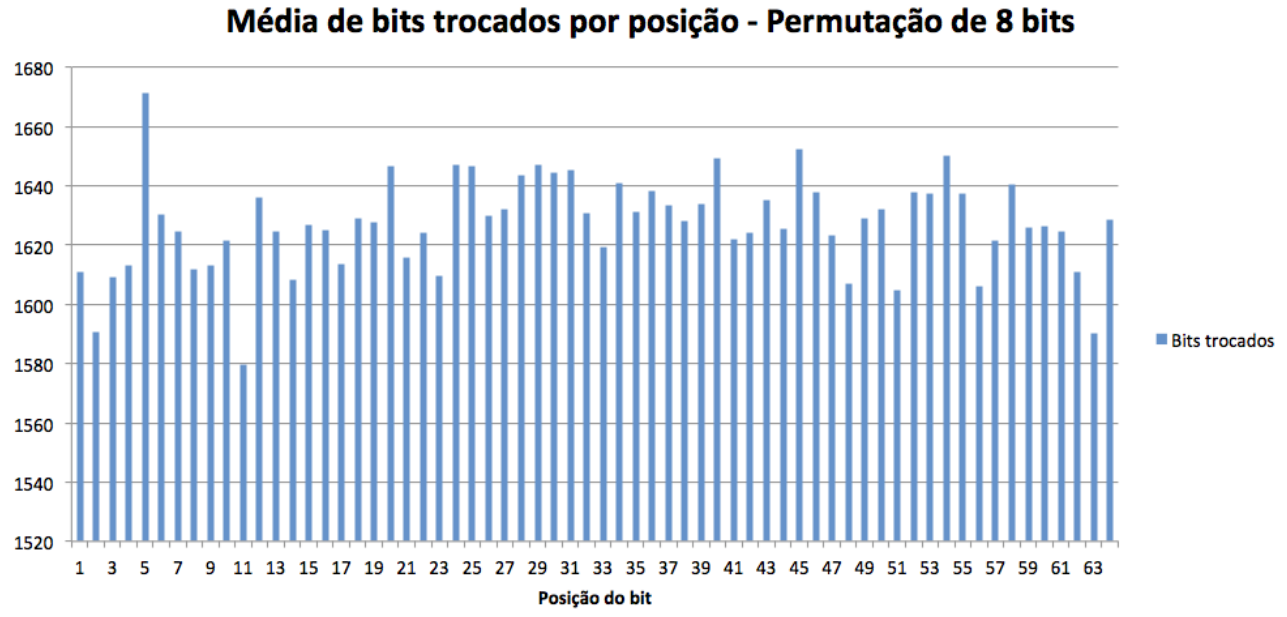

Figura 6.30: Média de bits trocados por posição em permutação de blocos de 8 bits.

Média de bits trocados por posição - Permutação de 16 bits

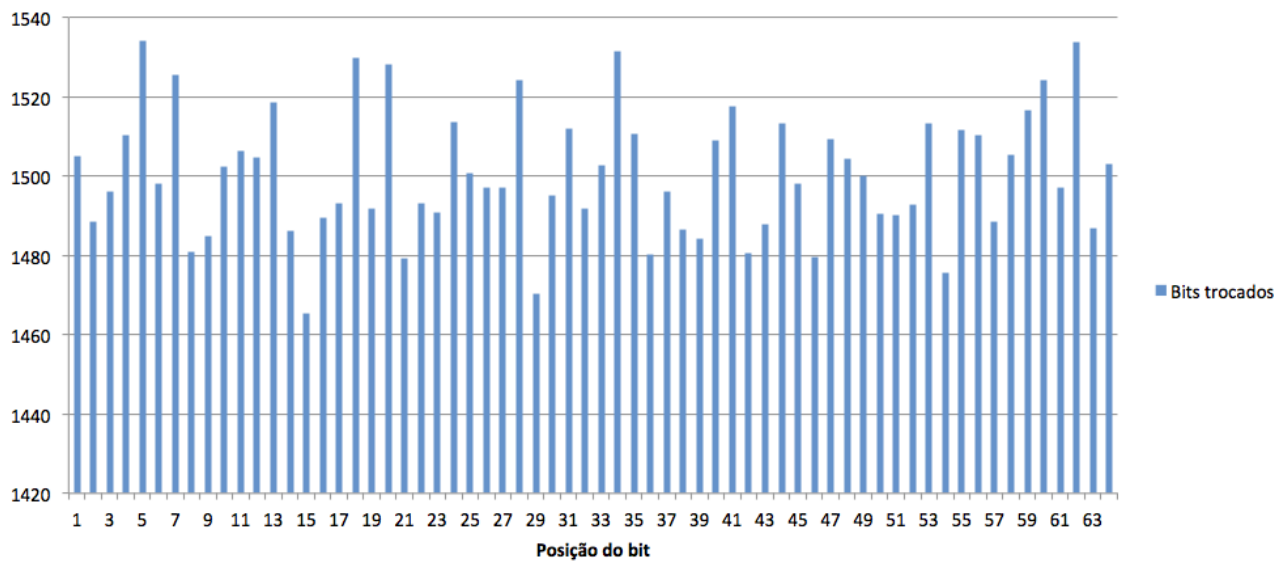

Figura 6.31: Média de bits trocados por posição em permutação de blocos de 16 bits.

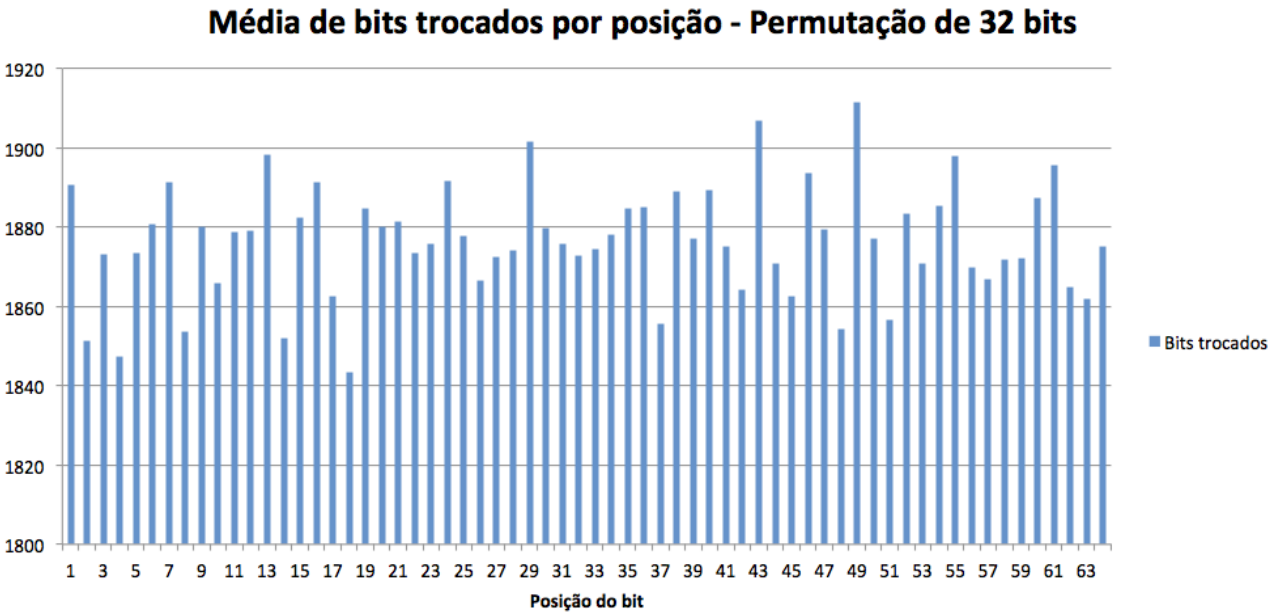

Figura 6.32: Média de bits trocados por posição em permutação de blocos de 32 bits. 
Média de bits trocados por posição - Permutação de 64 bits

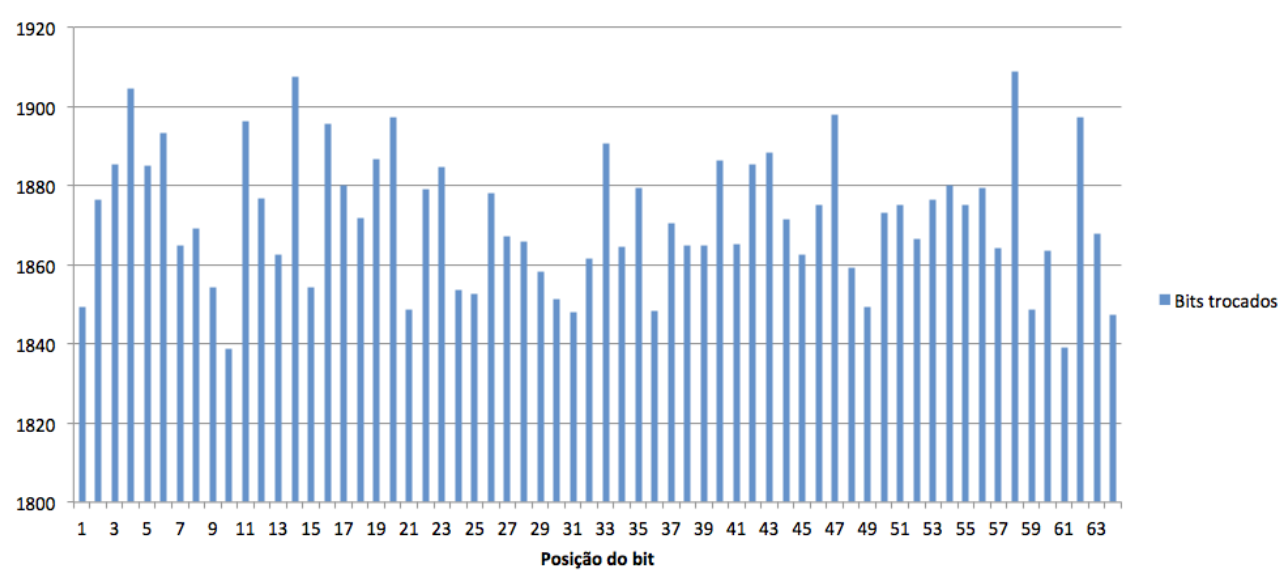

Figura 6.33: Média de bits trocados por posição em permutação de blocos de 64 bits. 


\section{Capítulo 7}

\section{Conclusões}

A cifra multicanal representa uma aplicação da nova instrução RdRand dos novos chips da Intel, uma operação simples que pode aumentar a segurança das futuras comunicações, modificada, a SMP, é resistente em relação a criptanálise diferencial, pode dar sobrevida a algumas cifras antigas fragilizadas por essa classe de ataques.

Removendo-se a dificuldade de obtenção dos blocos do texto-ilegível, por parte de um adversário, verificamos que ainda há uma certa complexidade sobre a combinação correta, o que explica porque a interceptação prática de dados das redes sem fio (telefonia celular, principalmente) são relativamente difíceis de serem obtidas e difundidas.

Em uma comunicação serializada (foi o caso, em nossos experimentos, com apenas uma interface de rede em ambos os agentes da comunicação), não representa um ganho de tempo, nem em transferência de dados, como se pudera pensar inicialmente, pois toda comunicação é em algum momento serializada pelo sistema operacional. Ainda sim, por outro lado não há uma explosão no tempo de processamento em função do número de canais, que nos experimentos foram dobrando em cada etapa, o que implica que a cifra pode realmente ser utilizada na prática, talvez com aplicações distribuídas apresente melhores tempos totais de comunicação.

Em relação à criptanálise diferencial, a permutação original da cifra multicanal mostrou-se totalmente ineficiente, e mais, na verdade um facilitador para obtenção da chave secreta. Mostra que esse tipo de ataque poderia ser empregado para analisar as redes que utilizam a técnica de FHSS, como meio de serialização dos dados.

Não obstante, a cifra multicanal modificada, a SMP, mostrou-se relativamente segura em relação a cifra multicanal, inclusive o mecanismo de difusão binária extraído do AES, poderia ser utilizado em outros sistemas como meio de fortalecê-los contra a criptanálise diferencial. Uma aplicação direta seria a própria rede GSM que poderia utilizá-lo depois da criptografia pelo A5 e antes da difusão por rádio frequência.

A cifra multicanal é uma proposta que requer mais estudos e experimentos, mas com os computadores cada vez mais interconectados e utilizando cada vez mais a computação em nuvem, podem surgir cenários onde se torne relevante e necessária.

\section{1 $\quad$ Sugestões para Pesquisas Futuras}

Aqui só avaliamos a cifra em relação a criptanálise diferencial, um trabalho semelhante poderia ser realizado em relação à criptanálise linear, uma outra técnica muito importante contra as cifras simétricas de bloco.

Um experimento de desempenho da SMP em relação ao AES poderia ser desenvolvido para a verificação se há ganho em eficiência de processamento na adoção da primeira.

$\mathrm{Na}$ cifra multicanal, os blocos são todos transmitidos para o cliente após a sua requisição. Um cenário de requisição e resposta poderia se explorado, de modo que o cliente devesse pedir cada um dos blocos ao servidor em uma sequência correta. Esse mecanismo teria a propriedade de identificar um intruso no sistema, pois o adversário ao não saber a sequência correta, poderia pedir um bloco 
errado, o que o identificaria. Um precaução importante é separar esse mecanismo de identificação de um adversário do mecanismo de montagem dos dados, pois do contrário, bastaria ao adversário escutar os múltiplos canais e verificar a ordem em que estão sendo pedidos os dados, para obter a sequência correta de montagem dos mesmos. 


\section{Referências Bibliográficas}

Barkan et al. (2006) Elad Barkan, Eli Biham e Nathan Keller. Instant ciphertext-only cryptanalysis of gsm encrypted communication (full version). Relatório técnico, Technion - Computer Science Departament. Citado na pág. 4

Biham e Shamir (1991) Eli Biham e Adi Shamir. Differential cryptanalysis of des-like cryptosystems. Em CRYPTO'91. Citado na pág. 1, 13, 14, 21

Cormen et al. (2009) Tomas H. Cormen, Charles E. Leiserson, Ronald L. Rivest e Clifford Stein. Introduction to Algorithms. The MIT Press, 3rd ed. ISBN 978-0-262-03384-8. Citado na pág. 17

Dunkelman et al. (2010) Orr Dunkelman, Nathan Keller e Adi Shamir. A practical-time attack on the a5/3 cryptosystem used in third generation gsm telephony. Cryptology ePrint Archive, Report 2010/013, 2010. http://eprint.iacr.org/. Citado na pág. 4

Eberspacher et al. (2001) Jorg Eberspacher, Hans-Joerg Vogel e Christian Bettstetter. GSM Switching, Services and Protocols. Wiley, 2nd. ed. Citado na pág. 4

Fazel e S.Kaizer (2008) K. Fazel e S.Kaizer. Multi-Carrier and Spread Spectrum Systems. Wiley, 2nd. ed. Citado na pág. 3

Hamming (1950) Richard W. Hamming. Error detecting and error correcting codes. Bell System Technical Journal, 29(147-160). Citado na pág. 26

Heys (2001) Howard Heys. A tutorial on linear and differential cryptanalysis. Relatório técnico. Citado na pág. 13

Hofemeier (2012) Gael Hofemeier. Intel digital random number generator (drng) - software implementation guide. http://software.intel.com/en-us/articles/intel-digital-random-numbergenerator-drng-software-implementation-guide, 2012. Acessado em 25/06/2013. Citado na pág. 21

Meel (1999) Jan Meel. Spread spectrum (ss) - introduction. Relatório técnico, Hoges Voor Wetenschap \& Kunst de Nayer Instituut. Citado na pág. 3

Menezes et al. (1996) Alfred J. Menezes, Scott A. Vanstone e Paul C. Van Oorschot. Handbook of Applied Cryptography. CRC Press, Inc., Boca Raton, FL, USA, 1st ed. ISBN 0849385237. Citado na pág. 11

Michtchenko e Vilnaski (2007) Valentin Michtchenko e Yuri Vilnaski. Harmed Texts and Multichannel cryptography. Minsk - Enciclopedics, 1st. ed. Citado na pág. 2

Nohl (2009) Karsten Nohl. Gsm: Srsly? 26th Caos Communication Congress(26C3), 2009. Citado na pág. 4

Takács (2007) Péter Takács. The extension of cns-logic for multi-channel protocols. Em Proceedings of the 7th International Conference on Applied Informatics, volume 2, páginas 147-153. Eger. Citado na pág. 2 
Terada (2008) Routo Terada. Segurança de dados - Criptografia em rede de computador. Blucher, 2a. ed. Citado na pág. 9, 15, 34, 37

Wegner (1960) Peter Wegner. A technique for counting ones in a binary computer. Communications of the ACM, 3(322). Citado na pág. 26

Wong e Stajano (2005) Ford-Long Wong e Frank Stajano. Multi-channel protocols. Em In Proc. Security Protocols Workshop. Springer. Citado na pág. 13 